NASA/TM-2005-213768

ARL-TR-3524
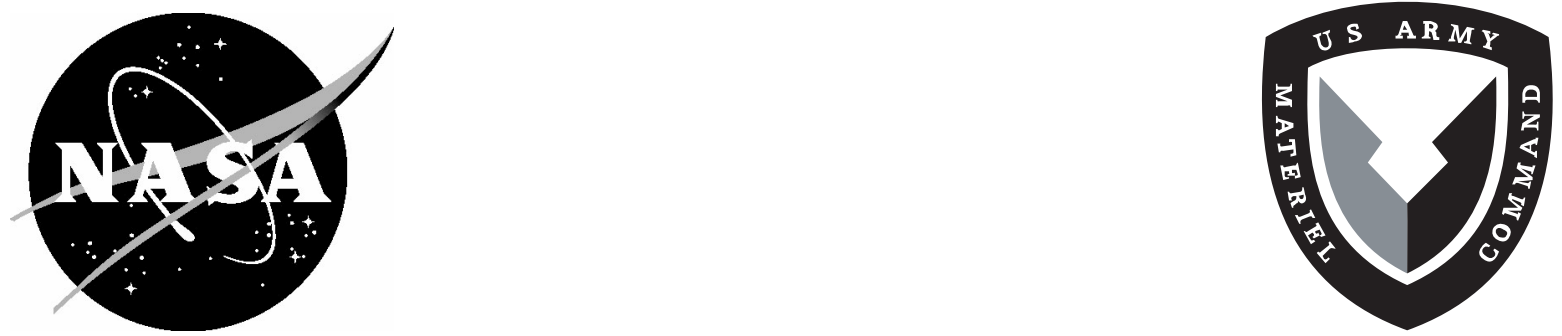

\title{
Influence of Compression and Shear on the Strength of Composite Laminates With Z-Pinned Reinforcement
}

T. Kevin O'Brien

U.S. Army Research Laboratory

Vehicle Technology Directorate

Langley Research Center, Hampton, Virginia

Ronald Krueger

National Institute of Aerospace, Hampton, Virginia 
Since its founding, NASA has been dedicated to the advancement of aeronautics and space science. The NASA Scientific and Technical Information (STI) Program Office plays a key part in helping NASA maintain this important role.

The NASA STI Program Office is operated by Langley Research Center, the lead center for NASA's scientific and technical information. The NASA STI Program Office provides access to the NASA STI Database, the largest collection of aeronautical and space science STI in the world. The Program Office is also NASA's institutional mechanism for disseminating the results of its research and development activities. These results are published by NASA in the NASA STI Report Series, which includes the following report types:

- TECHNICAL PUBLICATION. Reports of completed research or a major significant phase of research that present the results of NASA programs and include extensive data or theoretical analysis. Includes compilations of significant scientific and technical data and information deemed to be of continuing reference value. NASA counterpart of peerreviewed formal professional papers, but having less stringent limitations on manuscript length and extent of graphic presentations.

- TECHNICAL MEMORANDUM. Scientific and technical findings that are preliminary or of specialized interest, e.g., quick release reports, working papers, and bibliographies that contain minimal annotation. Does not contain extensive analysis.

- CONTRACTOR REPORT. Scientific and technical findings by NASA-sponsored contractors and grantees.
- CONFERENCE PUBLICATION. Collected papers from scientific and technical conferences, symposia, seminars, or other meetings sponsored or co-sponsored by NASA.

- SPECIAL PUBLICATION. Scientific, technical, or historical information from NASA programs, projects, and missions, often concerned with subjects having substantial public interest.

- TECHNICAL TRANSLATION. Englishlanguage translations of foreign scientific and technical material pertinent to NASA's mission.

Specialized services that complement the STI Program Office's diverse offerings include creating custom thesauri, building customized databases, organizing and publishing research results ... even providing videos.

For more information about the NASA STI Program Office, see the following:

- Access the NASA STI Program Home Page at http://www.sti.nasa.gov

- E-mail your question via the Internet to help@sti.nasa.gov

- Fax your question to the NASA STI Help Desk at (301) 621-0134

- Phone the NASA STI Help Desk at (301) 621-0390

- Write to:

NASA STI Help Desk NASA Center for AeroSpace Information 7121 Standard Drive Hanover, MD 21076-1320 
NASA/TM-2005-213768

ARL-TR-3524
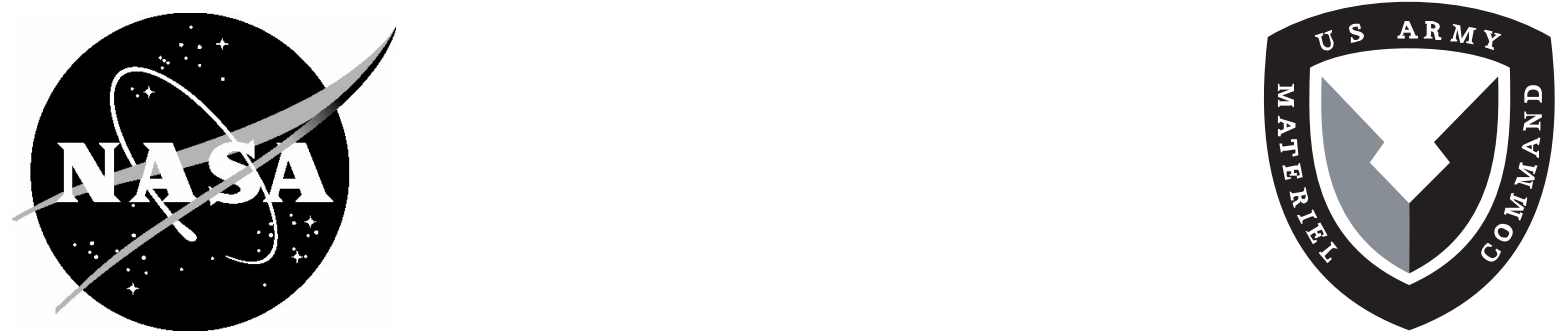

\section{Influence of Compression and Shear on the Strength of Composite Laminates With Z-Pinned Reinforcement}

T. Kevin O'Brien

U.S. Army Research Laboratory

Vehicle Technology Directorate

Langley Research Center, Hampton, Virginia

Ronald Krueger

National Institute of Aerospace, Hampton, Virginia

National Aeronautics and

Space Administration

Langley Research Center

Hampton, Virginia 23681-2199

June 2005 
The use of trademarks or names of manufacturers in the report is for accurate reporting and does not constitute an official endorsement, either expressed or implied, of such products or manufacturers by the National Aeronautics and Space Administration or the U.S. Army.

Available from:

NASA Center for AeroSpace Information (CASI)

7121 Standard Drive

Hanover, MD 21076-1320

(301) 621-0390
National Technical Information Service (NTIS) 5285 Port Royal Road Springfield, VA 22161-2171

(703) 605-6000 


\title{
INFLUENCE OF COMPRESSION AND SHEAR ON THE STRENGTH OF COMPOSITE LAMINATES WITH Z-PINNED REINFORCEMENT
}

\author{
T. Kevin O'Brien ${ }^{1}$, Ronald Krueger ${ }^{2}$
}

\begin{abstract}
The influence of compression and shear loads on the strength of composite laminates with z-pins is evaluated parametrically using a 2D Finite Element Code (FLASH) based on Cosserat couple stress theory. Meshes were generated for three unique combinations of z-pin diameter and density. A laminated plate theory analysis was performed on several layups to determine the bi-axial stresses in the zero degree plies. These stresses, in turn, were used to determine the magnitude of the relative load steps prescribed in the FLASH analyses. Results indicated that increasing pin density was more detrimental to in-plane compression strength than increasing pin diameter. Compression strengths of lamina without z-pins agreed well with a closed form expression derived by Budiansky and Fleck. FLASH results for lamina with z-pins were consistent with the closed form results, and FLASH results without z-pins, if the initial fiber waviness due to z-pin insertion was added to the fiber waviness in the material to yield a total misalignment. Addition of $10 \%$ shear to the compression loading significantly reduced the lamina strength compared to pure compression loading. Addition of 50\% shear to the compression indicated shear yielding rather than kink band formation as the likely failure mode. Two different stiffener reinforced skin configurations with z-pins, one quasi-isotropic and one orthotropic, were also analyzed. Six unique loading cases ranging from pure compression to compression plus $50 \%$ shear were analyzed assuming material fiber waviness misalignment angles of 0,1 , and 2 degrees. Compression strength decreased with increased shear loading for both configurations, with the quasi-isotropic configuration yielding lower strengths than the orthotropic configuration.
\end{abstract}

\footnotetext{
${ }^{1}$ Army Research Laboratory, Vehicle Technology Directorate, Langley Reseach Center,Hampton, VA.

${ }^{2}$ National Institute of Aerospace (NIA), 144 Research Drive, Hampton, VA.
} 


\section{List of Symbols}

C length of resin pocket parallel to fiber direction

$\mathrm{A}_{\mathrm{r}} \quad$ fraction of the total reinforced area covered by z-pins

$\mathrm{A}_{\mathrm{Z}} \quad$ cross sectional area of a single z-pin

$\mathrm{D}_{\mathrm{z}} \quad$ z-pin diameter

$\mathrm{D}_{\mathrm{z}}{ }^{\prime} \quad$ height of $\mathrm{z}$-pin plus resin pocket normal to fiber direction

d fiber diameter

$\mathrm{E}_{11}, \mathrm{E}_{\mathrm{L}} \quad$ Stiffness of lamina parallel to fiber direction

$\mathrm{E}_{22}, \mathrm{E}_{\mathrm{T}} \quad$ Stiffness of lamina transverse to fiber direction

$\mathrm{E}_{\mathrm{Tc}} \quad$ Compression stiffness of lamina transverse to fiber direction

G Shear modulus

$\mathrm{G}_{\mathrm{f}} \quad$ Fiber shear modulus

$\mathrm{G}_{\mathrm{LT}}, \mathrm{G}_{12} \quad$ Lamina shear modulus in principal material directions

$\mathrm{G}_{\mathrm{sec}} \quad$ Lamina secant shear modulus

$\mathrm{H}_{\mathrm{z}} \quad$ vertical spacing between $\mathrm{z}$-pins in unit cell

$\mathrm{L}_{\mathrm{z}} \quad$ Horizontal spacing between z-pins in unit cell

n Ramberg-Osgood curve fitting parameter

$\mathrm{N}_{\mathrm{x}}, \mathrm{N}_{\mathrm{y}} \quad$ Axial force resultant on laminate in $\mathrm{X}, \mathrm{Y}$ direction

$\mathrm{N}_{\mathrm{xy}} \quad$ Shear force resultant on laminate in $\mathrm{X}-\mathrm{Y}$ plane

$\mathrm{r}_{\mathrm{z}} \quad$ areal density of z-pins

$\mathrm{u}_{\mathrm{x}}, \mathrm{u}_{\mathrm{y}} \quad$ Displacement in $\mathrm{X}, \mathrm{Y}$ direction

$\mathrm{V}_{\mathrm{f}} \quad$ Fiber volume fraction

w kink band width

$\alpha \quad$ Ramberg-Osgood curve fitting parameter

$\beta \quad$ kink band inclination angle 


$\begin{array}{ll}\gamma_{\mathrm{e}} & \text { Effective shear strain } \\ \gamma_{\mathrm{y}} & \text { Yield strain in shear } \\ v_{12} & \text { Lamina Poisson's ratio } \\ \bar{\phi} & \text { Fiber misalignment angle } \\ \sigma_{\mathrm{c}} & \text { Strength, critical value of stress } \\ \sigma_{\mathrm{Ty}} & \text { Yield strength in tension } \\ \sigma_{\mathrm{xx}}, \sigma_{\mathrm{yy}} & \text { Normal stress in X, Y direction } \\ \sigma_{\mathrm{xy}}, \sigma_{\mathrm{yx}} & \text { Shear stress in X-Y plane } \\ \sigma_{\mathrm{ult}} & \text { Strength of skin/stiffener-flange laminate } \\ \sigma_{\mathrm{ultc}} & \text { Compression strength of skin/stiffener-flange laminate } \\ \sigma_{11}, \sigma_{22} & \text { Normal stress in 1,2 direction } \\ \sigma_{12}, \sigma_{21} & \text { Shear stress in 1-2 plane } \\ \tau_{\mathrm{e}} & \text { Effective yield strength in shear } \\ \tau_{\mathrm{y}} & \text { Yield strength in shear } \\ \tau_{\mathrm{xy}}, \tau_{\mathrm{yx}} & \text { Shear stress in X-Y plane } \\ \tau_{12}, \tau_{21} & \text { Shear stress in 1-2 plane }\end{array}$




\section{Introduction}

One of the most common failure modes for composite structures is delamination [1-2]. Recently, z-pins ${ }^{*}$ have been proposed to provide through-thickness reinforcement to composite laminates through a combination of friction and adhesion [3-6]. Z-pins are pultruded rods of carbon fiber and epoxy matrix. The z-pins are ultrasonically inserted through the thickness of a laminated composite prepreg, which is then cured in an autoclave. This approach to through-thickness reinforcement offers an alternative to stitching, and can provide much higher areal densities of reinforcement [7]. Furthermore, z-pins may be used effectively to reinforce a local region of a component, such as a terminated stiffener flange, without requiring a different manufacturing procedure than the rest of the structure.

Although the toughening properties of stitches, z-pins and similar structures have been studied extensively, investigations on the effect of $\mathrm{z}$ pins on the in-plane properties of laminates are limited [7-9]. Steeves examined the effect of z-pins on the in-plane tensile and compressive properties of composite laminates [7]. He demonstrated that disruption in the alignment of the fibers in the composite leads to a significant reduction in the in-plane compressive strength. The z-pins may cause significant misalignment of the fibers of the composite because the diameter of the $\mathrm{z}$ pins $(\sim 280$ to $510 \mu \mathrm{m})$ is large relative to the diameter of the fibers $(\sim 7 \mu \mathrm{m})$.

Previously, Sun and coworkers studied the influence of shear loads on the uni-axial compression strength of composites by testing an off-axis unidirectional lamina and extrapolating the compression strength [10-12]. They found that the addition of small shear loads significantly reduce the compression strength of unidirectional composite lamina. In this study, the influence of additional shear loads, along with axial compression, on the strength some commonly utilized laminates with z-pins will be evaluated parametrically. First, closed form expressions for compression strength of composite lamina will be reviewed and compared to FE based predictions. Next, the strength of some typical laminates, with and without z-pins, under combined compression and shear loads will be predicted.

\footnotetext{
${ }^{*}$ The generic term z-pin will be used throughout the paper versus the trade mark Z-Fiber ${ }^{\mathbf{T M}}$ registered by Aztex Inc.
} 


\section{Background}

In general, strength is defined as the net cross sectional stress at the maximum load achieved during testing. The compression strengths of unidirectional fiber-reinforced composite lamina are much less than their corresponding tensile strengths. This lower compression strength is typically attributed to the mechanism of fiber micro-buckling where the fiber looses the local support of the surrounding matrix material. As shown in figure 1, micro-buckling initiates from an imperfection (fiber waviness with misalignment angle $\bar{\phi}$,) that forms a kink band of width, w, and inclination angle, $\beta$.

Several models have been proposed over the years for predicting the compression strength of unidirectional composite lamina. Rosen assumed that the micro-buckling mechanism that leads to collapse is an elastic bifurcation [13]. This leads to the simple relationship

$$
\sigma_{\mathrm{c}}=\mathrm{G}
$$

where " $G$ " is the lamina shear modulus. However, this elastic bifurcation assumption leads to an over-estimation of compression strength by a factor of four [14]. Argon [15] later developed a simple expression for compression strength

$$
\sigma_{c}=\tau_{y} / \bar{\phi}
$$

based on the assumption that micro-buckling was influenced primarily by plastic deformation in the matrix (governed by the yield strength in shear, $\tau_{\mathrm{y}}$ )

and local misalignment between the fiber direction and the load axis, $\bar{\phi}$, due to fiber waviness in the material. Hence, the composite lamina was assumed to fail in compression via imperfection sensitive plastic buckling. Budiansky and Fleck [14] further refined this approach for a composite with a matrix that undergoes strain hardening, with the strength given as 


$$
\frac{\sigma_{c}}{G}=\frac{1}{1+n(\alpha)^{1 / n}\left[\frac{\bar{\phi}}{\gamma_{y}(n-1)}\right]^{\frac{n-1}{n}}}
$$

where $\alpha$ and $n$ are parameters in the Ramberg-Osgood matrix strain hardening law, below, and the shear strain $\gamma_{\mathrm{y}}=\tau_{\mathrm{y}} / \mathrm{G}$

$$
\frac{\gamma}{\gamma_{y}}=\frac{\tau}{\tau_{y}}+\alpha\left(\frac{\tau}{\tau_{y}}\right)^{n}
$$

For inclined kink bands, where $\beta>0$, the Budiansky and Fleck equation becomes

$$
\frac{\sigma_{c}}{G}=\frac{1+R^{2} \tan ^{2} \beta}{1+n(\alpha)^{1 / n}\left[\frac{\bar{\phi}}{\gamma_{y}(n-1)} \sqrt{1+R^{2} \tan ^{2} \beta}\right]^{\frac{n-1}{n}}}
$$

where $\mathrm{R}$ is defined as

$$
\mathrm{R}=\frac{\sigma_{\mathrm{Ty}}}{\tau_{\mathrm{y}}} \approx \frac{\mathrm{E}_{\mathrm{T}}}{\mathrm{G}}
$$

where $\sigma_{\mathrm{Ty}}$ is the plane-strain lamina yield strength in transverse tension, $\mathrm{E}_{\mathrm{T}}$ is the lamina transverse Young's modulus, and $\alpha$ and $n$ are parameters in the modified Ramberg-Osgood matrix strain hardening law 


$$
\frac{\gamma_{e}}{\gamma_{y}}=\frac{\tau^{e}}{\tau_{y}}+\alpha\left(\frac{\tau}{e}\right)^{n}
$$

where the effective shear stress is

$$
\tau_{\mathrm{e}}=\sqrt{\sigma_{21}-\frac{\sigma_{22}^{2}}{\mathrm{R}^{2}}}
$$

and the effective shear strain is

$$
\gamma_{\mathrm{e}}=\left[\frac{1}{\mathrm{G}_{\mathrm{Sec}}}-\frac{1}{\mathrm{G}}\right] \tau_{\mathrm{e}}
$$

where $G_{\text {sec }}$ is the secant modulus of the shear stress versus total shear strain curve for the composite lamina.

Figure 2 shows the compression strength of a typical carbon epoxy composite lamina as predicted from equations 3 and 5 as a function of the fiber misalignment angle, $\bar{\phi}$, due to fiber waviness. Results are plotted for two different kink band inclination angles $(\beta=0$ and $30 \mathrm{deg})$ each evaluated assuming a shear yield strength of $108 \mathrm{Mpa}$ and using $\alpha=3 / 7$ and two different exponents $(n=3,19)$ in the Ramberg-Osgood strain hardening law. As shown in figure 2, compression strengths were significantly degraded for very small amounts of fiber waviness (1-2 degrees). However, compression strengths were fairly insensitive to $n$. In addition, zero degree kink band inclination angles gave the most conservative results. Angles greater than zero have been attributed to coupon edge effects [16-18].

In order to better assess the influence of critical parameters on lamina compression strength, Fleck and Shu developed a finite element code called FLASH. This FE code is based on a 2D general Cosserat couple stress theory that assumes the unidirectional composite lamina is a homogeneous anisotropic material that carries couple stress as well as classical Cauchy point stress [19-21]. The constitutive response is deduced from a unit cell consisting of a fiber, represented by a linear elastic Timoshenko beam, 
embedded in a non-linear elastic-plastic matrix. The fiber diameter, $\mathrm{d}$, is the length scale in the constitutive law that controls fiber bending resistance. The continuum theory was implemented within a two-dimensional finite element code that uses 6-noded triangular elements with 3 degrees of freedom at each node (two-displacements and one rotation corresponding to rotation of the fiber cross section). The finite element procedure is based upon a Lagrangian formulation of the finite deformation of the composite and can accommodate both geometric and material non-linearities. The code models finite deformation using a Newton-Raphson incremental solution procedure with a modified Riks algorithm in the final stage to handle snapback behavior associated with fiber micro-buckling. Boundary loading is piecewise proportional with a loading parameter, $\lambda$, for each loading stage [20].

The FLASH code assumes micro-buckling initiates from an imperfection in the form of fiber waviness. Inputs include lamina stiffness properties $\left(E_{L}, E_{T}, E_{T c}, G_{L T}, G_{f}\right)$ normalized by the shear yield strength $\left(\tau_{y}\right)$ and Ramberg-Osgood strain hardening law parameters $(\alpha, n)$. FLASH allows options for input of fiber misalignment angle due to fiber waviness either as (1) an elliptical patch of waviness, or (2) an arbitrary distribution of initial fiber waviness through initial misalignment angle, $\bar{\phi}$, at the Gauss integration point for each element. The first option prescribes the elliptical patch along one edge of the unit cell, and hence, was not useful for this study with an embedded void to simulate a lamina with an embedded z-pin. Steeves used the second option to input fiber misalignment distribution obtained from digital image analysis of specimens tested in a Scanning Electron Microscope (SEM) [7].

\section{Analysis Formulation}

For this study, the FLASH code was obtained from Cambridge University and was installed on a Unix based workstation at NASA Langley. Sikorsky Aircraft Company manufactured carbon epoxy laminates reinforced with small z-pins of $0.280 \mathrm{~mm}(0.011 \mathrm{in})$ diameter and large $\mathrm{z}$ pins of $0.508 \mathrm{~mm}$ (0.02 in) diameter. Three specimen types were manufactured containing reinforcement fields with $4 \%$ areal density for the large z-pin and 2\% and $4 \%$ areal density for the small z-pins respectively. Finite element meshes with the z-pin and surrounding resin rich regions 
simulated as voids were generated for three unique combinations of pin diameter and density. Geometric parameters used to generate the finite element meshes of the unit cells for different z-pin diameters and z-pin areal densities are shown in figure 3 . The size of the unit cell depends on the areal density, $r_{z}$ (in \%) of the z-pins in the unit cell and the diameter of a single zpin, $D_{z}$ as shown in Figure 3 . The spacing $L_{z}=H_{z}$ for a perfect, rectangular zpin field can be calculated as

$$
L_{Z}=H_{Z}=\sqrt{\frac{A_{Z}}{A_{r}}}
$$

where $A_{Z}$ is the cross sectional area of a single z-pin

$$
A_{Z}=\frac{\pi D_{Z}^{2}}{4}
$$

and $A_{r}$ denotes the fraction of the total reinforced area covered by z-pins

$$
A_{r}=\frac{r_{Z}}{100}
$$

The length of the resin pocket, $C$, may be determined from micrographs of the reinforced laminate.

It was assumed that the fiber is completely surrounded by resin as shown in figure 4 , and hence, the transverse dimension of the void, $\mathrm{D}_{\mathrm{z}}$, was increased by $0.02 \mathrm{~mm}$ compared to the z-pin diameter, $\mathrm{D}_{\mathrm{z}}$. The unit cell parameters were measured from micrographs taken from different specimens with z-pins. Averaged data shown in table 1 were used as input for the FLASH finite element analyses. Finite element meshes, are shown in figure 5 for the small pin with $2 \%$ and $4 \%$ areal density and the large pin with $2 \%$ areal density. All meshes generated were composed of six-noded triangular plane-strain elements. The size of the elements was varied to provide the greatest mesh refinement near the resin pocket, and in the region of greatest fiber misalignment. All dimensions were normalized by the fiber diameter, as required as input to FLASH. Carbon Epoxy material data, including the measured strain hardening parameters for the Ramberg-Osgood law, were measured at Sikorsky Aircraft Company and used as input for the FLASH analyses (table 2). 
The FLASH code requires input of the fiber misalignment angle representative of the inherent waviness in the composite material. Input of an arbitrary distribution of the fiber misalignment in FLASH is possible. However, these data were not readily available. Hence, the second option for input of fiber misalignment angle was used to prescribe a uniform distribution of constant fiber waviness in unit cells simulating lamina with embedded z-pins. This option was also chosen to provide a conservative estimate of the influence of fiber waviness. In order to perform a parametric study of the effect of fiber misalignment on laminate in-plane strength, uniform distributions of initial fiber misalignment angles from 0 to 10 degrees were input to each of the three models.

A laminated plate theory analysis was performed on three layups, subjected to either pure compression or equal compression and shear loading $\left(\mathrm{N}_{\mathrm{x}}=\mathrm{N}_{\mathrm{xy}}\right)$, to determine the bi-axial stresses in the zero degree plies (fig.6). Normalized ply stresses are shown in table 3 . Transverse $\left(\sigma_{22}\right)$ and shear $\left(\tau_{12}\right)$ stresses in the zero degree plies were normalized by the axial compression stresses $\left(\sigma_{11}\right)$ in the fiber direction to identify the relative magnitudes of the zero degree ply stresses for the three laminates analyzed. Transverse stresses were negligible, except for the cross ply laminate where they consisted of only $2 \%$ of the axial compression stress. For the three laminates subjected to combined external compression and shear loads of equal magnitude, shear stresses in the zero degree plies where approximately $10 \%$ of the axial compression stresses for the orthotropic and quasi-isotropic laminate, and approximately $50 \%$ of the axial compression stresses for the cross ply laminate.

In order to perform a parametric study, these relative percentages of axial compression, transverse tension, and shear stresses in the zero degree plies were used to determine the magnitude of the relative load steps prescribed in the FLASH analyses as shown in table 4. The compression stress is gradually incremented by FLASH until it reaches the specified limit defined by the user $\left(\sigma_{11} \tau_{\mathrm{y}}=-1000\right.$, where $\tau_{\mathrm{y}}$ is the shear yield strength of the material). This limit was deliberately chosen to be well above the onset of fiber microbuckling to assure that the analysis reached the failure point and did not terminate prematurely. For the combined load cases, the other loads were incremented in the proportions shown in table 4. A typical run lasted just under two hours to obtain a strength prediction. 
Unit cells were analyzed for five load cases: (1) a pure axial compression load case, (2) a combined axial compression and $2 \%$ transverse tension load case, (3) a combined axial compression and 10\% shear load case, (4) a combined axial compression and 50\% shear load case, and (5) an axial compression with both a $2 \%$ transverse tension load case and a $10 \%$ shear loading. Load and boundary conditions used in this study for axial compression (figure 7) were identical to those used by Steeves and others $[7,19]$. However, appropriate load and boundary conditions had to be determined before simulating shear loading in FLASH. Ultimately, boundary conditions identical to those used for the simulation of axial compression loading cases were used for shear loading (see Appendix). These boundary conditions were selected for the remainder of the study because they were also ideally suited for combining shear loading with axial compression loading. Further details for setting up models of unit cells with z-pins using FLASH are documented in reference 22.

\section{Analysis Results}

Figure 8 shows the compression strength, corresponding to the onset of fiber microbuckling, as a function of fiber waviness for the three z-pin configurations analyzed. Results indicated that increasing pin density was more detrimental to compression strength than increasing pin diameter. Figure 9 shows the technique used to calculate the misalignment angle, $\bar{\phi}$, associated with z-pin insertion for the three unit cell geometries based on the geometric points used to generate the unit cell finite element meshes [22]. The z-pin insertion angle was greater for the smaller diameter pins than for the larger diameter pins. In figure 10, compression strength predictions for lamina with z-pins were plotted as a function of the total misalignment angle due to z-pin insertion and fiber waviness. This has the effect of offsetting the z-pin results along the horizontal axis by the amount of the initial misalignment due to z-pin insertion as shown in figure 9. FLASH results were also generated for lamina with no-z-pins by closing the void to create a new unit cell mesh (figure 11). Results are plotted in figure 10 for comparison. As shown in figure 10, compression strengths of lamina without z-pins agreed well with a closed form expression derived by Budiansky and Fleck (eq.3). FLASH results for lamina with z-pins were consistent with the closed form results, and FLASH results without z-pins, if the initial fiber waviness due to z-pin insertion from figure 9 was added to fiber waviness in 
the material to yield a total $\bar{\phi}$.

Figures 12-14 show the stress-displacement plots and shear stress contours for the three z-pin configurations analyzed assuming three values of fiber waviness ( 0,1 and 5 degrees). In the plots of stress versus displacement, the average stress along the lower left edge of the unit cell is plotted versus the displacement (normalized by the fiber diameter) at the lower left corner of the unit cell [22]. The zero degree case reflects specimen response due to initial misalignment associated with z-pin insertion from figure 9 alone. Each stress-displacement plot has a maxima indicating the onset of an unstable event (fiber microbuckling) followed by a finite deformation as the kink band forms and grows. The shear stress contours are plotted at the final load step and mimic the region where kink band formation would be anticipated. This becomes increasingly more obvious for higher values of fiber waviness.

As shown in figure 15, the addition of $10 \%$ shear to the compression loading significantly reduced the lamina strength compared to pure compression loading predicted by the Budiansky and Fleck equation. The FLASH results with z-pins were still consistent with FLASH results without z-pins when the initial fiber waviness due to z-pin insertion from figure 9 was added to fiber waviness. Figures 16-18 show the stress-displacement plots and shear stress contours for the three z-pin configurations analyzed assuming three values of fiber waviness ( 0,1 and 5 degrees). As noted previously for compression loading, each stress-displacement plot has a maxima indicating the onset of an unstable event (fiber microbuckling) followed by a finite deformation as the kink band forms and grows. The shear stress contours, plotted at the final load step, clearly indicate the region where kink band formation would be anticipated. These high shear stress regions are more obvious for this combined compression and $10 \%$ shear loading than for the compression only loading shown in figures 12-14.

As shown in figure 19, the addition of $50 \%$ shear to the compression loading appeared to drastically reduce the lamina strength compared to pure compression loading predicted by the Budiansky and Fleck equation. However, the FLASH results with z-pins were no longer consistent with FLASH results without z-pins when including the initial misalignment angle due to $\mathrm{z}$-pin insertion. The results for the $2 \%$ density small z-pin configuration slightly decreased with fiber waviness angle. However, the 
results for the other two configurations did not vary with fiber waviness angle. Figures 20-22 show the stress-displacement plots and shear stress contours for the three z-pin configurations analyzed assuming three values of fiber waviness (0,1 and 5 degrees). Unlike the previous load cases, these plots indicated no decrease in stress for two configurations, and only a very gradual decrease in stress for the third configuration, with increased displacement with no indication of an instability followed by finite deformation. Furthermore, for two of the three configurations, the shear stress contours plotted at the final load step did not clearly indicate if kink band formation would be anticipated. In addition, as shown in figure 23, the applied shear stress was close to, and in one case exceeded, the shear yield strength of the material (table 2). This is in contrast to the compression plus $10 \%$ shear case, also shown in figure 23 , where the applied shear stresses were consistently lower than the shear yield strength. Hence, gradual shear yielding may be the failure mode for this compression plus $50 \%$ shear loading rather than kink band formation. As shown in tables 3 and 4, this load case corresponds to equal compression and shear loading on a cross-ply $[0 / 90]_{\mathrm{s}}$ laminate. Hence, laminates without 45 degress plies may be more likely to fail by shear yielding than microbuckling.

As shown in figures 24-26, the addition of $2 \%$ transverse tension (table 4) to pure compression loading, or to compression plus $10 \%$ shear loading, has no significant influence on predicted strengths.

\section{Strength prediction for stiffener reinforced skin laminates under combined compression and shear loading}

Two different stiffener reinforced skin configurations with z-pins were analyzed (figure 27). The first configuration consisted of an 8-ply $(45 / 0 /-45 / 90)_{\mathrm{s}}$ quasi-isotropic skin bonded to a stiffener with a 16-ply (45/0/$45 / 90)_{2 \mathrm{~s}}$ quasi-isotropic flange. The second configuration consisted of a 6ply $(45 / 0 /-45)_{\mathrm{s}}$ orthotropic skin bonded to a stiffener with an 18-ply (45/0/0/$45 / 0 / 45 / 0 /-45 / 0)_{s}$ flange. For both configurations, the total 24-ply combined laminate where the skin meets the stringer flange was modeled with $2 \%$ areal density small diameter z-pins $\left(D_{z}=0.28 \mathrm{~mm}\right)$. A laminated plate theory analysis was performed for both 24-ply laminates using the carbon epoxy material properties in table 5. These properties differ from those in table 2 only for the lower value of $\mathrm{E}_{11}$ used to better represent the lamina compression stiffness in the fiber direction. The applied net compression 
stress was specified and the corresponding stresses in the individual plies were calculated.

For the quasi-isotropic configuration, the ratio of the applied net compression stress to the compression stress in the zero degree plies was 0.392. Interestingly, although the skin and stringer flange alone were balanced and symmetric laminates, the total 24-ply laminate was not. Nevertheless, no significant coupling was predicted by laminate theory, which yielded equal stresses in all the zero degree plies.

As expected, the 24-ply unsymmetric orthotropic configuration exhibited compression and bending coupling resulting in the maximum zero degree ply stresses in the outermost zero-degree skin ply. For this ply, the ratio of the applied net compression stress on the laminate to the compression stress in the zero degree ply was 0.480 . The laminate theory calculation was performed allowing the full bending deformation due to the coupling that arises from the unsymmetric skin-flange laminate. If, however, this bending deformation is constrained in the structural configuration, the constraint should be applied when performing the laminate theory analysis to estimate the zero degree ply stresses. Alternatively, the zero degree ply stresses could be obtained directly from a numerical analysis of the skinstiffener region if the individual plies are modeled discretely.

Unidirectional compression strengths predicted from FLASH were multiplied by the appropriate factor for each configuration and loading to calculate predicted strengths for the skin/stiffener-flange laminates. For each configuration, six unique loading cases ranging from $\mathrm{N}_{\mathrm{xy}} / \mathrm{N}_{\mathrm{x}}=0$ to $\mathrm{N}_{\mathrm{xy}} / \mathrm{N}_{\mathrm{x}}=$ 0.5 , were assumed in the FLASH analysis using material properties in table 5 and assuming material fiber waviness misalignment angles of 0,1 , and 2 degrees. Table 6 shows the normalized zero degree ply stresses (axial, transverse, and shear) for the six loadings on the two stringer reinforced skin configurations analyzed. The axial compression stress in the zero degree plies is shown as -1000 times the shear yield strength, $\tau_{\mathrm{y}}$. The magnitude of the other normalized stress components are shown relative to the normalized compression stress. These relative magnitudes were used as input to the FLASH code for each load case studied. No transverse stresses developed in the zero degree plies for the quasi-isotropic configuration. Transverse stresses in the zero degree plies of the orthotropic configuration were small, with magnitudes of $3.5 \%$ of the axial compression stresses in the zero degree plies. For both configurations, the ratio of the shear stresses to the axial 
compression stresses in the zero degree plies were roughly $10 \%$ of the ratio of the applied shear to the applied compression, $\mathrm{N}_{\mathrm{xy}} / \mathrm{N}_{\mathrm{x}}$. For example, when the orthotropic configuration has an applied shear load that is $50 \%$ of the applied compression load $\left(\mathrm{N}_{\mathrm{xy}} / \mathrm{N}_{\mathrm{x}}=0.5\right)$, the resulting shear stress in the zero degree plies is only $5 \%$ of the axial compression stress in the zero degree plies $\left(\sigma_{11} / \tau_{\mathrm{y}}=-1000, \tau_{12} / \tau_{\mathrm{y}}=50\right)$.

Figures 28 and 29 show the zero degree ply strengths as a function of the misalignment angle predicted using the FLASH code with loadings prescribed based on the ratio of axial compression and shear, $\mathrm{N}_{\mathrm{xy}} / \mathrm{N}_{\mathrm{x}}$. for the two configurations analyzed. Similarly, figures 30 and 31 show the skin/stiffener-flange laminate strengths, corresponding to the onset of fiber microbuckling in the zero degree plies, as a function of the misalignment angle predicted using the appropriate laminated plate theory scale factor described earlier for each configuration. The reduction in compression strength with increased shear loading is apparent for both skin/stiffenerflange configurations.

Figure 32 compares the strength of the skin/stiffener-flange laminates for the quasi-isotropic and orthotropic skin/stiffener-flange configurations for $\mathrm{N}_{\mathrm{xy}} / \mathrm{N}_{\mathrm{x}}=0.5$. Results indicate that the quasi-isotropic configuration should have lower strengths than the orthotropic configuration.

Figure 33 shows the combined shear plus compression strength, $\sigma_{\text {ult }}$, normalized by the compression only strength, $\sigma_{\text {ultc }}$, as a function of the normalized loading, $\mathrm{N}_{\mathrm{xy}} / \mathrm{N}_{\mathrm{x}}$, for the quasi-isotropic skin/stiffener-flange laminate assuming three values of misalignment angle, 0,1 and 2 degrees. Although the absolute strength is lower for laminates with larger misalignment angles (fig.30), the normalized strength reduction $\left(\sigma_{\text {ult }} / \sigma_{\text {ultc }}\right)$ is slightly less for larger misalignment angles (fig.33).

Figure 34 shows the combined shear plus compression strength, normalized by the compression only strength, as a function of the normalized loading, $\mathrm{N}_{\mathrm{xy}} / \mathrm{N}_{\mathrm{x}}$, for the orthotropic skin/stiffener-flange laminate assuming three values of misalignment angle, 0,1 and 2 degrees. Although the absolute strength is lower for laminates with larger misalignment angles (fig.31), the normalized strength reduction is slightly less for larger misalignment angles (fig.34). 
Figure 35 compares the combined shear plus compression strength, normalized by the compression only strength, as a function of the normalized loading, $\mathrm{N}_{\mathrm{xy}} / \mathrm{N}_{\mathrm{x}}$, for the quasi-isotropic and orthotropic skin/stiffener-flange laminates assuming a misalignment angle of one degree. Although the strength is lower for the quasi-isotropic laminates than the orthotropic laminates, the normalized strength reduction is slightly less for the quasi-isotropic laminates.

\section{Conclusions}

The influence of combined compression and shear loads on the strength of lamina in some commonly utilized laminates was evaluated parametrically. A 2D Finite Element Code (FLASH) developed at Cambridge University based on Cosserat couple stress theory was used to model unit cells simulating unidirectional lamina with inserted z-pins. The FLASH code assumes micro-buckling initiates from an imperfection in the form of fiber waviness with a characteristic misalignment angle. Finite element meshes with the z-pin and surrounding resin rich regions simulated as voids were generated for three unique combinations of pin diameter and density. Carbon epoxy material property data, including measured strain hardening parameters for the Ramberg-Osgood law, were generated as input for the FLASH analyses. A laminated plate theory analysis was performed on three layups, subjected to either pure compression or equal compression and shear loading, to determine the bi-axial stresses in the zero degree plies. The relative percentage of axial compression, transverse tension, and shear stresses on the zero degree plies was used to determine the magnitude of the relative load steps prescribed in the FLASH analyses.

Parametric study results indicated that increasing pin density was more detrimental to in-plane compression strength than increasing pin diameter. Compression strengths of lamina without z-pins agreed well with a closed form expression derived by Budiansky and Fleck. FLASH results for lamina with z-pins were consistent with the closed form results, and FLASH results without z-pins, if the initial fiber waviness due to z-pin insertion was added to the fiber waviness in the material to yield a total misalignment. Addition of $10 \%$ shear to the compression loading significantly reduced the lamina strength compared to pure compression loading. Addition of 50\% shear to the compression loading appeared to drastically reduce the lamina strength compared to pure compression loading only. However, the applied 
shear stress was close to, and in one case exceeded, the shear yield strength of the material. Hence, for this loading failure is likely due to shear yielding rather than kink band formation.

Two different stiffener reinforced skin configurations with z-pins, one quai-isotropic and one orthotropic, were also analyzed. For both configurations, the total 24-ply combined laminate where the skin meets the stringer flange was modeled. A laminated plate theory analysis was performed for both 24-ply laminates. The ratio of the applied net compression stress on the laminate to the compression stress in the zero degree plies was calculated to predict strengths for the skin/stiffener-flange laminates. Six unique loading cases ranging from pure compression to compression plus 50\% shear were analyzed assuming material fiber waviness misalignment angles of 0,1 , and 2 degrees. Compression strength decreased with increased shear loading for both configurations, with the quasi-isotropic configuration yielding lower strengths than the orthotropic configuration. Although the predicted strength was lower for laminates with larger misalignment angles, the normalized strength reduction (combined loading strength divided by pure compression strength) was slightly less for larger misalignment angles. Furthermore, although the predicted strength was lower for the quasi-isotropic laminates than the orthotropic laminates, the normalized strength reduction was slightly less for the quasi-isotropic laminates. 


\section{References}

1. Tay, T.E., Characterization and analysis of delamination fracture in composites - An overview of developments from 1990 to 2001. Applied Mechanics Reviews, 2003. 56(1): p. 1-32.

2. O'Brien, T.K., "Fracture Mechanics of Composite Delamination," ASM Handbook, Vol.21, Composites, August, 2001, p.241-245.

3. Clarke, A., Greenhalgh, E., Meeks, C. and Jones, C., Enhanced Structural Damage Tolerance of CFRP Primary Structures by Z-pin Reinforcement, $44^{\text {th }}$ AIAA SDM Conference, paper AIAA-2003-1679, Norfolk, VA, 2003.

4. Freitas, G., Fusco, T. and Campbell, T., Z-fiber technology and products for enhancing composite design. in AGARD Conference Proceedings 590: Bolted/Bonded Joints in Polymeric Composites. Advisory Group for Aerospace Research and Development, 1997, pp 8-17.

5. Cartie, D. and I. Partridge. Z-pinned composite laminates: Improvements in delamination resistance. in 5th International Conference on Deformation and Fracture of Composites. 1999: Institute of Materials. 
6. Barrett, J.D., The mechanics of z-fiber reinforcement. Composite Structures, 1996. 36: p. 23-32.

7. Steeves, C.A., Mechanics of Failure in Composite Structures, Ph.D. Dissertation, Department of Engineering, University of Cambridge: Cambridge, United Kingdom, 2001.

8. Massbo, R. and B.N. Cox, Unusual Characteristics of Mixed-Mode Delamination Fracture in the Presence of Large-Scale Bridging. Mechanics of Composite Materials and Structures, 2001. 8: p. 61-80.

9. Rugg, K.L., B.N. Cox, and R. Massabò, Mixed mode delamination of polymer composite laminates reinforced through the thickness by Zfibers. Composites A: applied science and manufacturing, 2002. 33(2): p. 177-190.

10. Sun, C.T., Novel Methods for Testing and Modelling Composite materials and Laminates, Proceedings of the Second International Conference on Composites Testing and Model Identification, CompTest 2004, Bristol, England, September, 2004.

11. Sun, C.T. and Jun, A.W., Compressive Strength of Unidirectional Composites with matrix non-linearity, Composites Science and Technology, Vol. 52, No. 4, pp.577-587

12. Sun, C.T. and Chung, I., An oblique end tab design for testing offaxis composites, Composites, Vol.24, No.8, 1993, pp. 619-623. 
13. Rosen, B.W., Mechanics of Composite Strengthening, Fibre Composite Materials, American Society of Metals Seminar, Chapter 3, 1965, pp 37-75.

14. Budiansky, B. and Fleck, N.A., Compressive Failure of Fibre Composites, J. Mechanics and Physics of Solids, Vol.41, No.1, 1993, pp.183-211.

15. Argon, A.S. Fracture of Composites, Treatise of Materials Science and Technology, Vol.1, Academic Press, New York, 1972.

16. Budiansky, B., Micromechanics, Computers and Structures, Vol.16, No.1, 1983, pp. 3-12.

17. Kyriakides, S. et.al, On the Compressive Failure of Fiber Reinforced Composites, EMRL report No. 93/11, Dept. of Aerospace Engineering, U. of Texas, Austin, Texas, 1993.

18. Fleck, N.A., Deng, L., and Budiansky, B., Prediction of kink band width in Fiber Composites, J. of Applied Mechanics, Vol.62, June, 1995, pp.329-337.

19. Fleck, N.A. and Shu, J.Y., Microbuckle Initiation in Fibre Composites: A Finite Element Study, J. Mechanics and Physics of Solids, Vol.43, No.2, 1995, pp.1887-1918. 
20. Shu, J.Y. and Fleck, N.A., User's Manual for Finite Element Code for Fibre Microbuckling, Cambridge University Engineering Department C-MATS Technical Report 224 (ISSN 0309-6505), May, 1995.

21. Liu, D. and Fleck, N.A., User's manual II for Finite Element Code FLASH for Fibre Microbuckling, Cambridge University Engineering Department C-MICROMECH Technical Report 29 (ISSN 03097420), November, 1999.

22. Krueger, R., Modelling of unit-cells with z-pins using FLASH: Preprocessing and Post-processing, NIA Report 2005-01. 


\section{APPENDIX}

\section{Boundary Conditions and Shear load application for Unit Cells}

The choice of available constraint conditions in FLASH was limited compared to commercial finite element software packages. For example, constraining the nodes along the top or bottom edge of the unit cell so that the edge remains straight and can only move in y-direction was not possible. This option would have been appropriate for enforcing pure shear deformation. With these restrictions the following approach was used:

- Different load and boundary conditions, such as those shown in figure A1, were chosen to simulate shear loading for simple models without z-pins using the linear finite element code ABAQUS ${ }^{\circledR}$

- Based on the deformation plots, the best combination of load and boundary conditions was selected and used for a model of nine unit cells as shown in figure A2. The prescribed displacements in Figure A1b could not be used in FLASH and were replaced by shear stresses on the top edge as shown in Figure A2a. It was assumed that the center cell is far enough away from the free boundaries to be representative of a unit cell.

- A full analysis of the nine unit cell model was performed using FLASH as shown in Figure A3.

- The deformed center cell shown in Figure A3b was selected as a reference. This meant that load and boundary conditions for subsequent models of unit cells had to be selected in such a way that the deformations matched the reference as closely as possible

A finite element model of a unit cell subjected to shear loading is shown in Figure A4a. Load and boundary conditions were identical to the case with nine cells shown in Figure A3. The deformed plot in Figure A4b indicates that the deformations of the top and bottom edges are excessively constrained compared to the reference configuration in Figure A3b. It was therefore decided to select a less rigid constraint.

The boundary conditions used for the models shown in Figures A5a and A6a were identical to those used earlier for the simulation of axial compression. Positive shear stresses were applied on all edges as shown in Figure A5a, and negative shear stresses were applied to the model of Figure A6a. The deformed configurations in Figures A5b and A6b suggested that these load and boundary conditions allow more realistic shear 
deformation compared to the reference configuration in Figure A3b than the load and boundary conditions represented in figure A4b. Hence, these boundary conditions were selected for the remainder of the study since they were also ideally suited for combining shear loading with axial and transverse loading.

\section{ACKNOWLEDGEMENTS}

This research was supported by Sikorsky Aircraft and the Aviation Applied Technology Directorate under Technology Investment Agreement No. DAAH10-02-2-0001 as part of the Survivable, Affordable, Repairable, Airframe Program (SARAP). The authors gratefully acknowledge Prof. Norman A. Fleck of Cambridge University, and Dr. Craig A. Steeves of Princeton University for providing the FLASH finite element code and insight into its use and application. The authors further acknowledge Dr. Jeffery Schaff of Sikorsky Aircraft for providing focus for the study. 
Table 1

Carbon/Epoxy UD Prepreg Unit Cell Parameter Dimensions

\begin{tabular}{|c|c|c|}
\hline \multicolumn{3}{|c|}{ Case A : Carbon/Epoxy UD Prepreg with $2 \%$ large diameter Z-Pins } \\
\hline & from & normalized with $d$ \\
\hline$D_{\mathrm{Z}}$ & $0.508 \mathrm{~mm}$ & - \\
\hline$D_{\mathrm{Z}}^{\prime}$ & $0.528 \mathrm{~mm}$ & 103.53 \\
\hline$H_{\mathrm{Z}}$ & $3.175 \mathrm{~mm}$ & 622.55 \\
\hline$L_{\mathrm{Z}}$ & $3.175 \mathrm{~mm}$ & 622.55 \\
\hline$C$ & $2.1844 \mathrm{~mm}$ & 428.31 \\
\hline \multicolumn{3}{|c|}{ Case B : Carbon/Epoxy UD Prepreg with 4\% small diameter Z-Pins } \\
\hline & from & normalized with $d$ \\
\hline$D_{\mathrm{Z}}$ & $0.28 \mathrm{~mm}$ & - \\
\hline$D_{\mathrm{Z}}^{\prime}$ & $0.3 \mathrm{~mm}$ & 58.8 \\
\hline$H_{\mathrm{Z}}$ & $1.2446 \mathrm{~mm}$ & 244 \\
\hline$L_{\mathrm{Z}}$ & $1.2446 \mathrm{~mm}$ & 244 \\
\hline$C$ & $0.868 \mathrm{~mm}$ & 170.2 \\
\hline \multicolumn{3}{|c|}{ Case C : Carbon/Epoxy UD Prepreg with $2 \%$ small diameter Z-Pins } \\
\hline & from & normalized with $d$ \\
\hline$D_{\mathrm{Z}}$ & $0.28 \mathrm{~mm}$ & - \\
\hline$D_{\mathrm{Z}}^{\prime}$ & $0.3 \mathrm{~mm}$ & 58.8 \\
\hline$H_{\mathrm{Z}}$ & $1.7526 \mathrm{~mm}$ & 343.65 \\
\hline$L_{\mathrm{Z}}$ & $1.7526 \mathrm{~mm}$ & 343.65 \\
\hline$C$ & $0.868 \mathrm{~mm}$ & 170.2 \\
\hline
\end{tabular}


Table 2

Carbon/Epoxy Material Properties

\begin{tabular}{|ll|}
\hline$E_{11}$ & $161 \mathrm{GPa}$ \\
$E_{22}$ (tension) & $11.4 \mathrm{GPa}$ \\
$E_{22}$ (compression) & $12.8 \mathrm{GPa}$ \\
$G_{12}$ & $5.17 \mathrm{GPa}$ \\
$G_{\mathrm{f}}$ & $22 \mathrm{GPa}$ \\
$\tau_{\mathrm{y}}$ & $39 \mathrm{MPa}$ \\
$d$ & $5.1 \mu \mathrm{m}$ \\
$V_{\mathrm{f}}$ & 0.59 \\
$v_{12}$ & 0.32 \\
$\alpha$ & 0.00923 \\
$n$ & 8.54 \\
\hline
\end{tabular}


Table 3

Normalized Zero-Degree ply Stresses from Laminate Analysis

\begin{tabular}{|c|c|c|c|}
\hline \multicolumn{5}{|c|}{ external load $\mathrm{N}_{\mathrm{x}}$} \\
\hline Laminate & $\sigma_{11} / \sigma_{11}$ & $\sigma_{22} / \sigma_{11}$ & $\tau_{12} / \sigma_{11}$ \\
\hline$[0 / 90]_{\mathrm{s}}$ & 1 & $-0.02\left(\sim 2 \% \sigma_{11}\right)$ & 0 \\
\hline$[0 / \pm 45]_{\mathrm{s}}$ & 1 & $0.003\left(\sim 0 \% \sigma_{11}\right)$ & 0 \\
\hline$[0 / 45 /-45 / 90]_{\mathrm{s}}$ & 1 & $-0.0001\left(\sim 0 \% \sigma_{11}\right)$ & 0 \\
\hline \multicolumn{5}{|c|}{ external load $\mathrm{N}_{\mathrm{x}}=\mathrm{N}_{\mathrm{xy}}$} \\
\hline$[0 / 90]_{\mathrm{s}}$ & $\sigma_{11} / \sigma_{11}$ & $\sigma_{22} / \sigma_{11}$ & $\tau_{12} / \sigma_{11}$ \\
\hline$[0 / \pm 45]_{\mathrm{s}}$ & 1 & $-0.02\left(\sim 2 \% \sigma_{11}\right)$ & $0.535\left(\sim 50 \% \sigma_{11}\right)$ \\
\hline$[0 / 45 /-45 / 90]_{\mathrm{s}}$ & 1 & $0.003\left(\sim 0 \% \sigma_{11}\right)$ & $0.073\left(\sim 10 \% \sigma_{11}\right)$ \\
\hline
\end{tabular}

Table 4

FLASH Input for Load Cases Used for Strength Reduction Analysis

\begin{tabular}{|l|c|c|c|c|c|}
\hline & $\begin{array}{c}\text { axial } \\
\text { compression }\end{array}$ & $\begin{array}{c}\text { compression/ } \\
2 \% \text { transverse } \\
\text { tension }\end{array}$ & $\begin{array}{c}\text { compression } \\
10 \% \text { shear }\end{array}$ & $\begin{array}{c}\text { compression } \\
50 \% \text { shear }\end{array}$ & $\begin{array}{c}\text { compression } \\
2 \% \text { tension } \\
10 \% \text { shear }\end{array}$ \\
\hline$\sigma_{11} / \tau_{\mathrm{y}}$ & -1000 & -1000 & -1000 & -1000 & -1000 \\
\hline$\sigma_{22} / \tau_{\mathrm{y}}$ & - & +20 & - & - & +20 \\
\hline$\tau_{12} / \tau_{\mathrm{y}}$ & - & - & 100 & 500 & 100 \\
\hline$\tau_{21} / \tau_{\mathrm{y}}$ & - & - & 100 & 500 & 100 \\
\hline
\end{tabular}


Table 5

Carbon/Epoxy Material Properties

\begin{tabular}{|ll|}
\hline$E_{11}$ (compression) & $143 \mathrm{GPa}$ \\
$E_{22}$ (tension) & $11.4 \mathrm{GPa}$ \\
$E_{22}$ (compression) & $12.8 \mathrm{GPa}$ \\
$G_{12}$ & $5.17 \mathrm{GPa}$ \\
$G_{\mathrm{f}}$ & $22 \mathrm{GPa}$ \\
$\tau_{\mathrm{y}}$ & $39 \mathrm{MPa}$ \\
$d$ & $5.1 \mu \mathrm{m}$ \\
$V_{\mathrm{f}}$ & 0.59 \\
$v_{12}$ & 0.32 \\
$\alpha$ & 0.00923 \\
$n$ & 8.54 \\
\hline
\end{tabular}


Table 6 - Normalized zero degree ply stresses in skin/ stringer-flange laminates

\begin{tabular}{|c|c|c|c|c|c|c|}
\hline $\begin{array}{c}\text { Ply } \\
\text { Stress }\end{array}$ & $\begin{array}{c}\mathrm{N}_{\mathrm{xy}} / \mathrm{N}_{\mathrm{x}} \\
=0\end{array}$ & $\begin{array}{c}\mathrm{N}_{\mathrm{xy}} / \mathrm{N}_{\mathrm{x}} \\
=0.1\end{array}$ & $\begin{array}{c}\mathrm{N}_{\mathrm{xy}} / \mathrm{N}_{\mathrm{x}} \\
=0.2\end{array}$ & $\begin{array}{c}\mathrm{N}_{\mathrm{xy}} / \mathrm{N}_{\mathrm{x}} \\
=0.3\end{array}$ & $\begin{array}{c}\mathrm{N}_{\mathrm{xy}} / \mathrm{N}_{\mathrm{x}} \\
=0.4\end{array}$ & $\begin{array}{c}\mathrm{N}_{\mathrm{xy}} / \mathrm{N}_{\mathrm{x}} \\
=0.5\end{array}$ \\
\hline$\sigma_{11} / \tau_{\mathrm{y}}$ & -1000 & -1000 & -1000 & -1000 & -1000 & -1000 \\
\hline$\sigma_{22} / \tau_{\mathrm{y}}$ & 0 & 0 & 0 & 0 & 0 & 0 \\
\hline$\tau_{12} / \tau_{\mathrm{y}}$ & 0 & 10 & 19 & 29 & 38 & 48 \\
\hline
\end{tabular}

(A) Quasi-isotropic configuration

\begin{tabular}{|c|c|c|c|c|c|c|}
\hline $\begin{array}{c}\text { Ply } \\
\text { Stress }\end{array}$ & $\begin{array}{c}\mathrm{N}_{\mathrm{xy}} / \mathrm{N}_{\mathrm{x}} \\
=0\end{array}$ & $\begin{array}{c}\mathrm{N}_{\mathrm{xy}} / \mathrm{N}_{\mathrm{x}} \\
=0.1\end{array}$ & $\begin{array}{c}\mathrm{N}_{\mathrm{xy}} / \mathrm{N}_{\mathrm{x}} \\
=0.2\end{array}$ & $\begin{array}{c}\mathrm{N}_{\mathrm{xy}} / \mathrm{N}_{\mathrm{x}} \\
=0.3\end{array}$ & $\begin{array}{c}\mathrm{N}_{\mathrm{xy}} / \mathrm{N}_{\mathrm{x}} \\
=0.4\end{array}$ & $\begin{array}{c}\mathrm{N}_{\mathrm{xy}} / \mathrm{N}_{\mathrm{x}} \\
=0.5\end{array}$ \\
\hline$\sigma_{11} / \tau_{\mathrm{y}}$ & -1000 & -1000 & -1000 & -1000 & -1000 & -1000 \\
\hline$\sigma_{22} / \tau_{\mathrm{y}}$ & 35 & 35 & 35 & 34 & 34 & 34 \\
\hline$\tau_{12} / \tau_{\mathrm{y}}$ & 0 & 10 & 20 & 30 & 40 & 50 \\
\hline
\end{tabular}

(B) Orthotropic configuration 


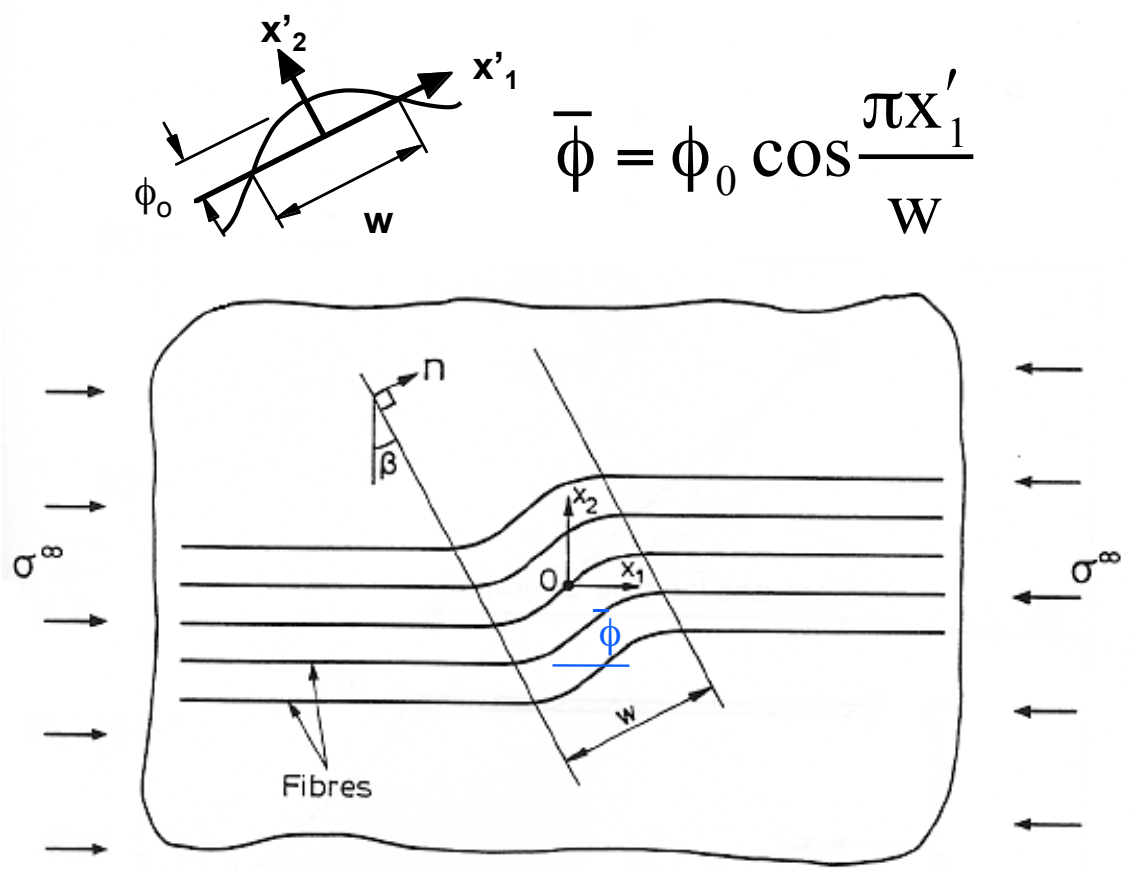

Figure 1. Fiber waviness parameters

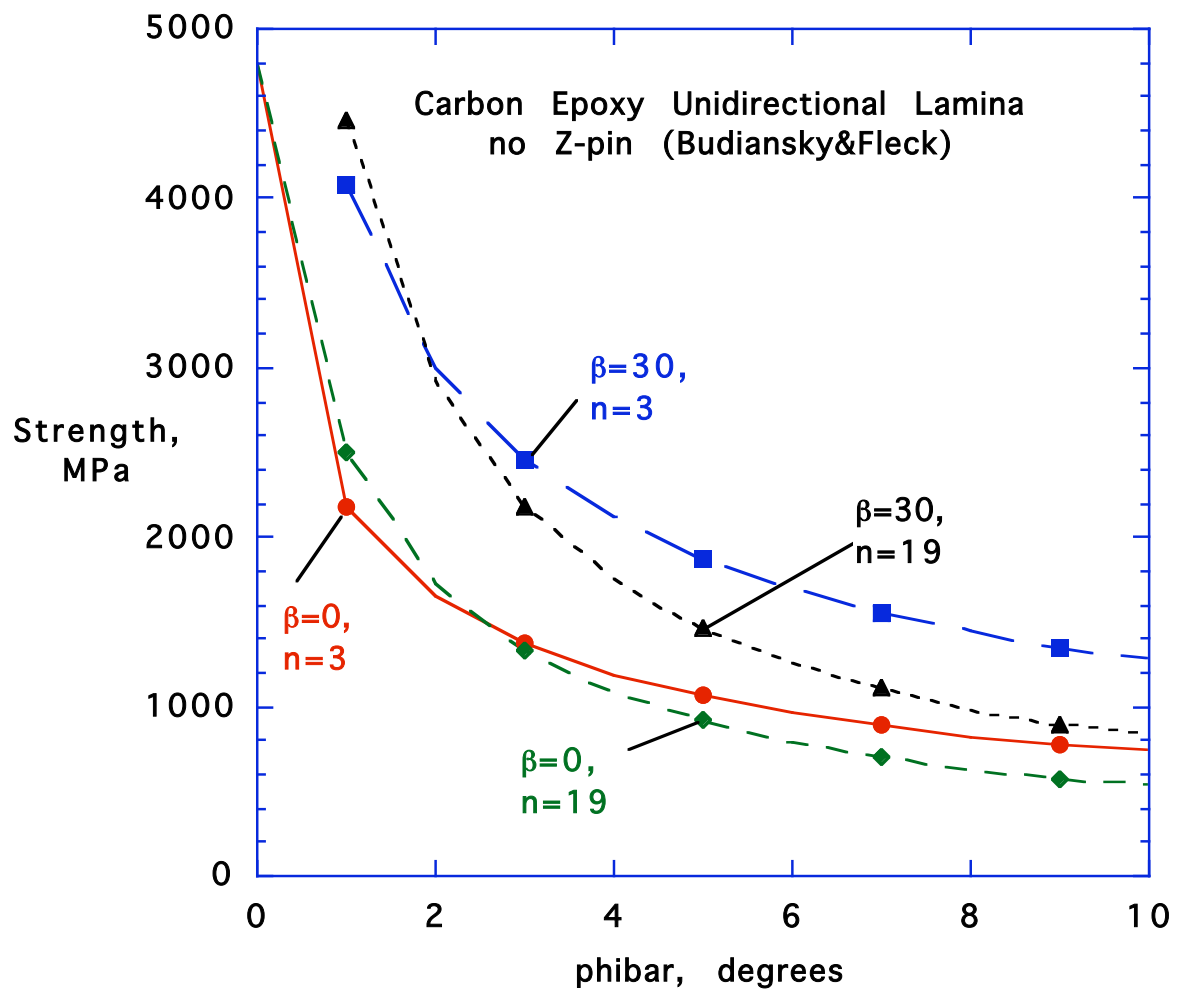

Figure 2. Compression strength prediction 


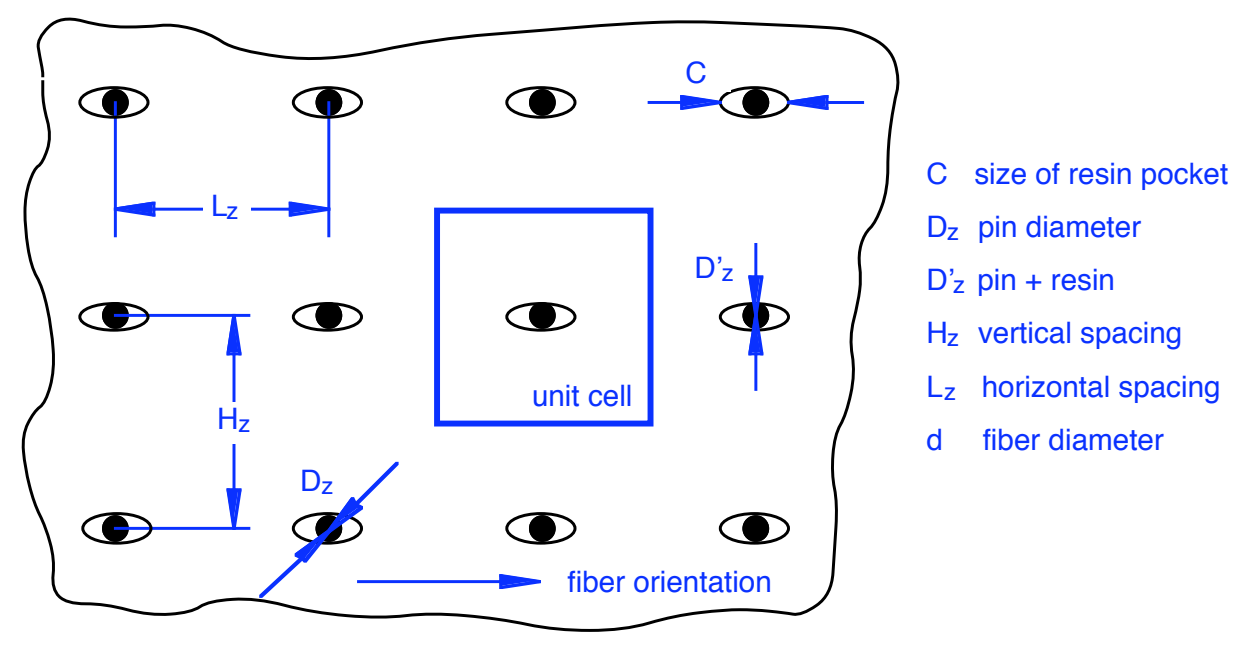

Figure 3. Z-pin geometric parameters

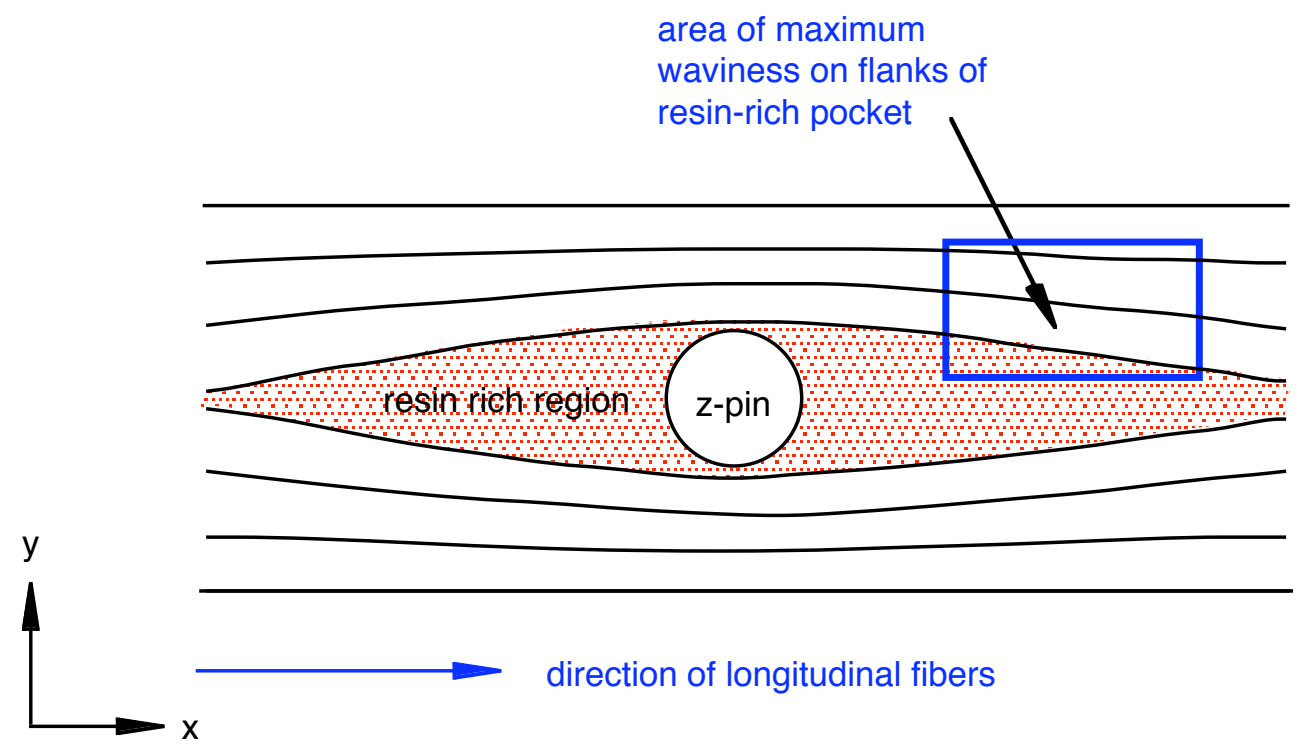

Figure 4. Fiber misalignment due to z-pin insertion 


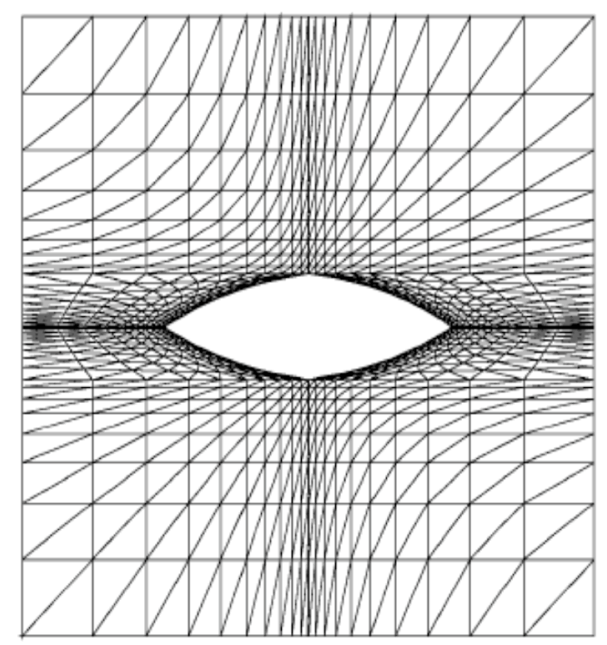

a) 2\% small z-pin

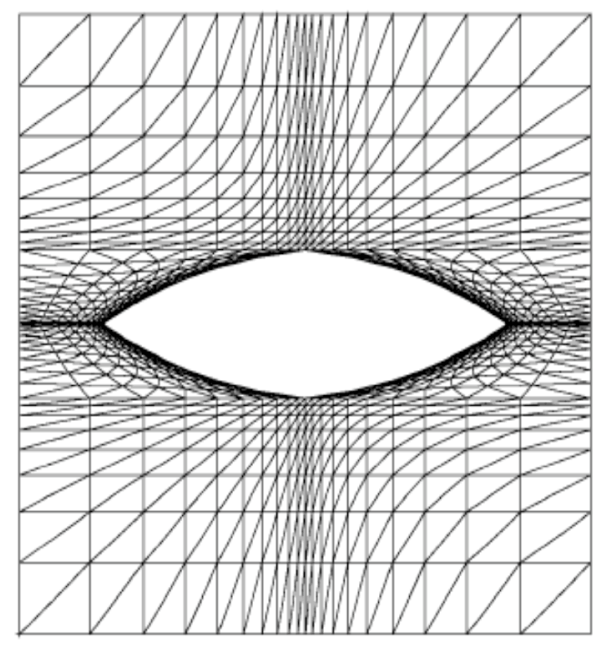

b) $4 \%$ small z-pin

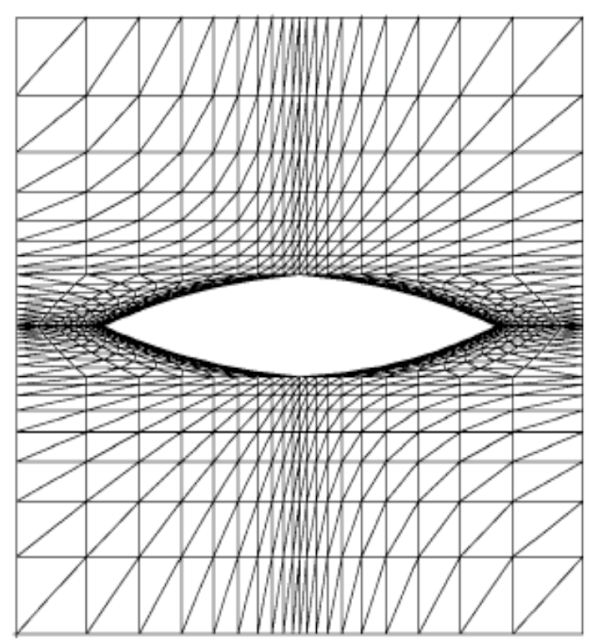

c) $2 \%$ large z-pin

Figure 5. FLASH models of carbon/epoxy lamina with embedded z-pins

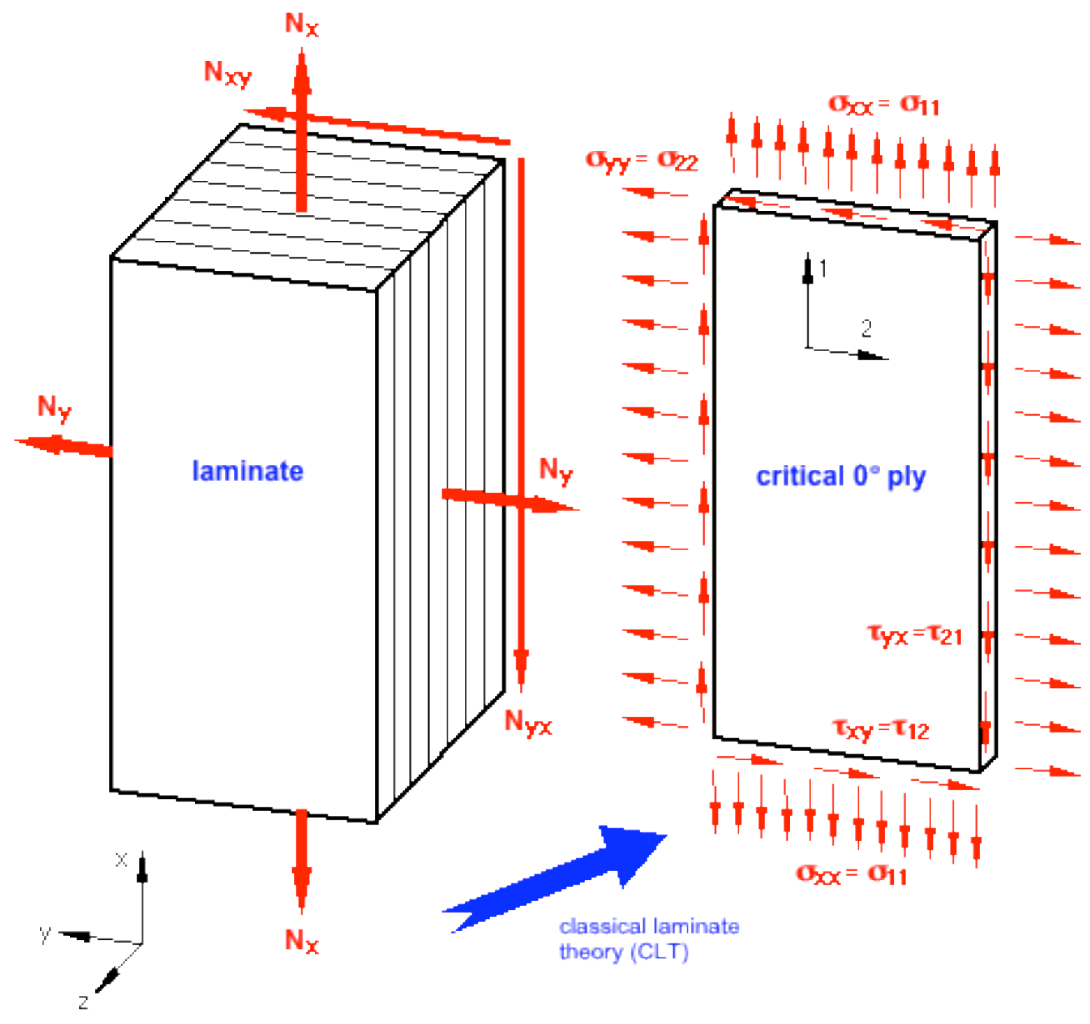

Figure 6. Laminate theory stress analysis 
$\mathrm{u}_{\mathrm{x}}=0.0$
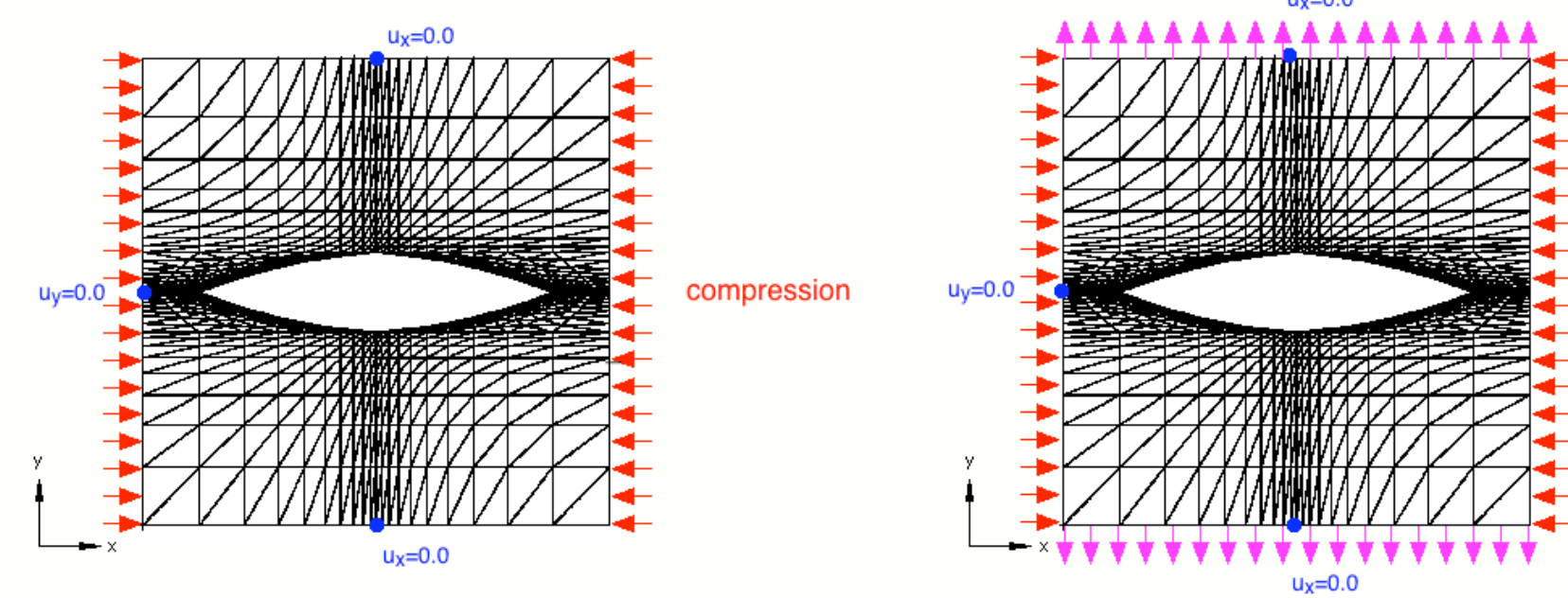

compression

$2 \%$ transverse tension

$\mathrm{u}_{\mathrm{x}}=0.0$
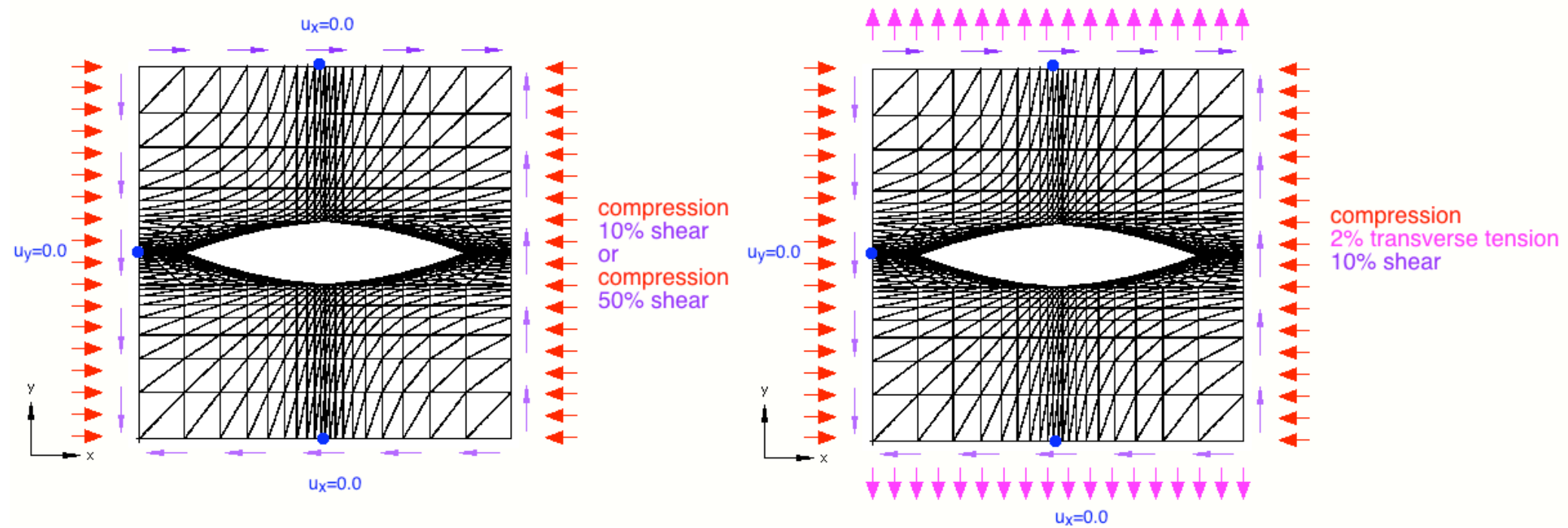

Figure 7. Loadings on unit cells with z-pins 


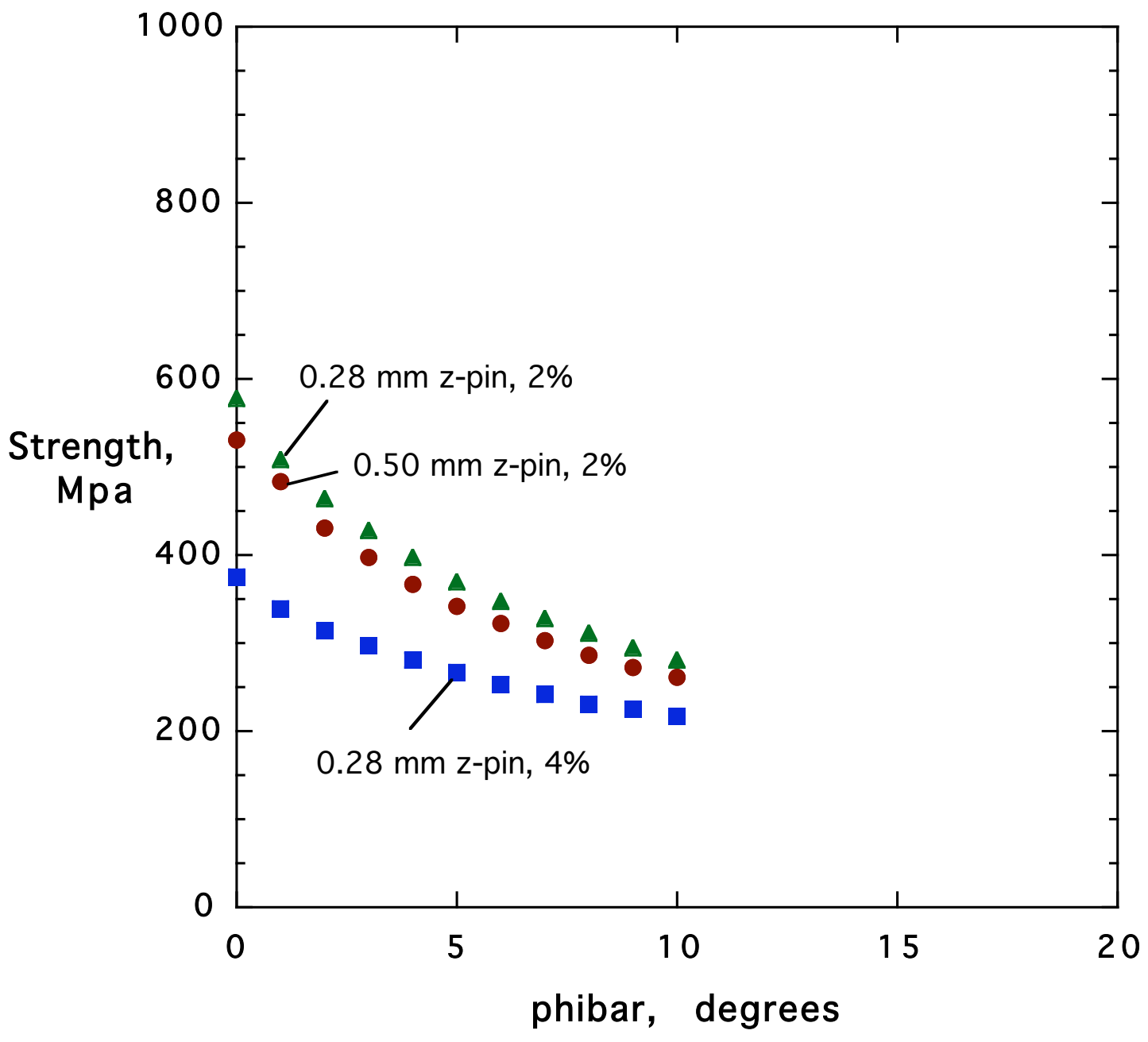

Figure 8. Influence of pin density and aerial weight percentage on compression strength 


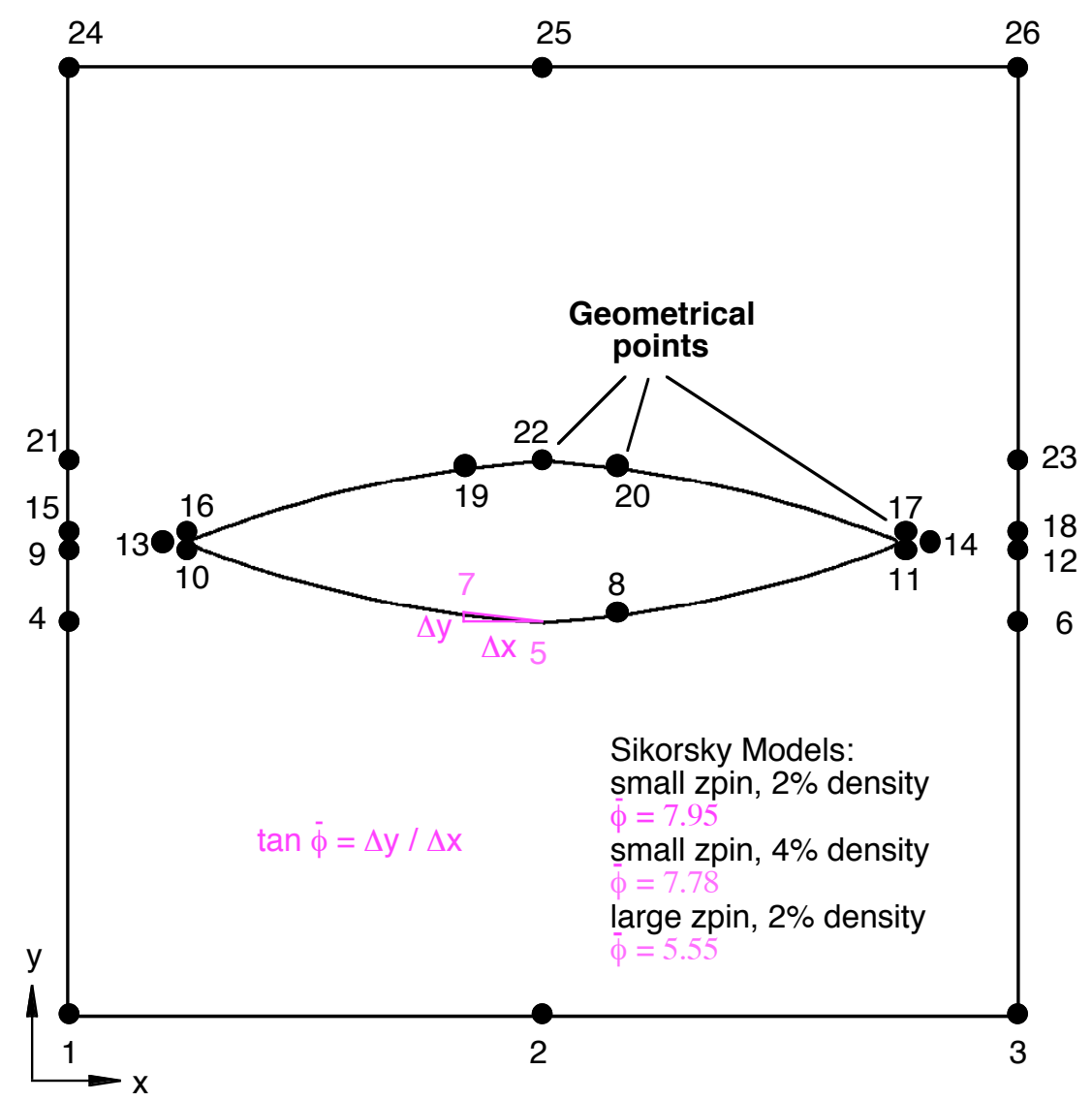

Figure 9. Calculation of fiber misalignment angle [22] 


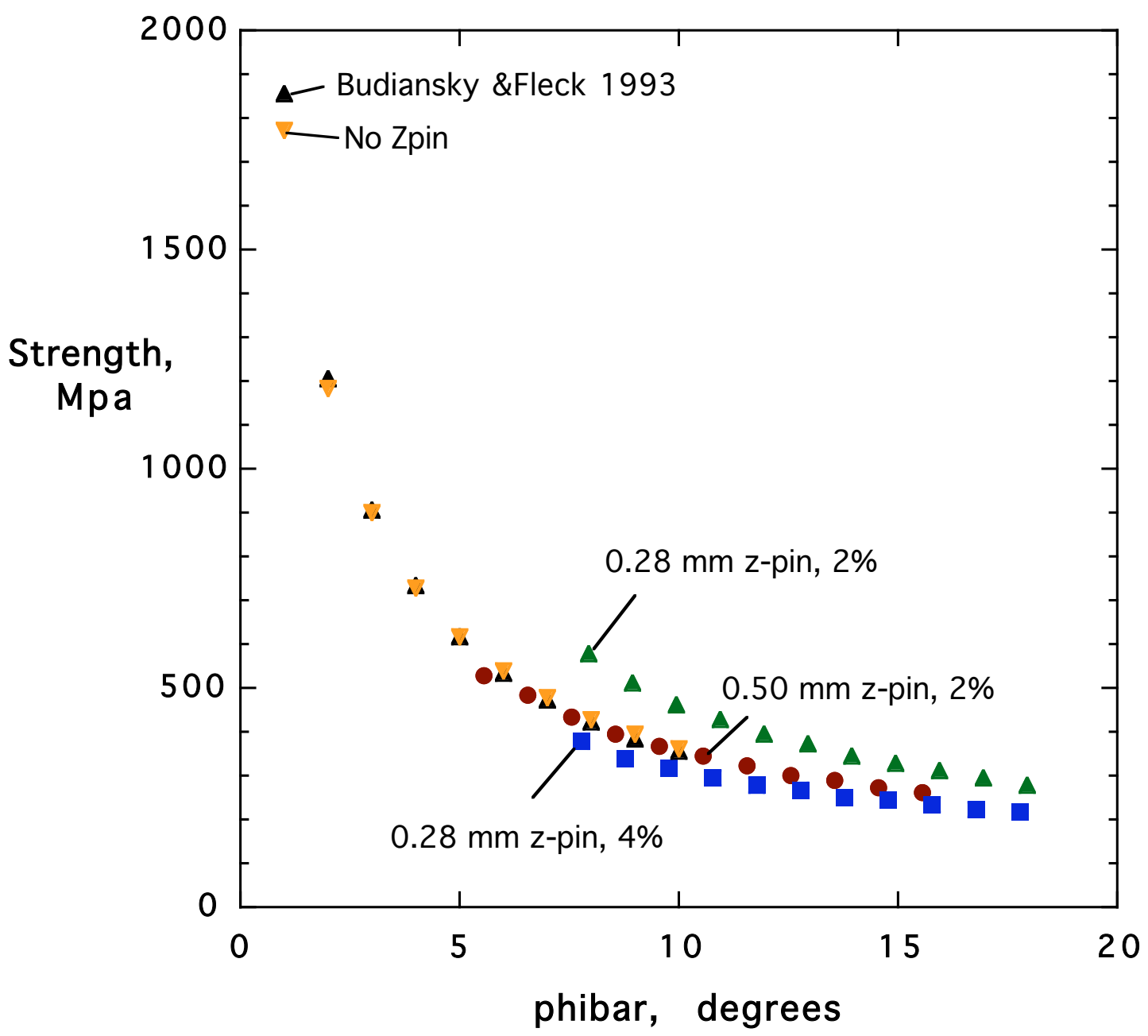

Figure 10. Predicted compression strengths with and without z-pins 


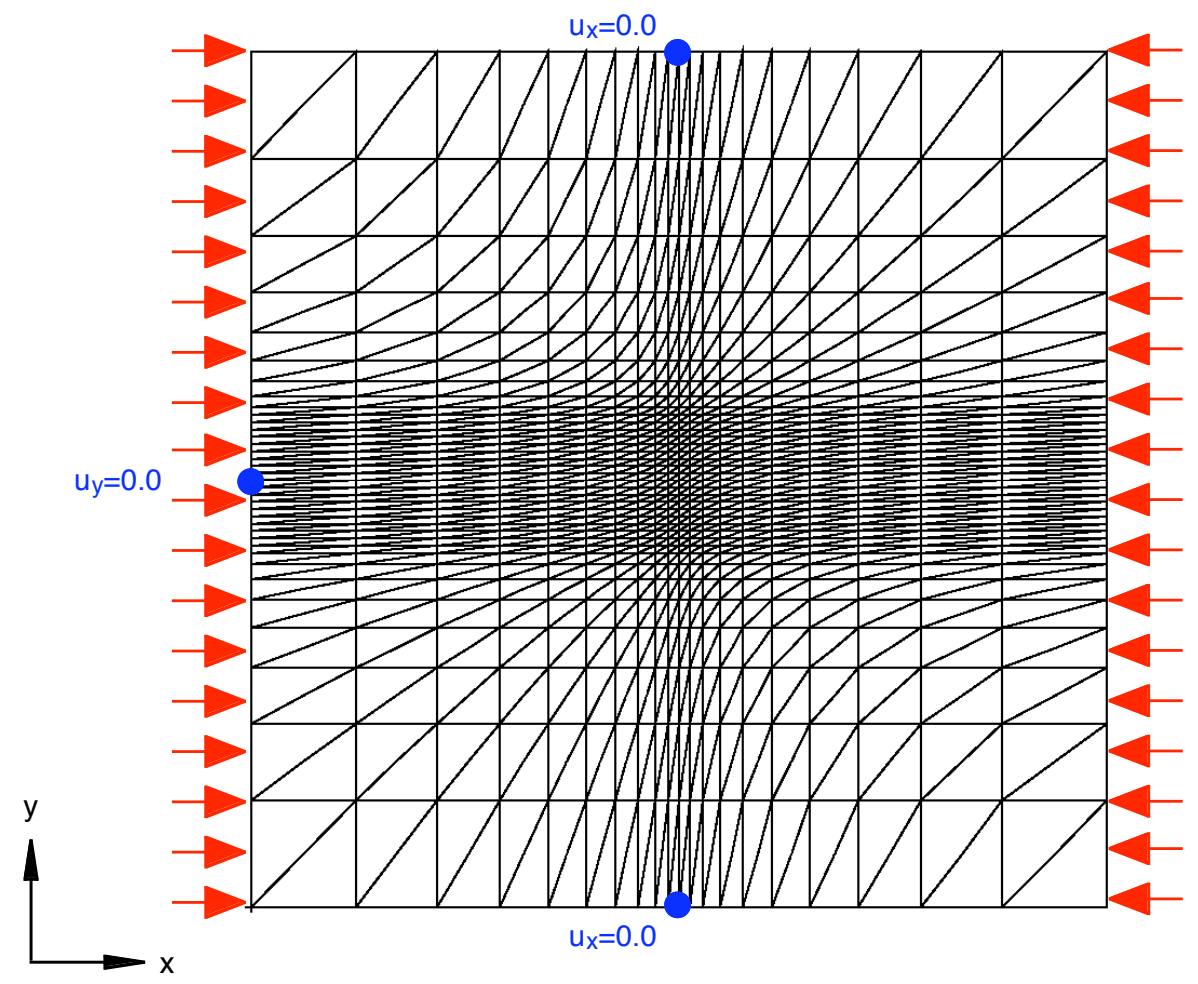

Figure 11. Unit cell mesh without z-pin 

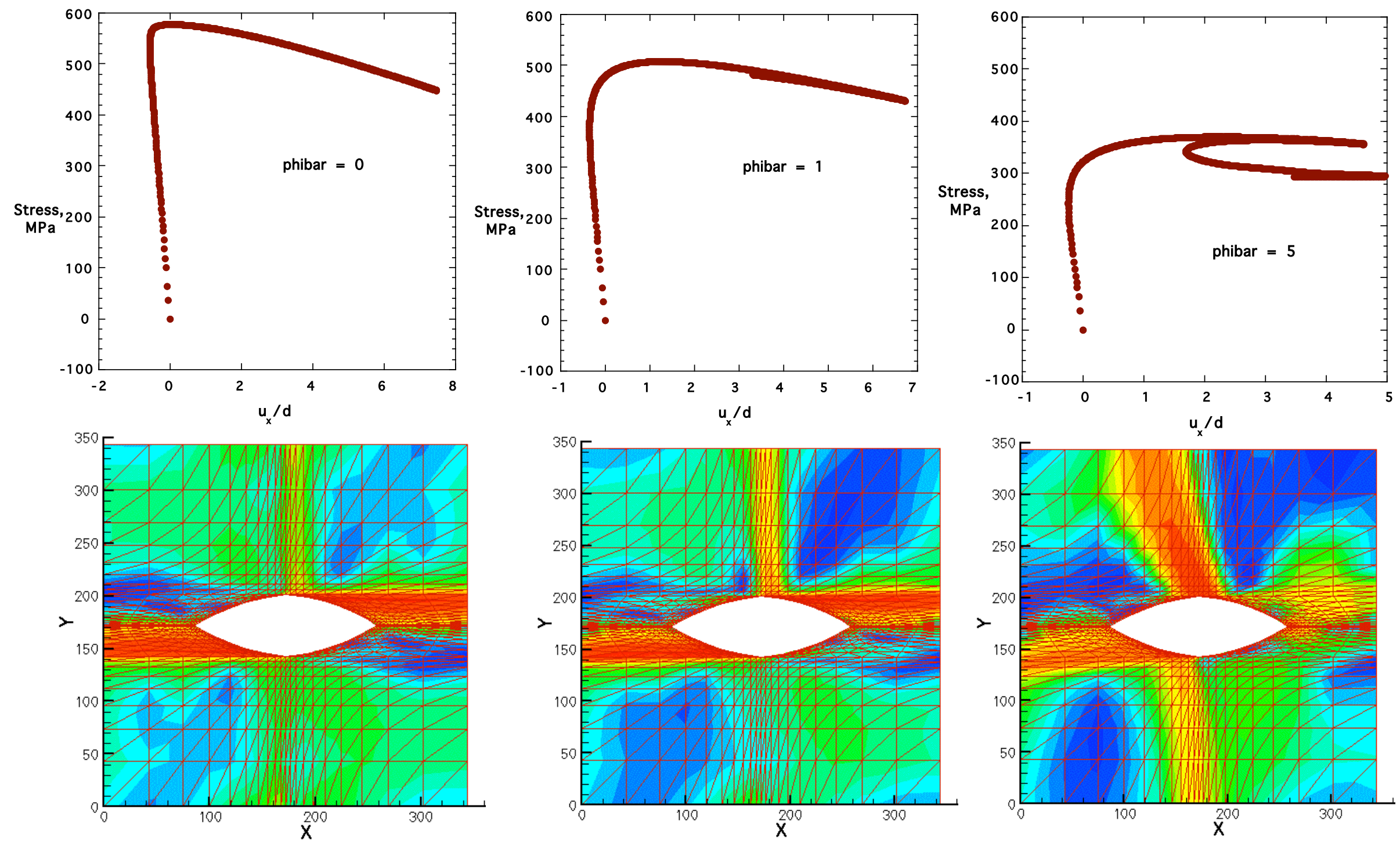

Shear Stress Contours

Figure 12. Influence of fiber waviness on response, small pin $2 \%$ areal density 

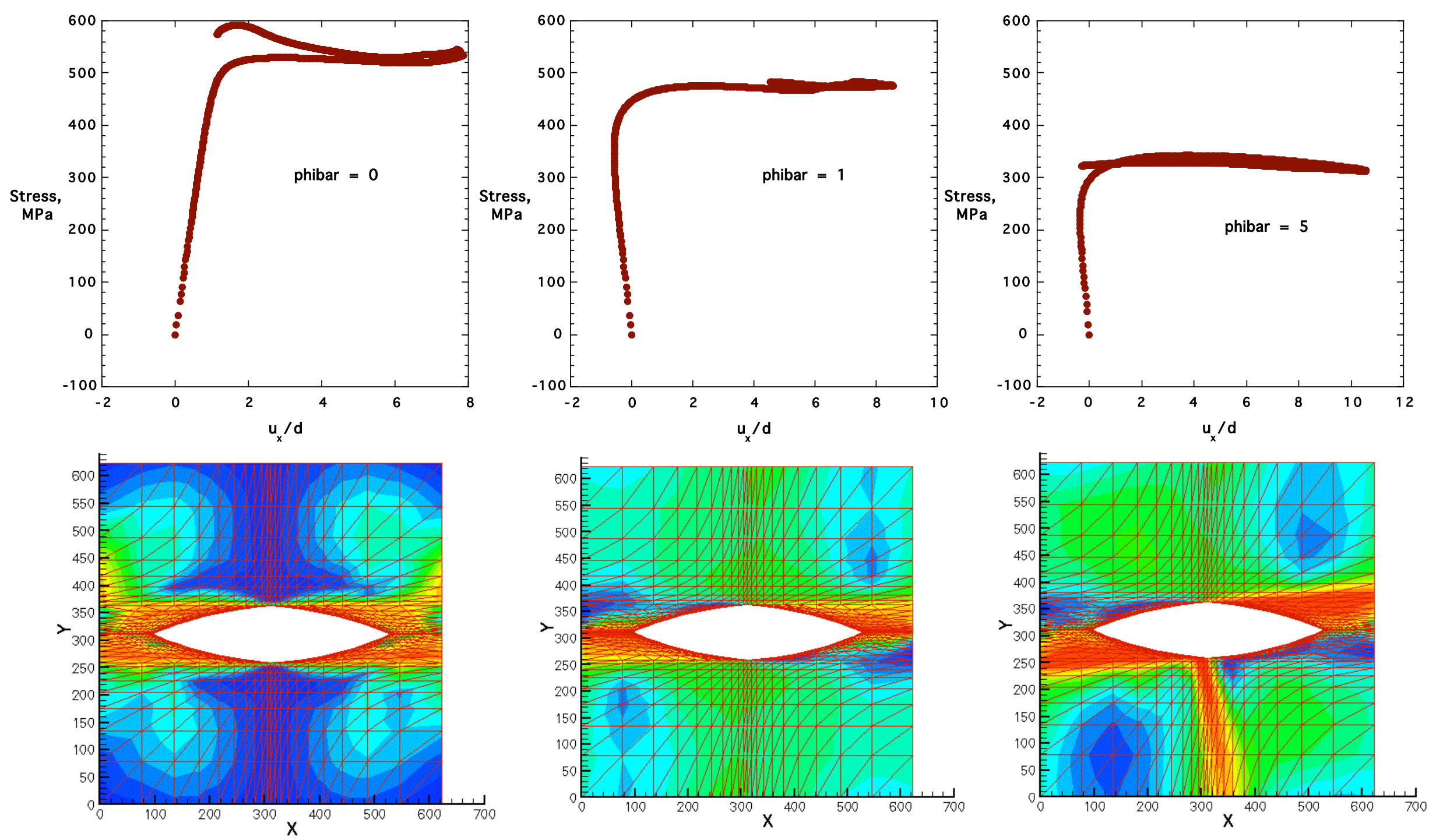

Shear Stress Contours

Figure 13. Influence of fiber waviness on response, large pin $2 \%$ areal density 

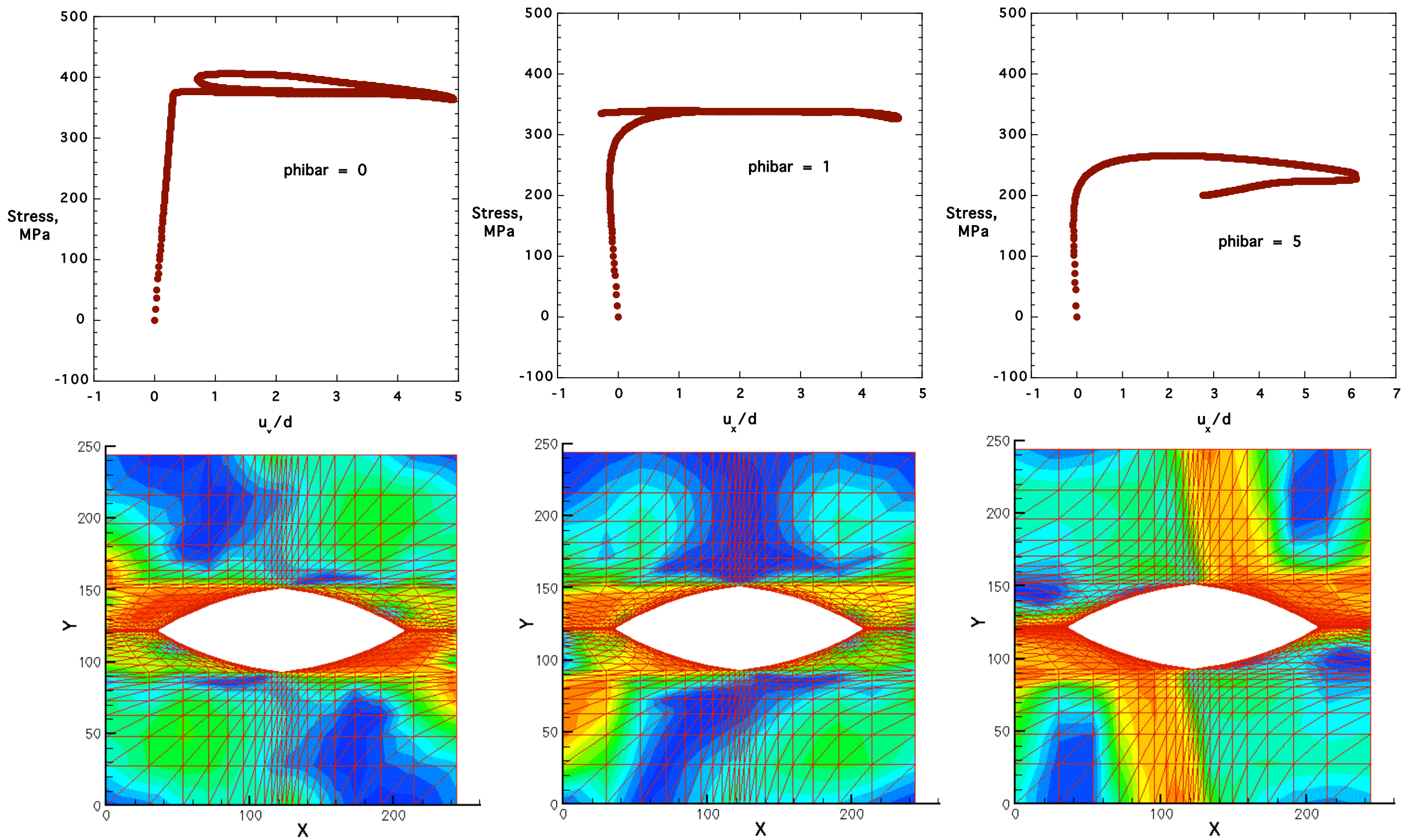

Shear Stress Contours

Figure 14. Influence of fiber waviness on response, small pin $4 \%$ areal density 


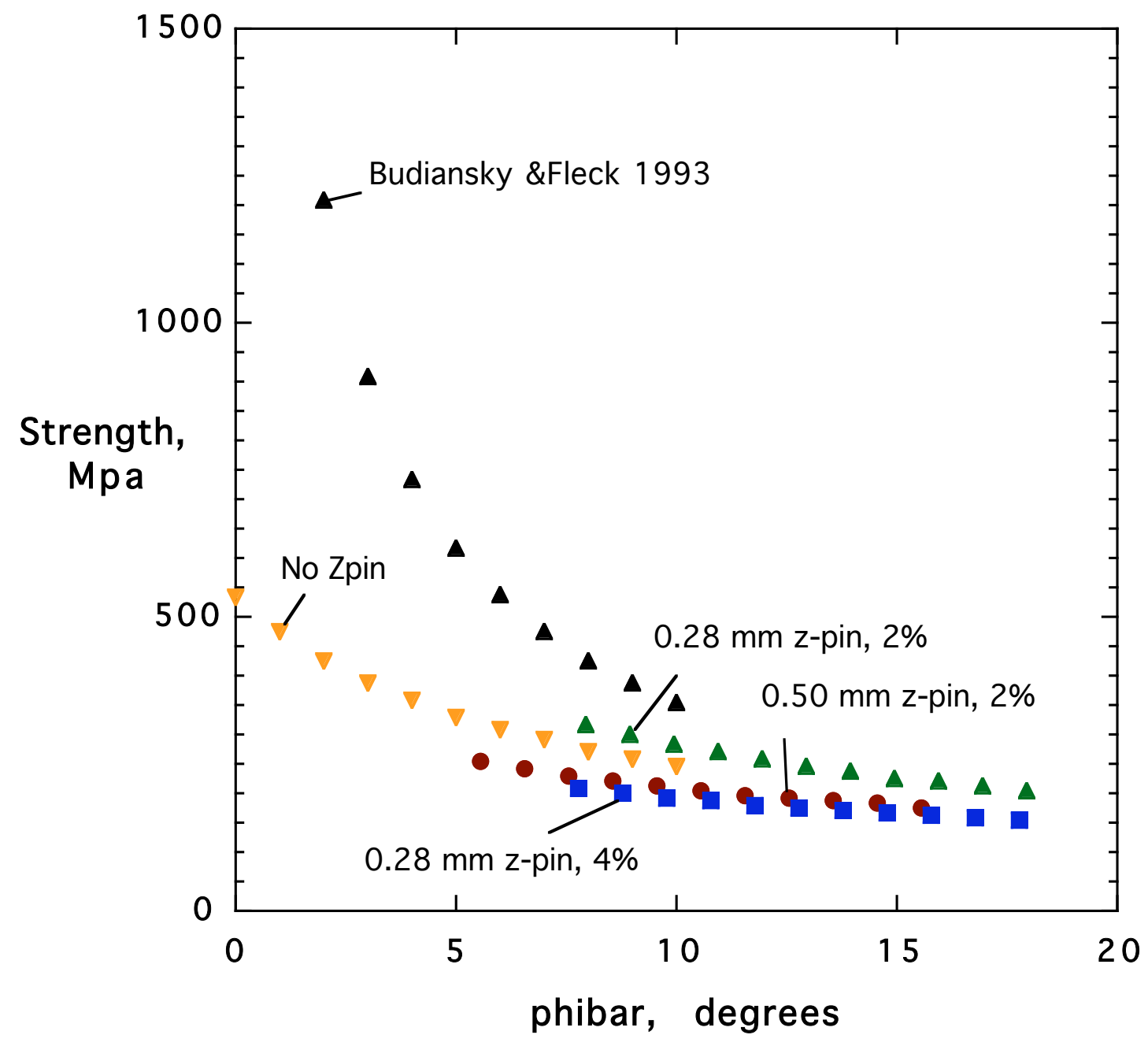

Figure 15. Predicted strengths for laminates with and without z-pins ; compression plus $10 \%$ shear 

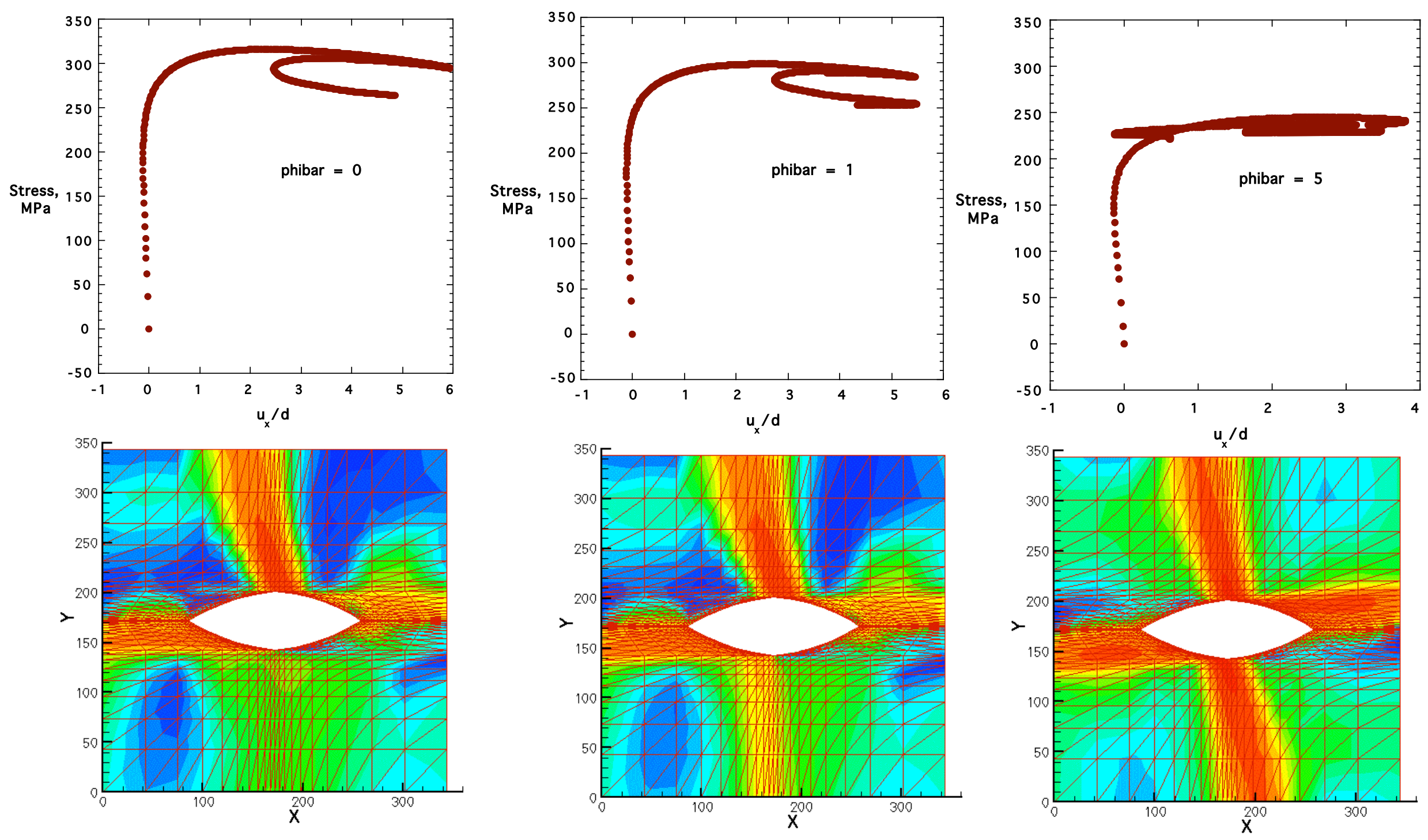

Shear Stress Contours

Figure 16. Influence of fiber waviness on compression plus $10 \%$ shear response, small pin $2 \%$ areal density 

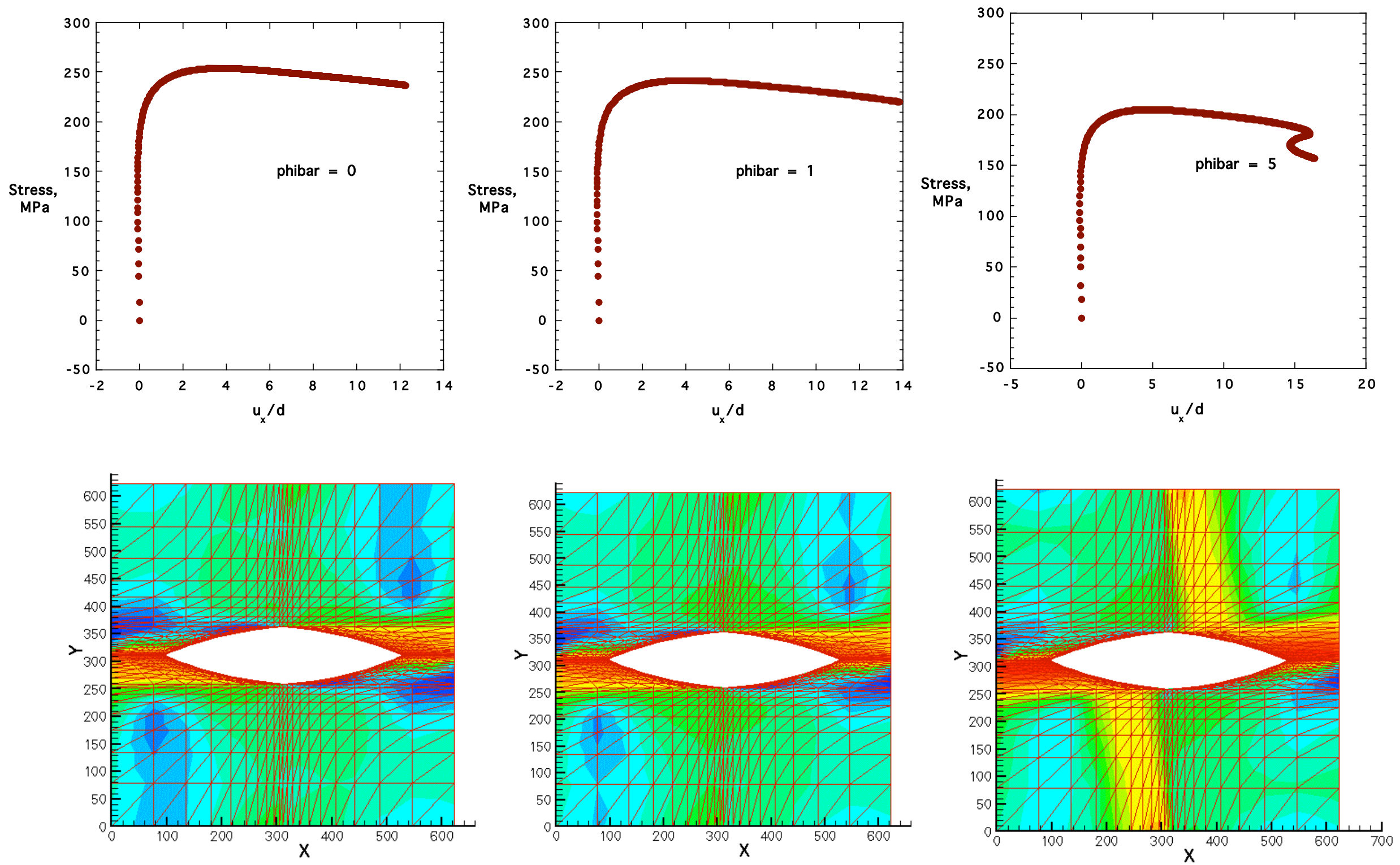

Shear Stress Contours

Figure 17. Influence of fiber waviness on compression plus $10 \%$ shear response, large pin $2 \%$ areal density 

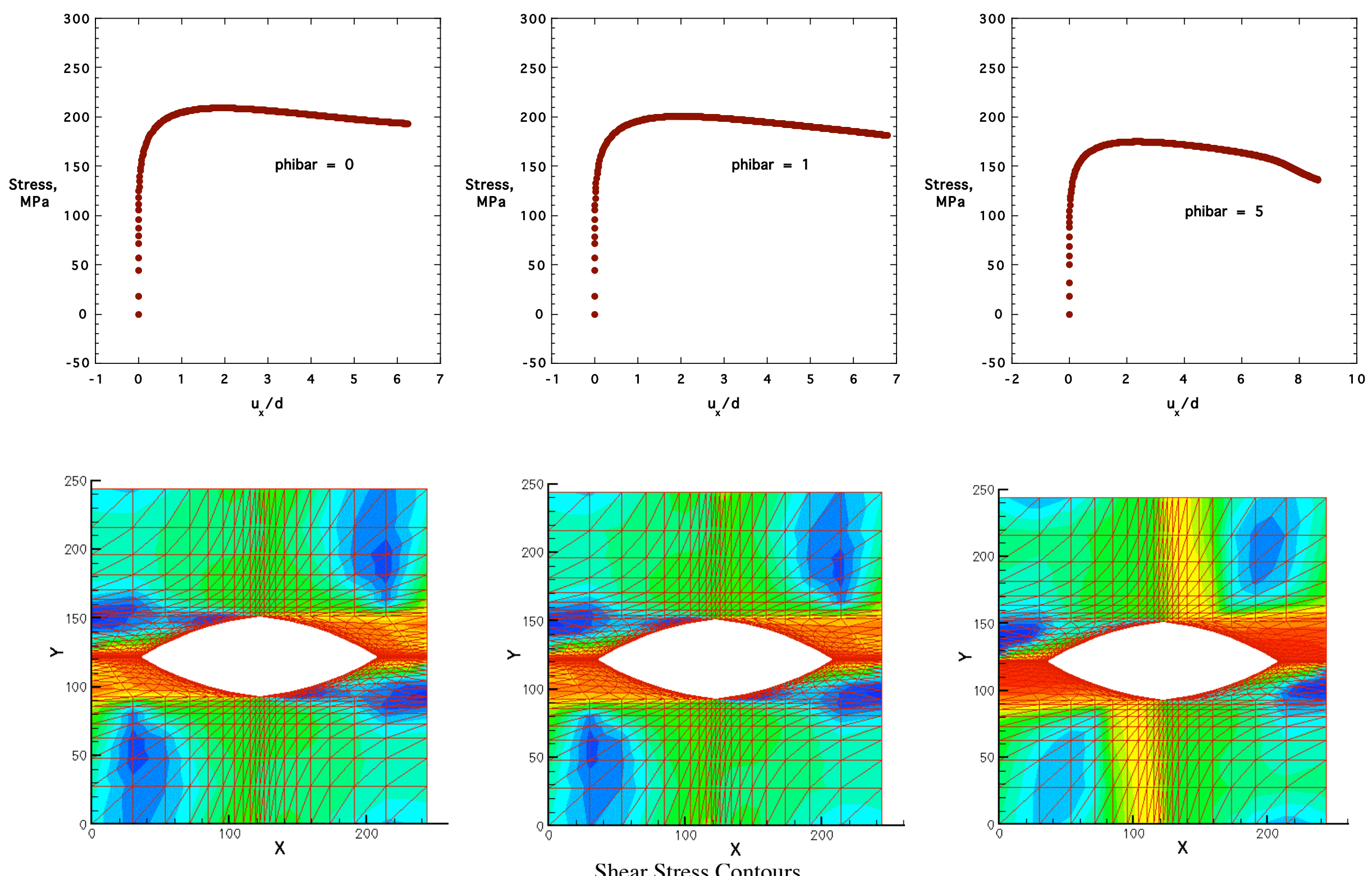

Figure 18. Influence of fiber waviness on compression plus $10 \%$ shear response, small pin $4 \%$ areal density 


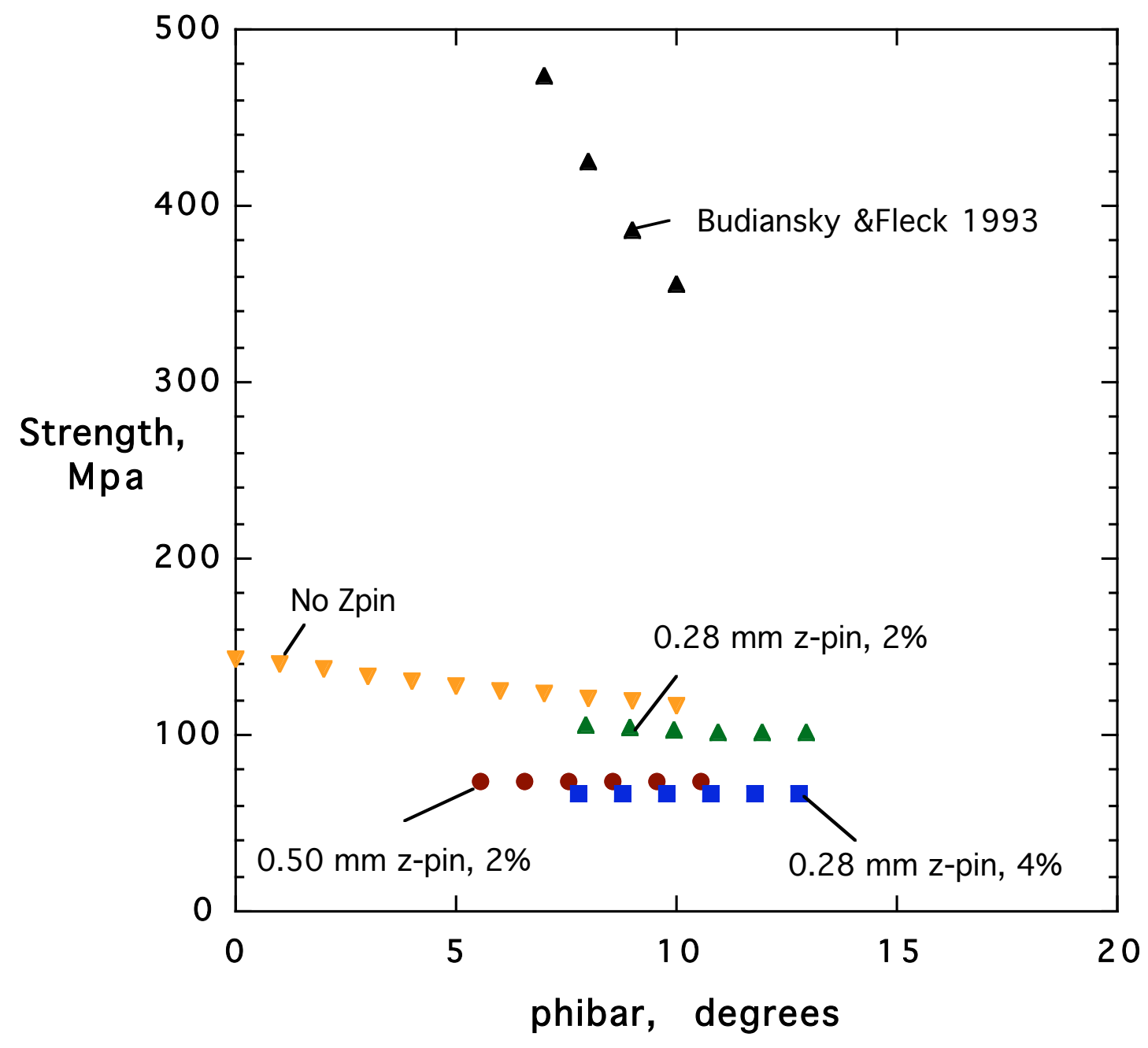

Figure 19. Predicted strengths for laminates with and without z-pins ; compression plus $50 \%$ shear 

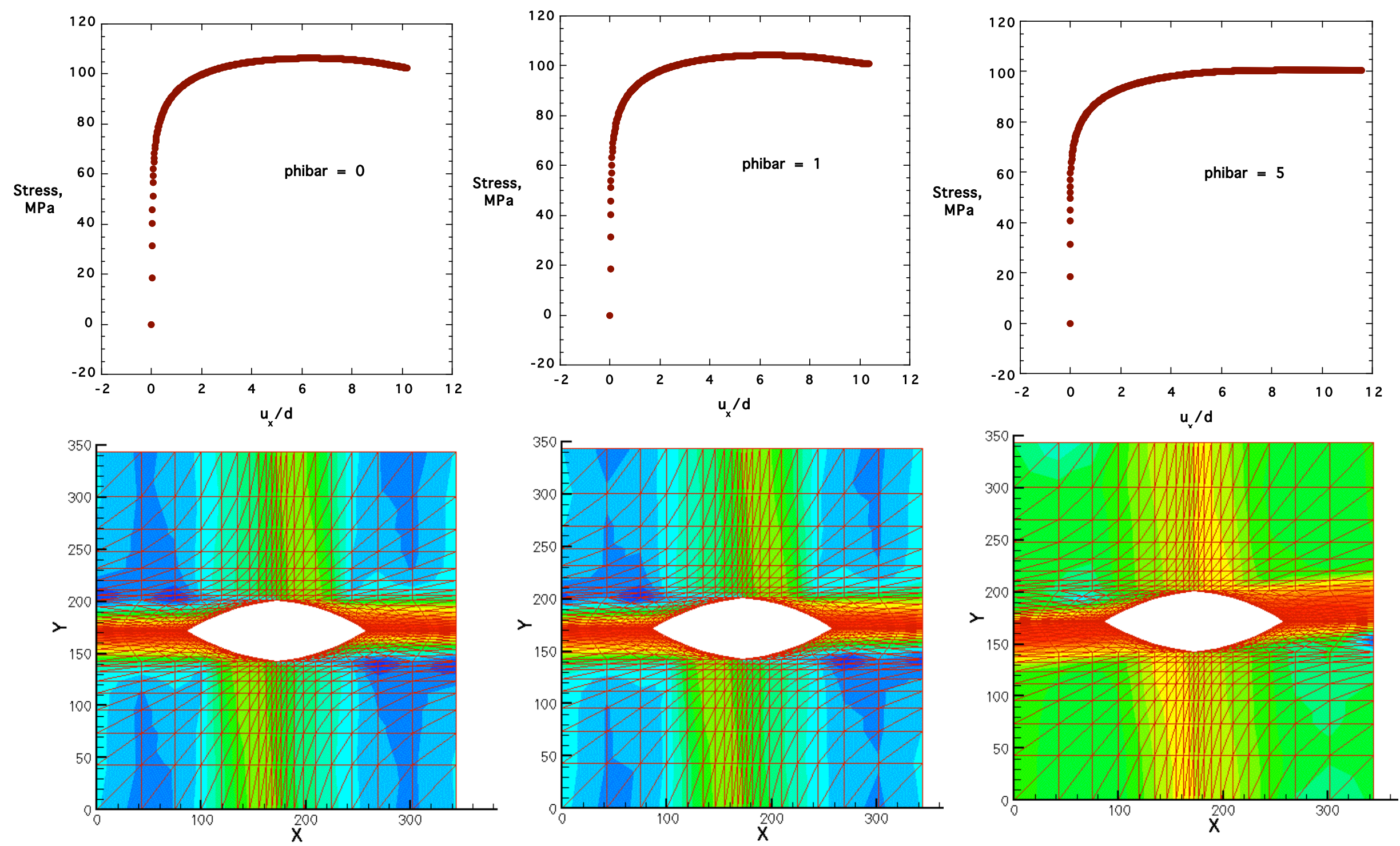

Shear Stress Contours

Figure 20. Influence of fiber waviness on compression plus $50 \%$ shear response, small pin $2 \%$ areal density 

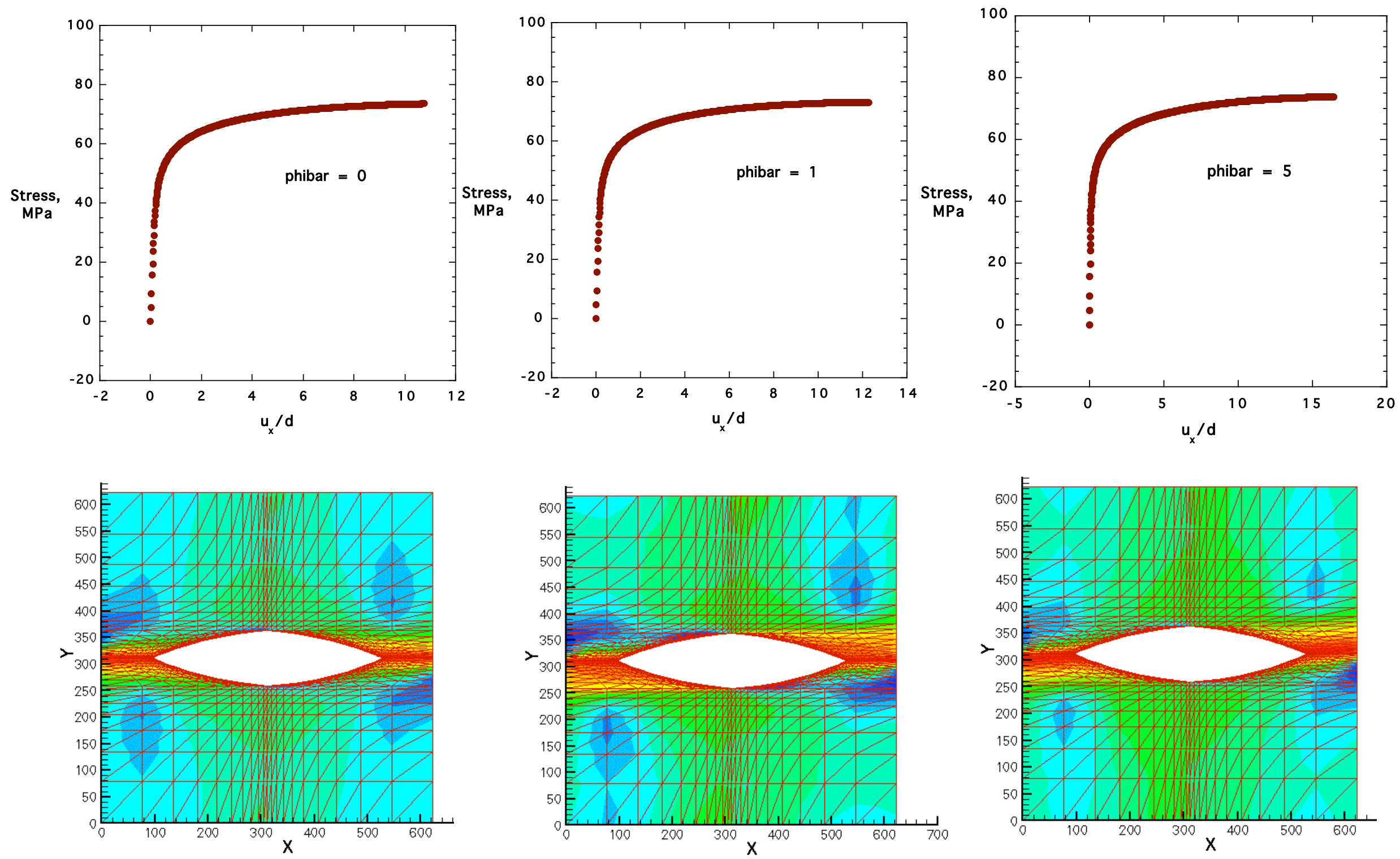

Shear Stress Contours

Figure 21. Influence of fiber waviness on compression plus $50 \%$ shear response, large pin $2 \%$ areal density 

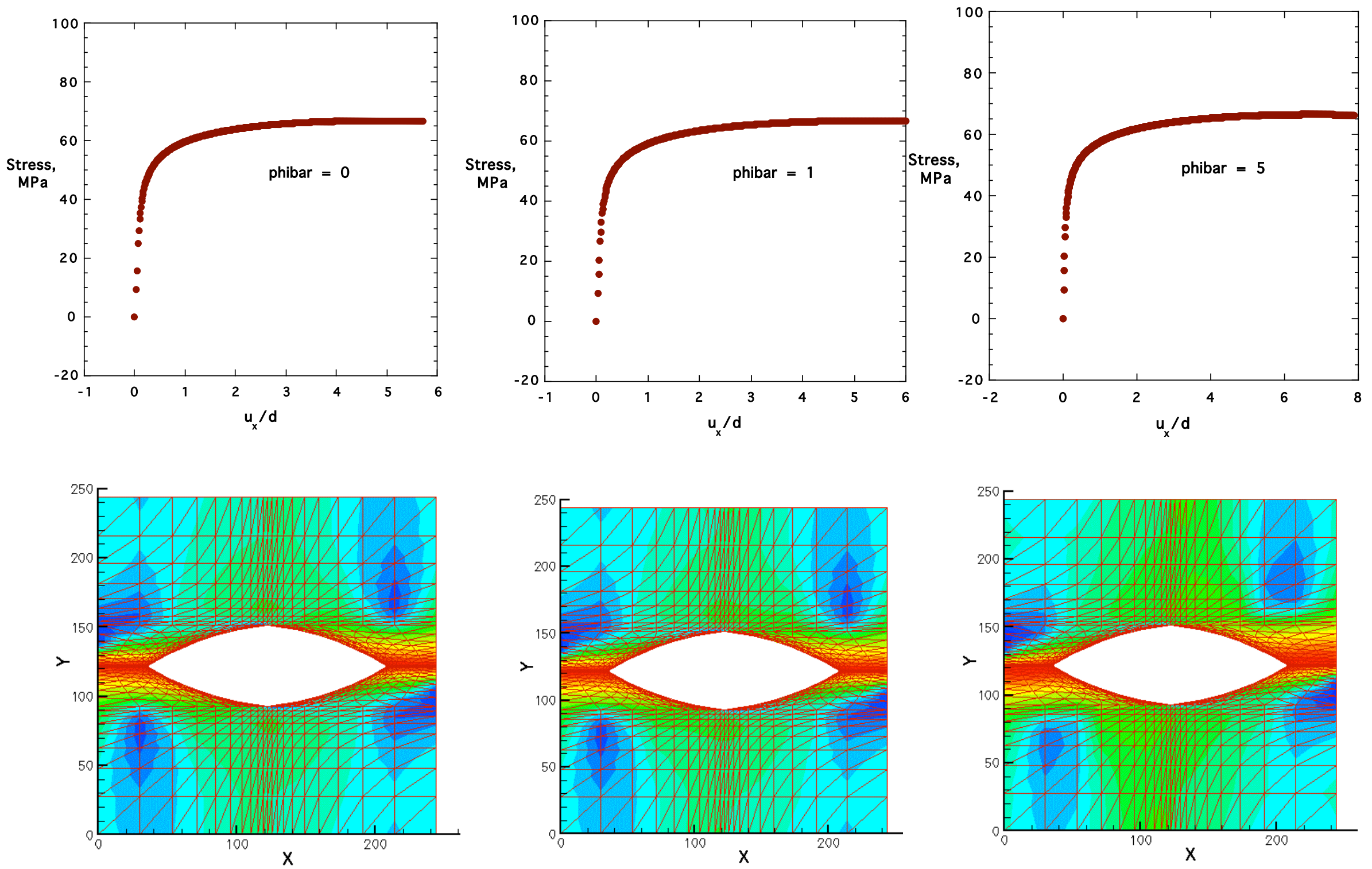

Shear Stress Contours

Figure 22. Influence of fiber waviness on compression plus 50\% shear response, small pin $4 \%$ areal density 


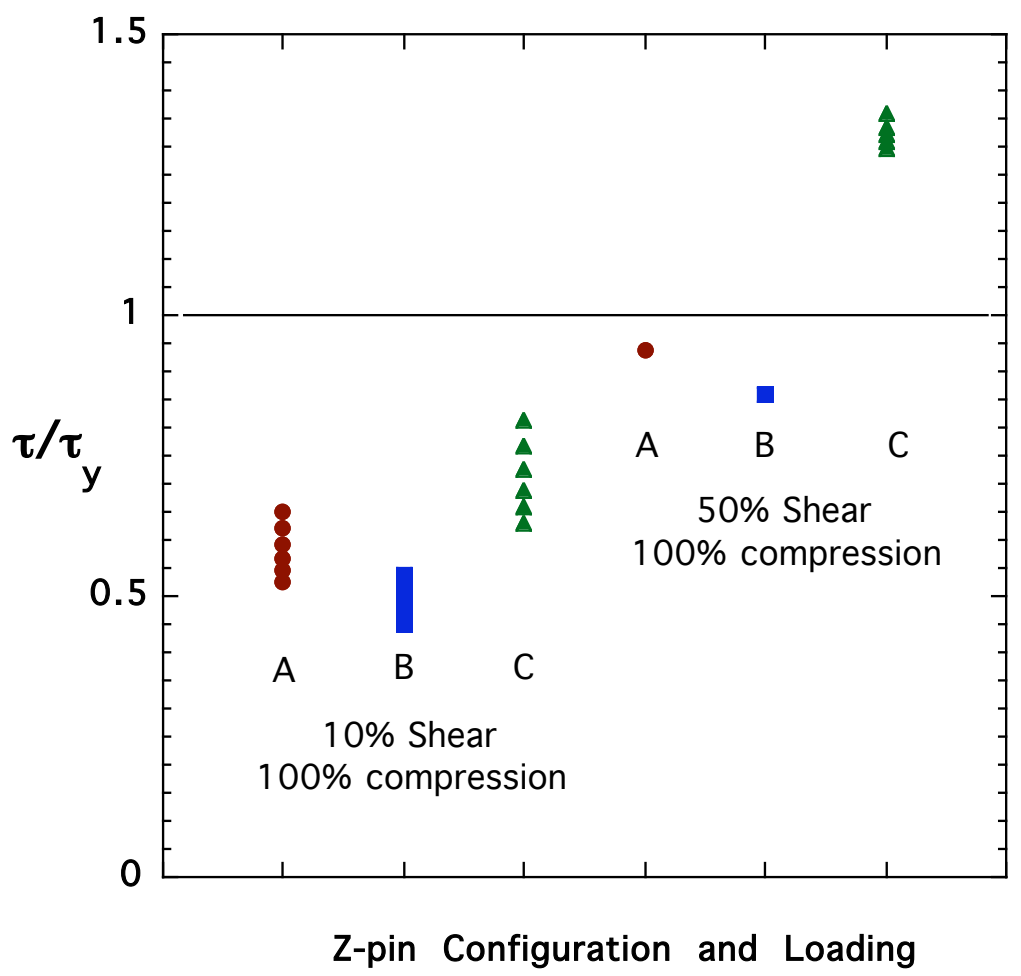

Figure 23. Ratio of applied shear stress at failure to shear yield strength of carbon/epoxy 


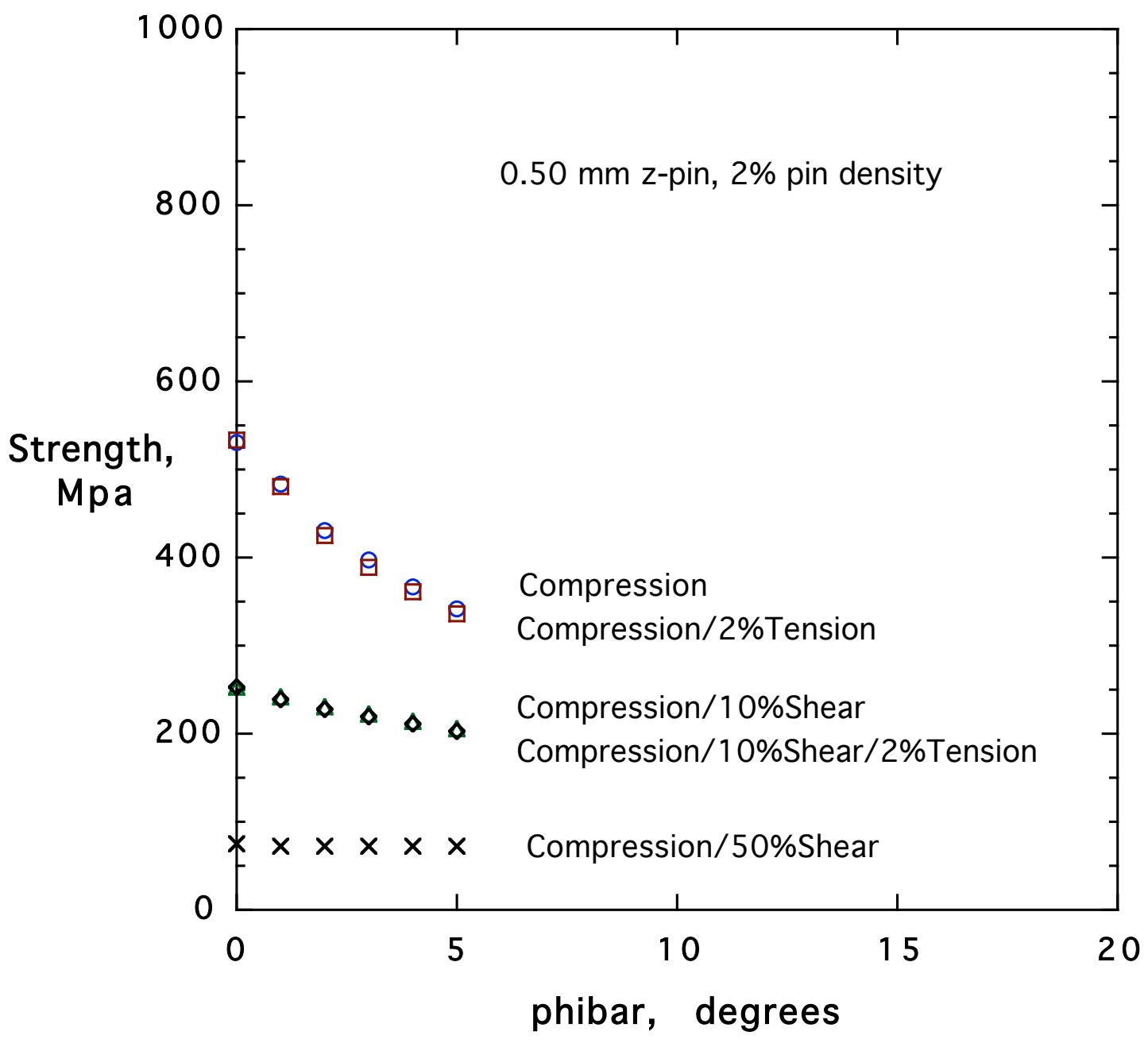

Figure 24. Comparison of strength predictions 


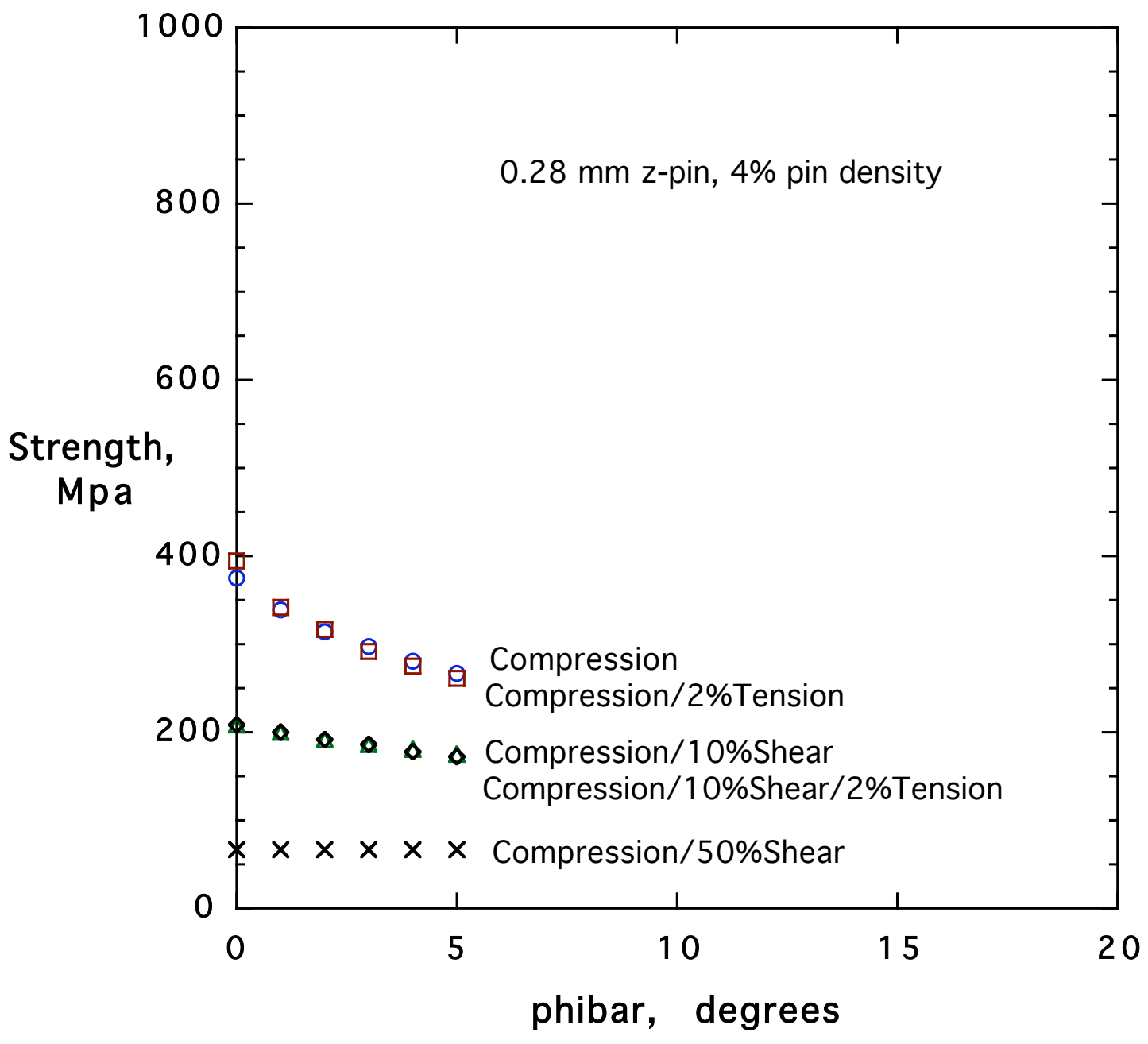

Figure 25. Comparison of strength predictions 


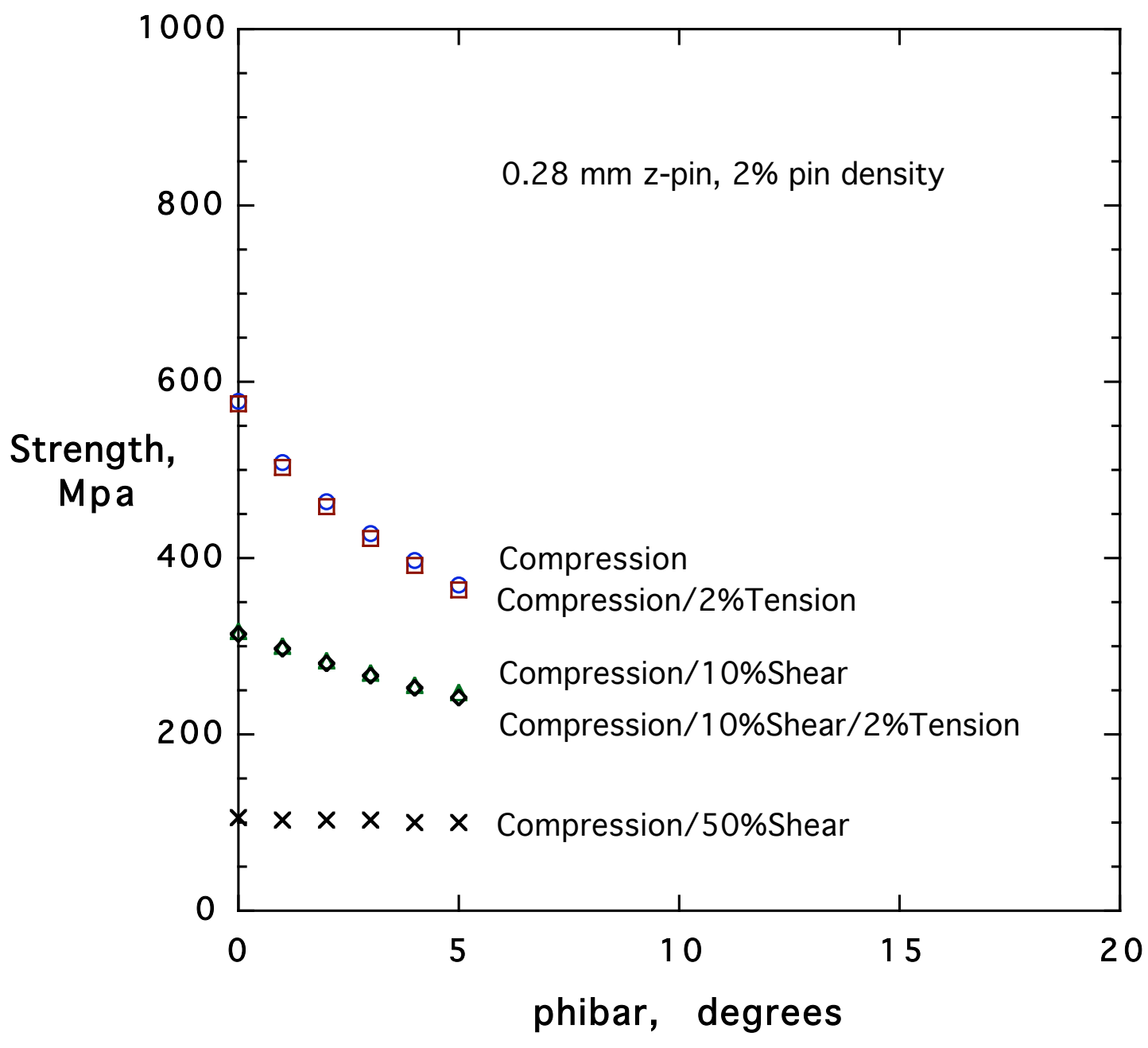

Figure 26. Comparison of strength predictions 


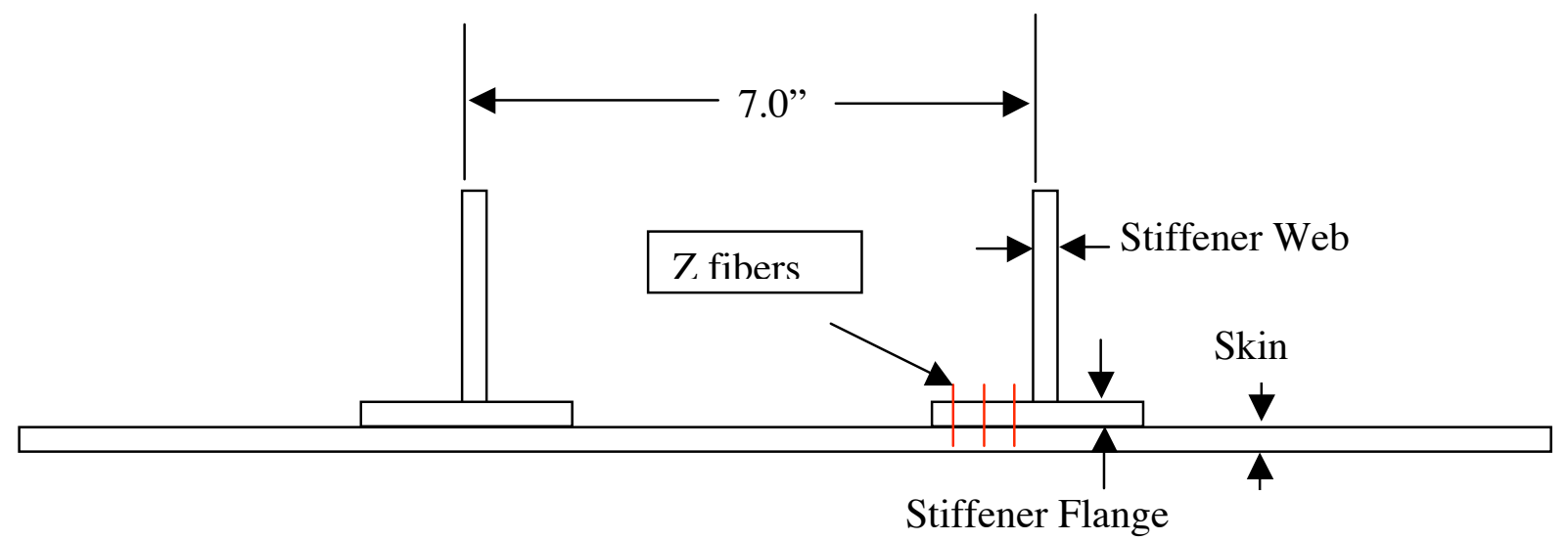

Fig.27 Stringer reinforced skin configurations 


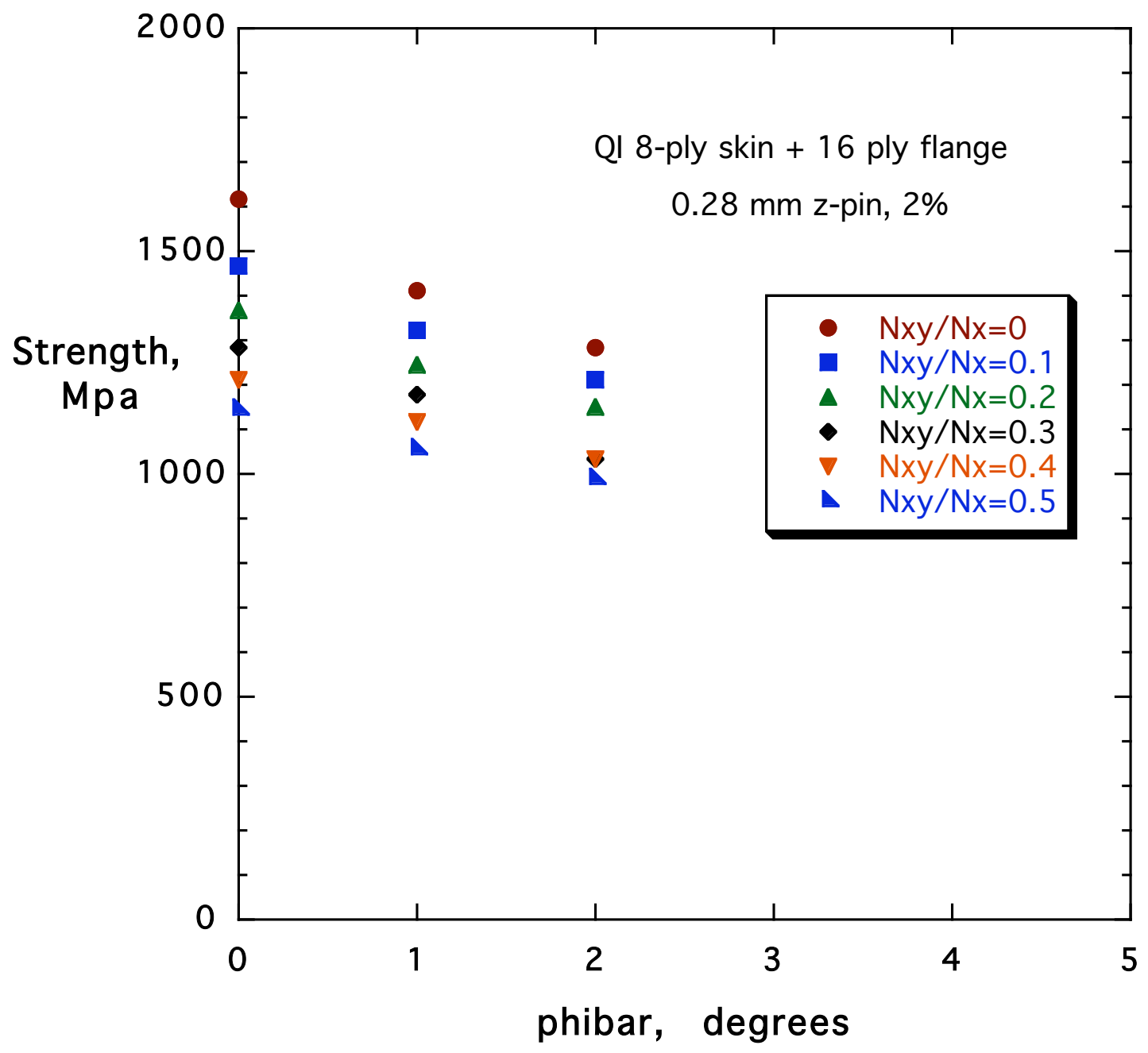

Fig.28 - Zero degree ply strengths as a function of fiber waviness angle for the quasi-isotropic stringer reinforced skin configuration 


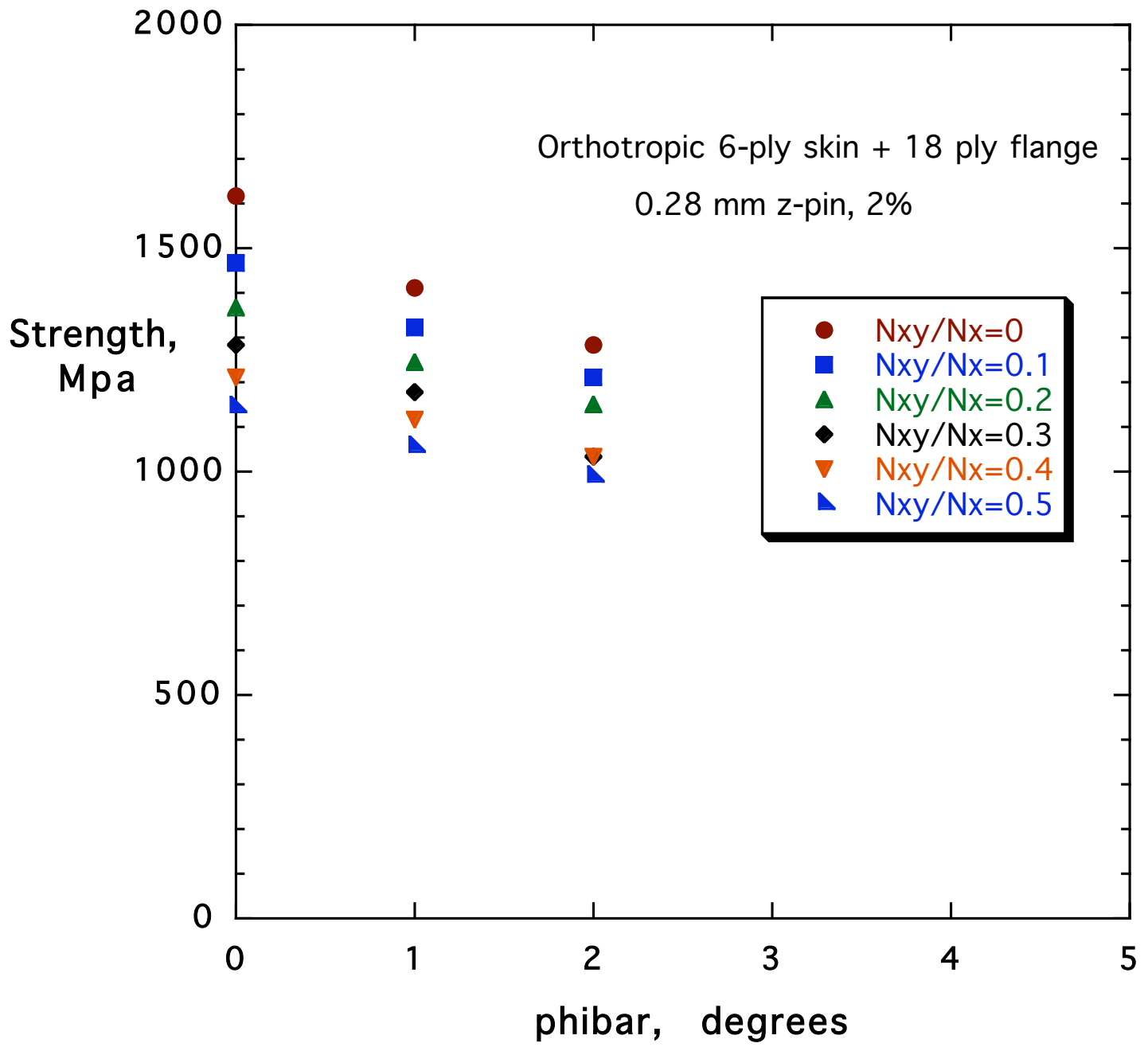

Fig.29 - Zero degree ply strengths as a function of fiber waviness angle for the orthotropic stringer reinforced skin configuration 


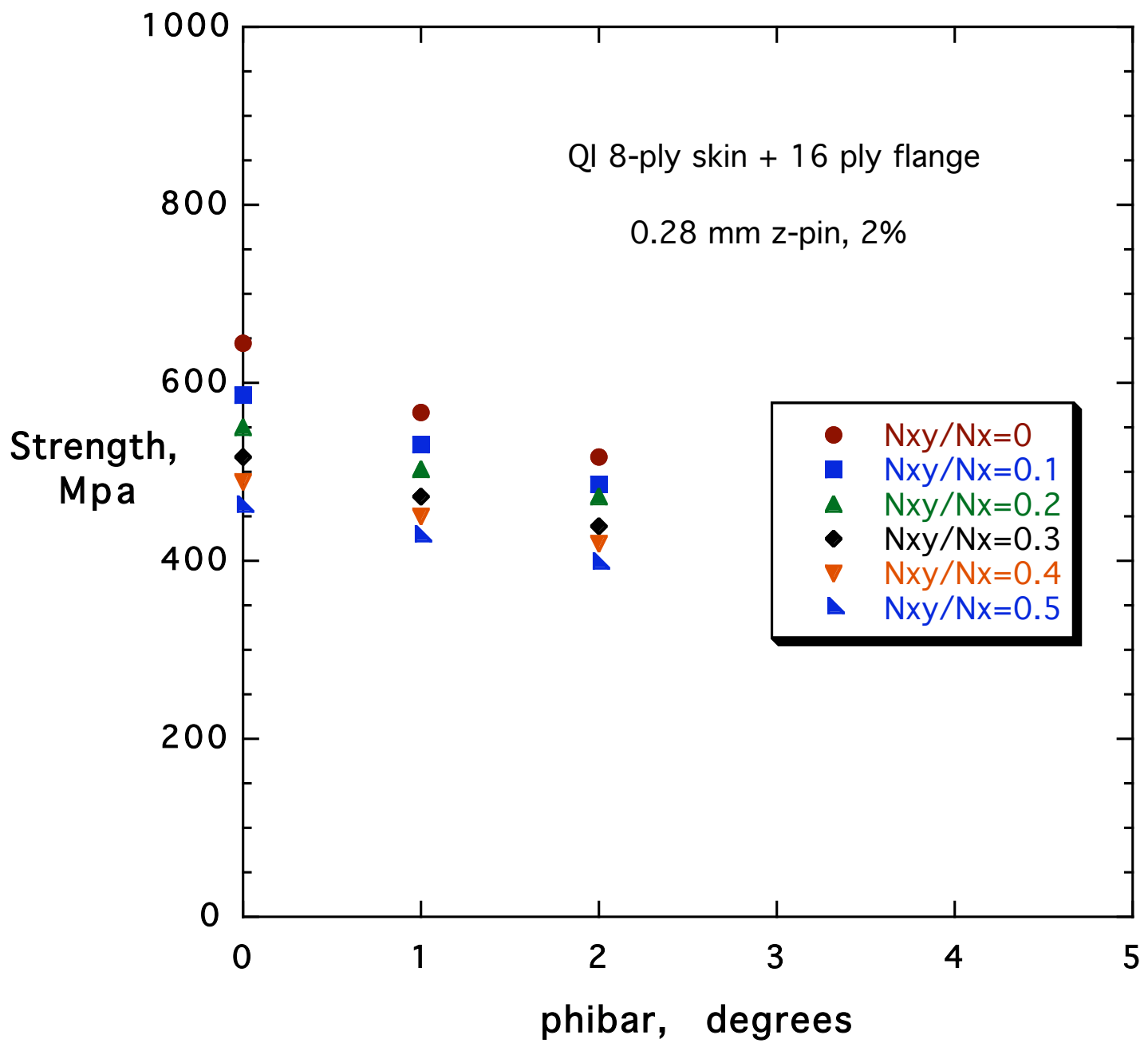

Fig.30 - Skin/stiffener-flange laminate strengths as a function of fiber waviness angle for the quasi-isotropic stringer reinforced skin configuration 


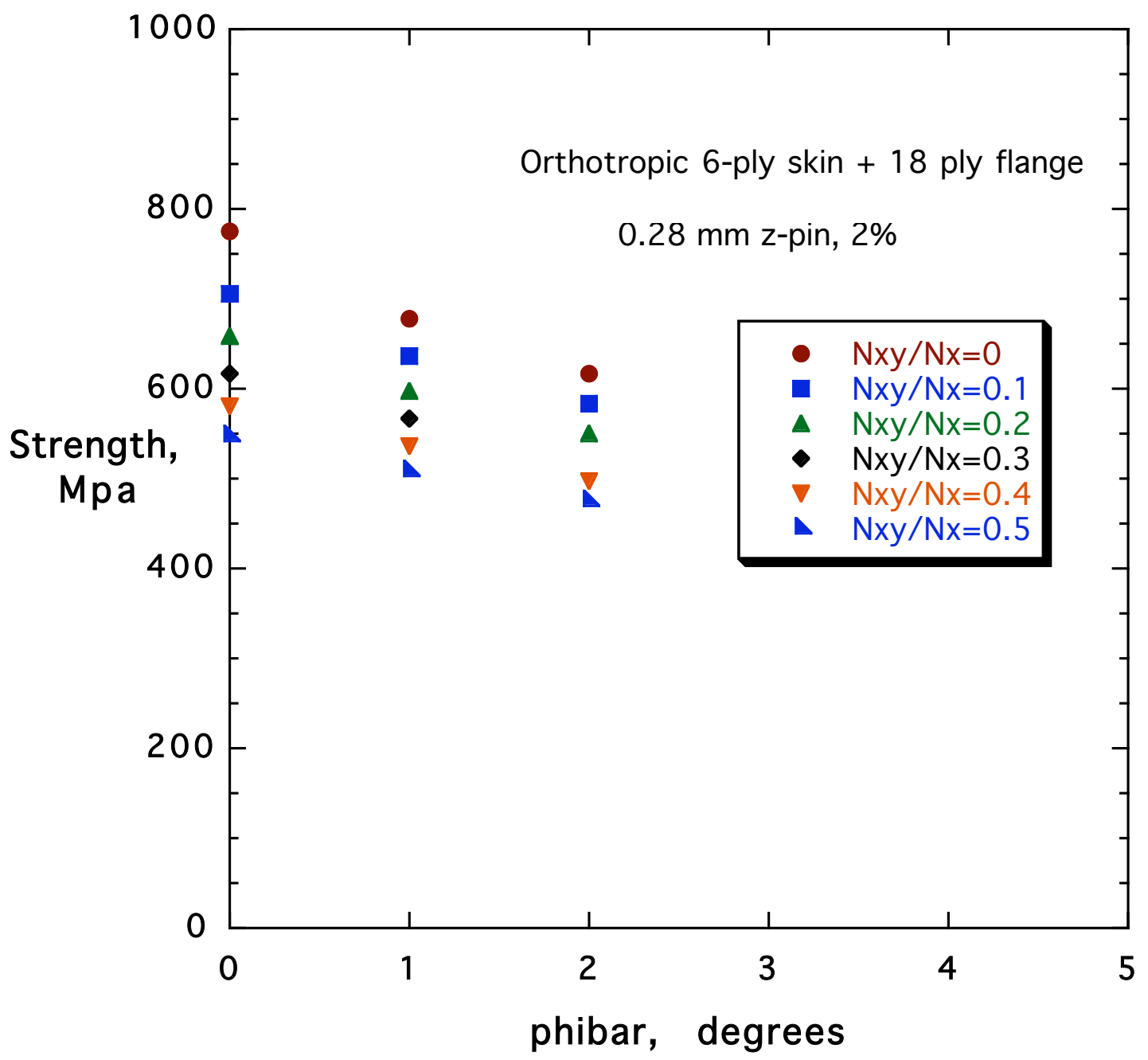

Fig.31 - Skin/stiffener-flange laminate strengths as a function of fiber waviness angle for the orthotropic stringer reinforced skin configuration 


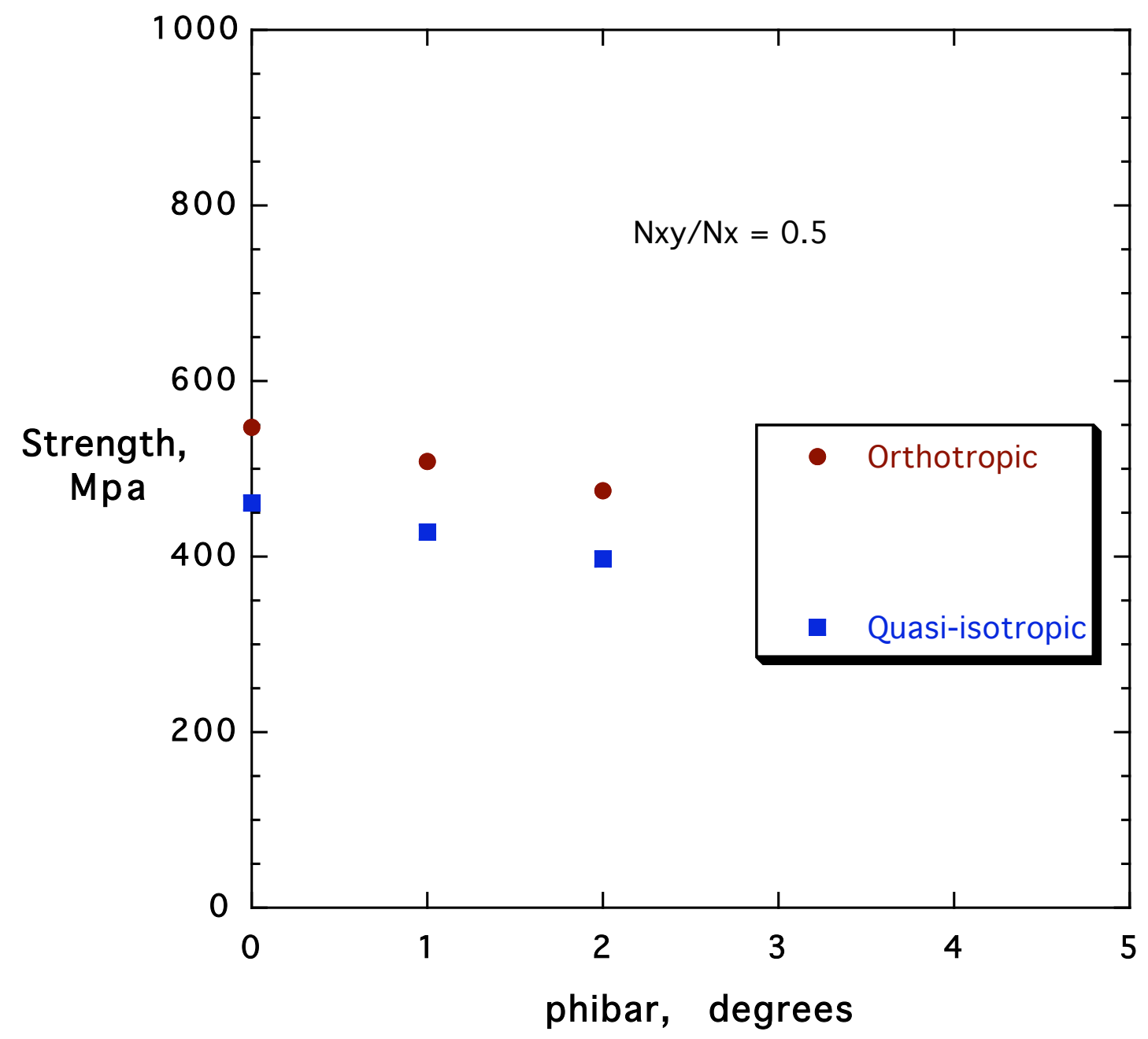

Fig.32 - Comparison of skin-plus-flange laminate strengths as a function of fiber waviness angle for the quasi-isotropic and orthotropic skin/stiffenerflange configurations. 


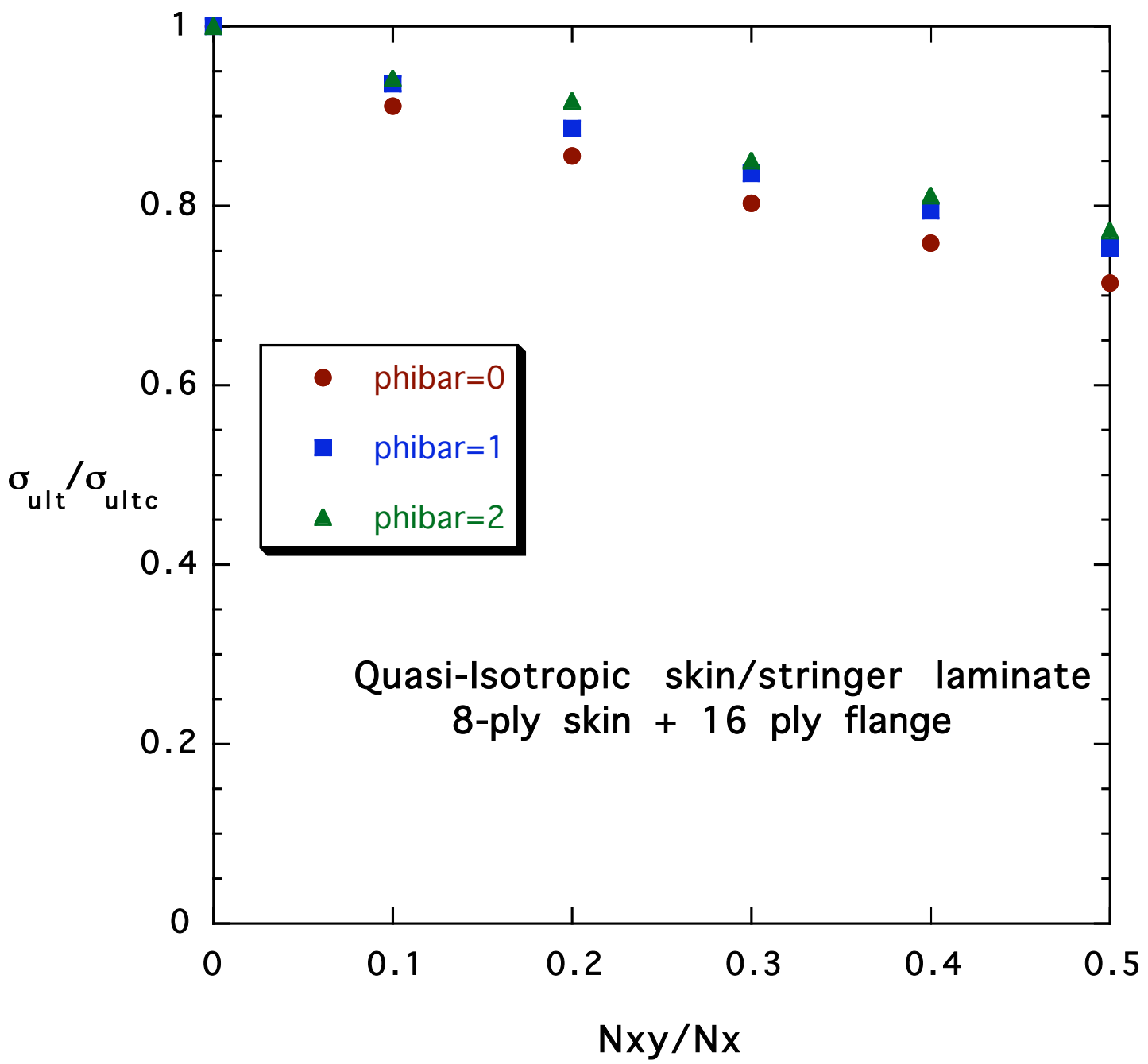

Fig.33 - Reduction in normalized compression strength for quasi-isotropic configuration 


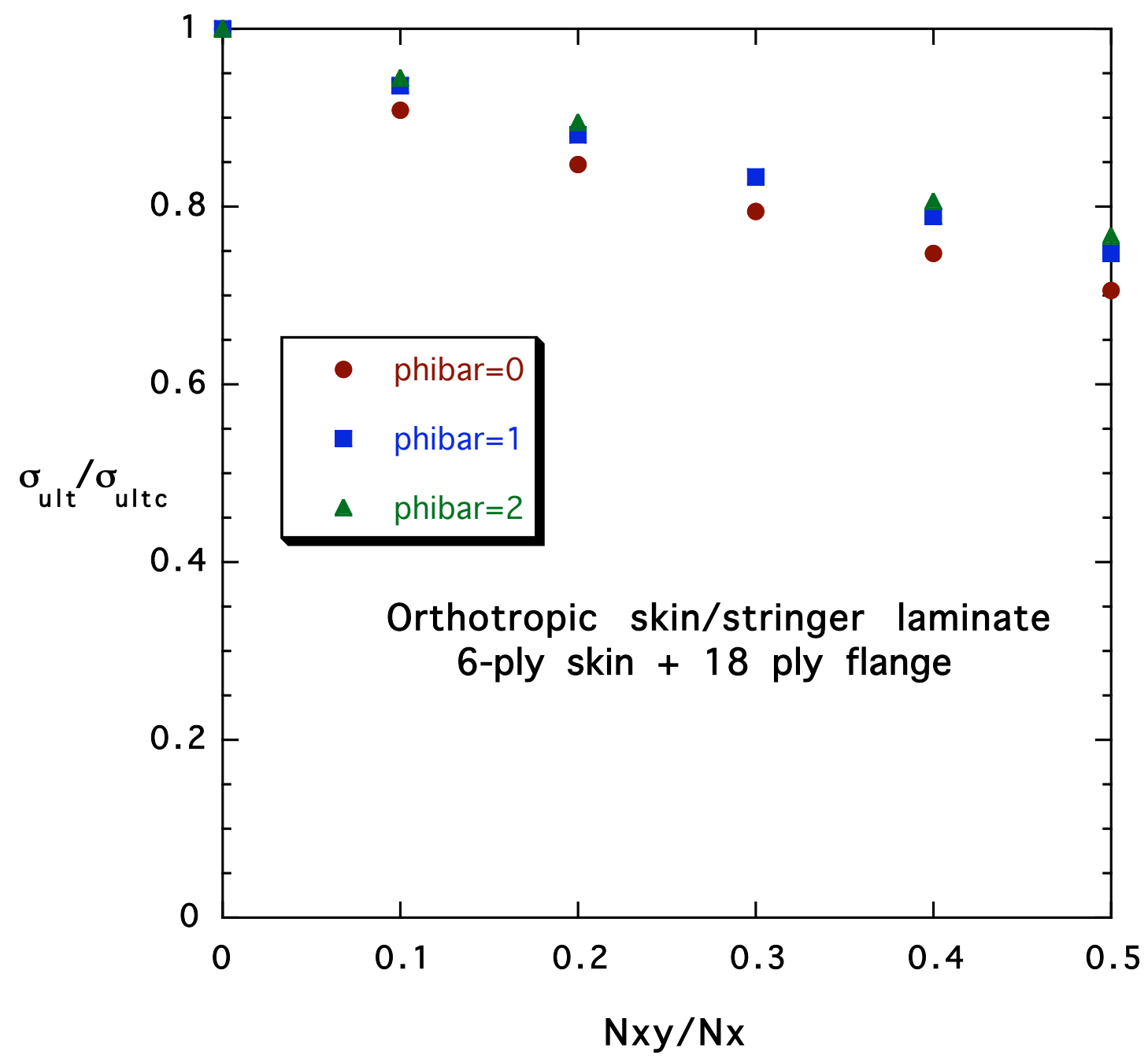

Fig.34 - Reduction in normalized compression strength for orthotropic configuration 


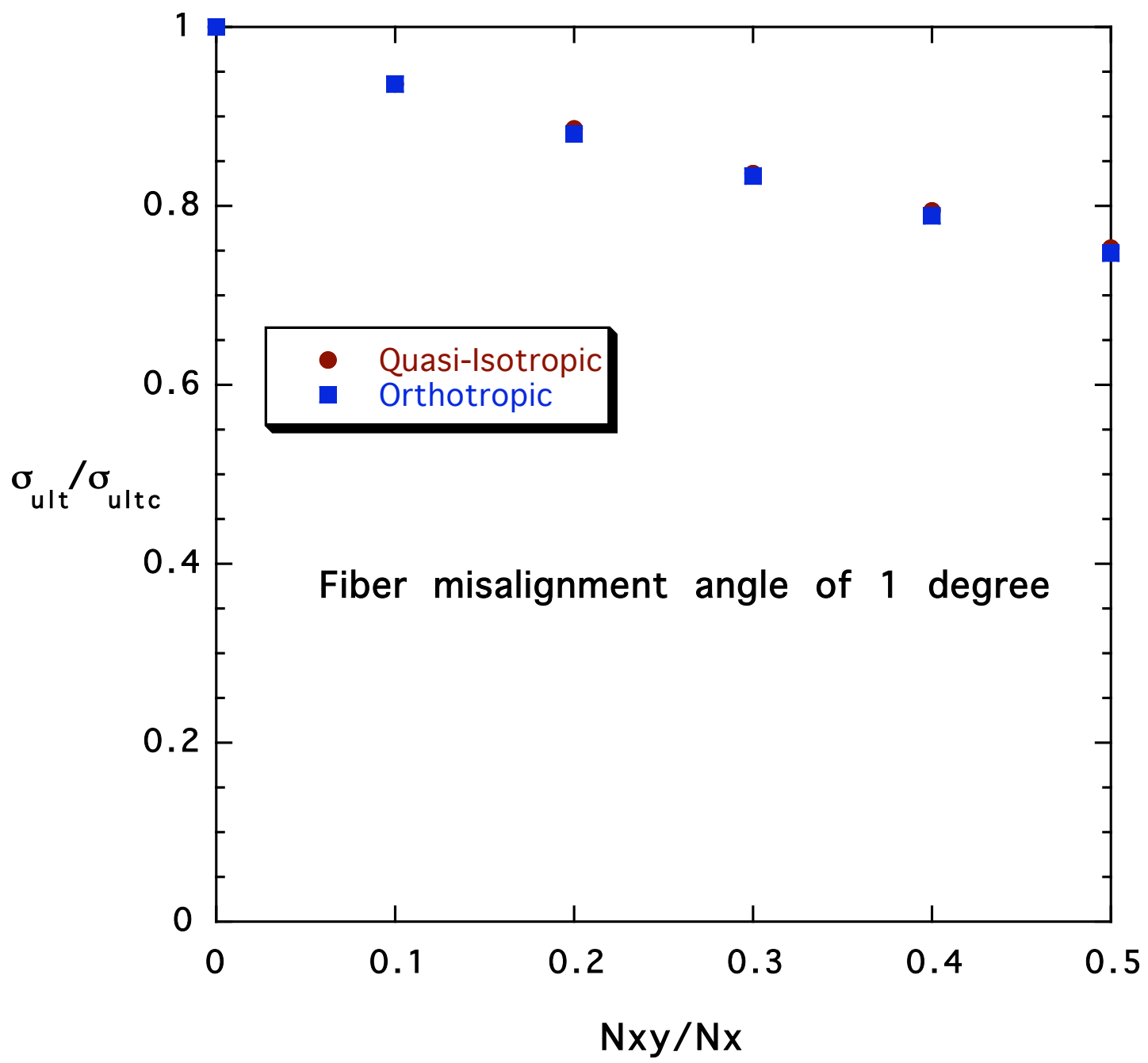

Fig. 35 - Comparison of normalized compression strengths for quasiisotropic and orthotropic configurations 


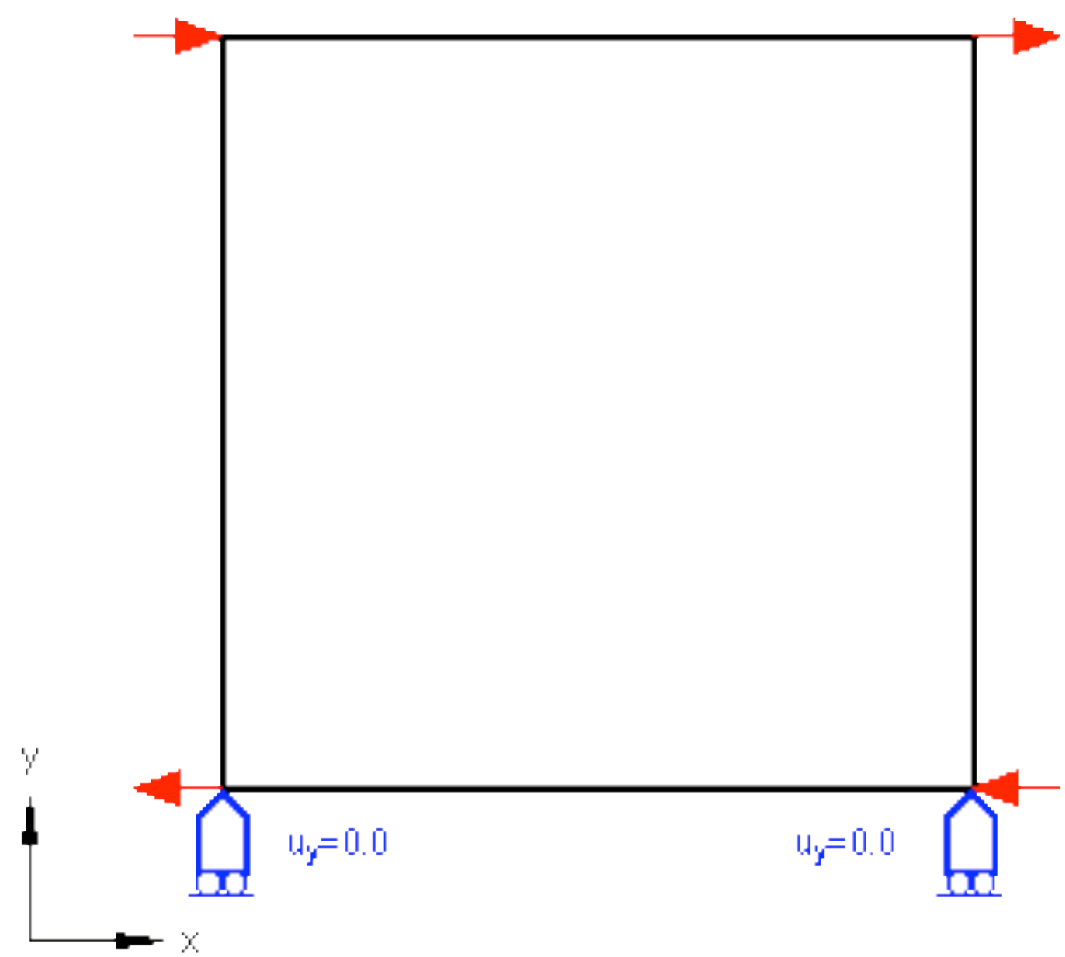

a. Schematic of model subjected to corner loads

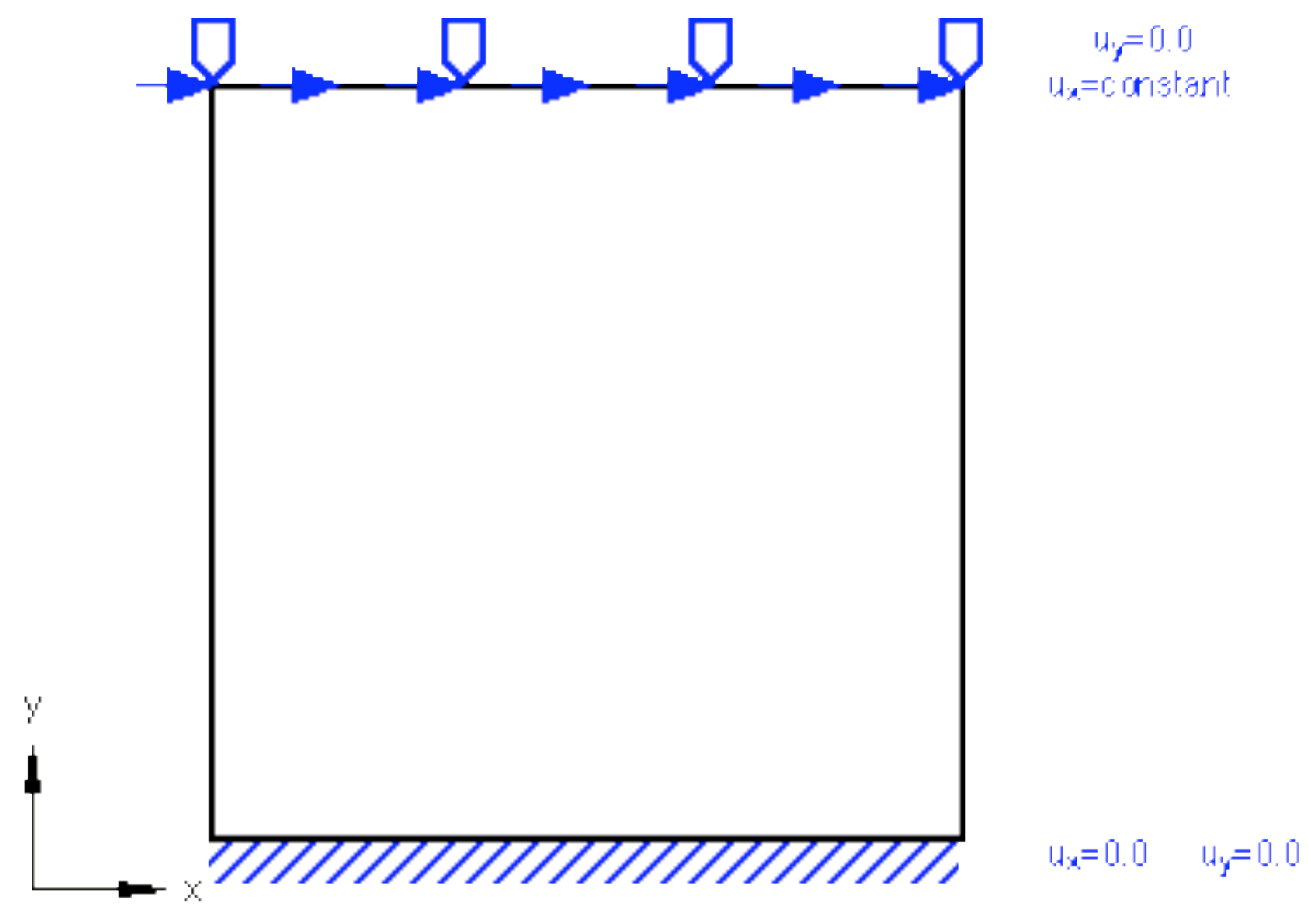

b. Schematic of model subjected to constant edge displacement

Figure A1: Load and boundary conditions used to introduce shear loading 


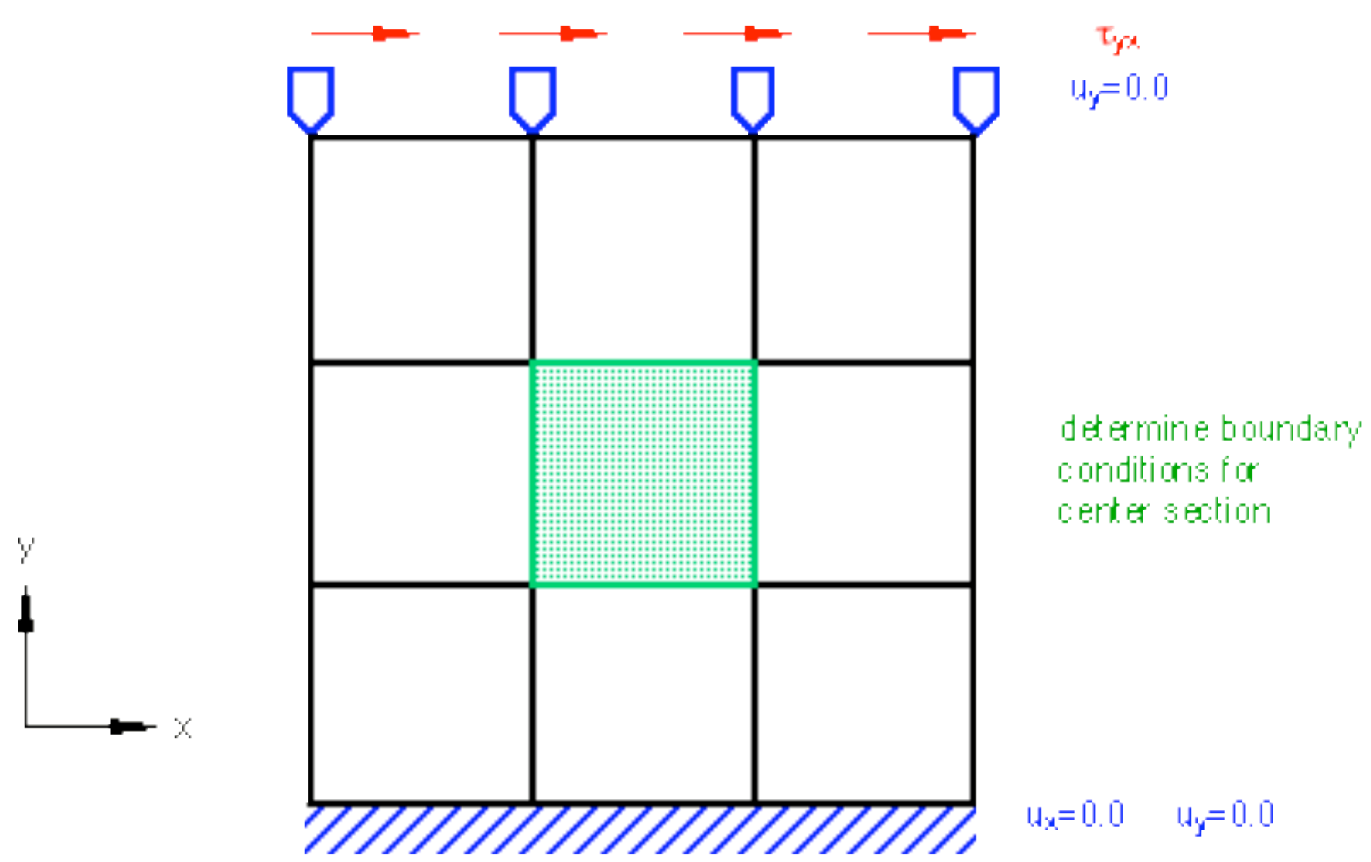

a. Schematic of finite element model with shear load and boundary conditions

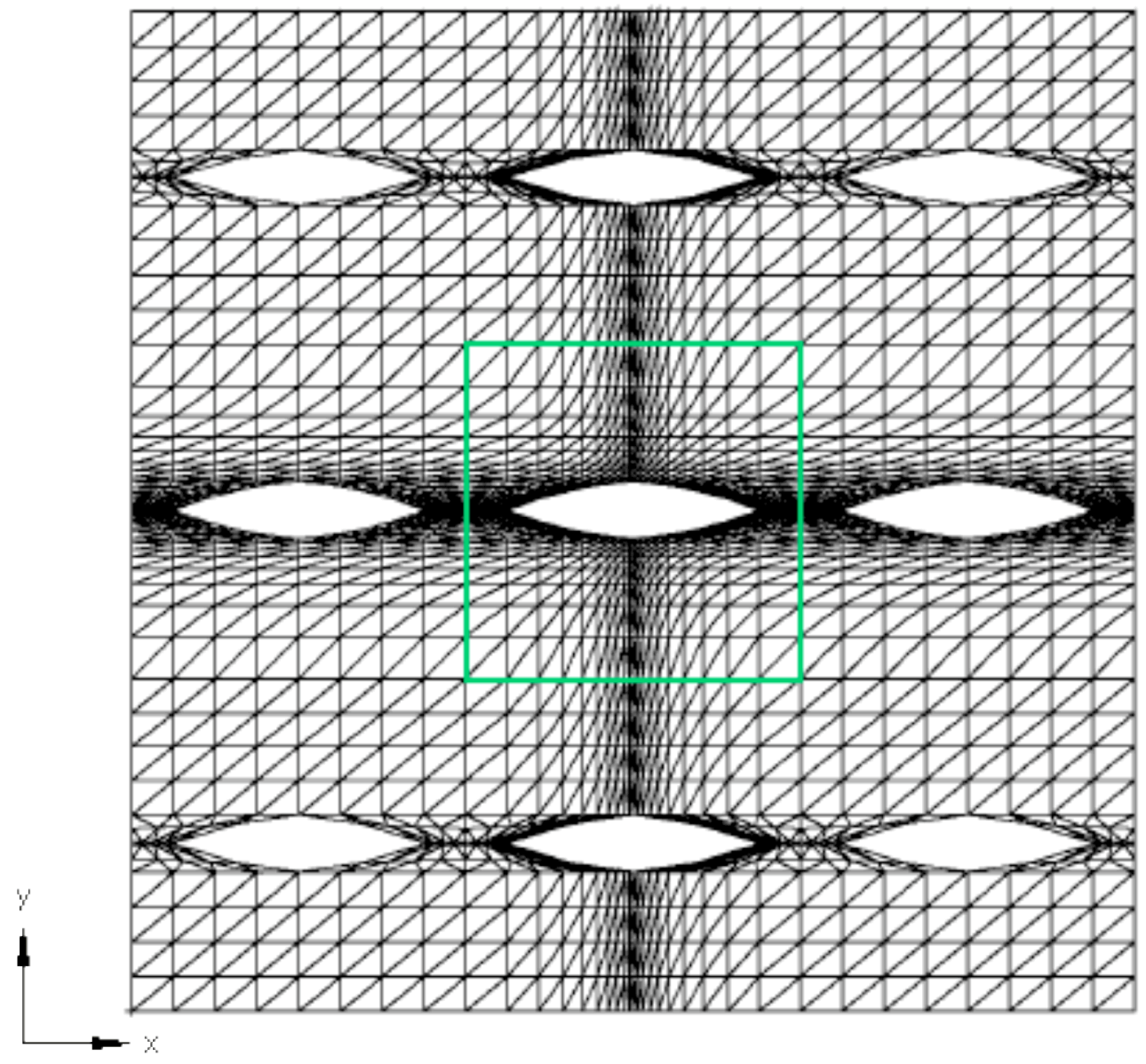

b. Finite element mesh and highlighted center section

Figure A2: Finite element model with nine unit cells subjected to simple shear loading 


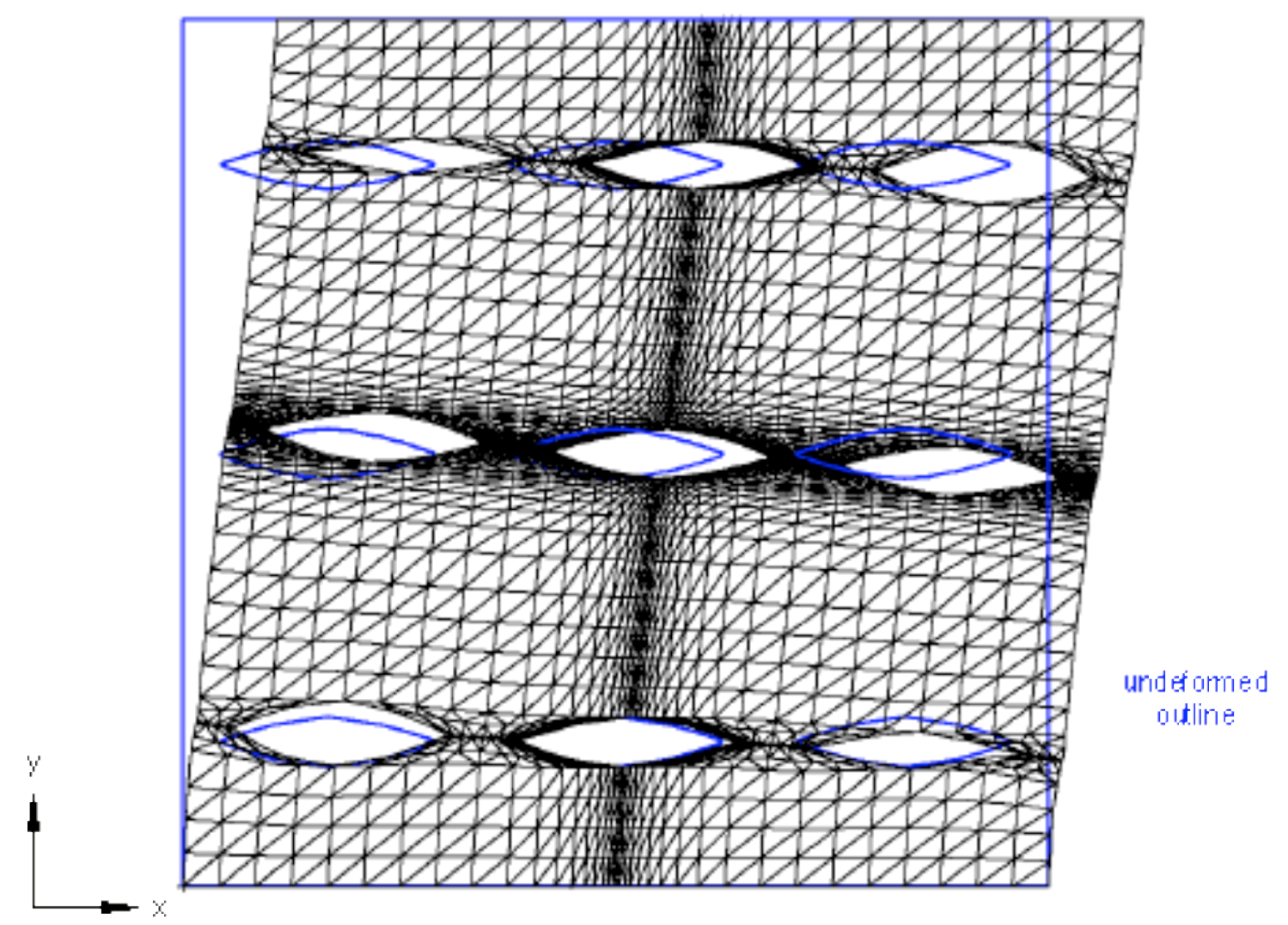

a. Deformed finite element model

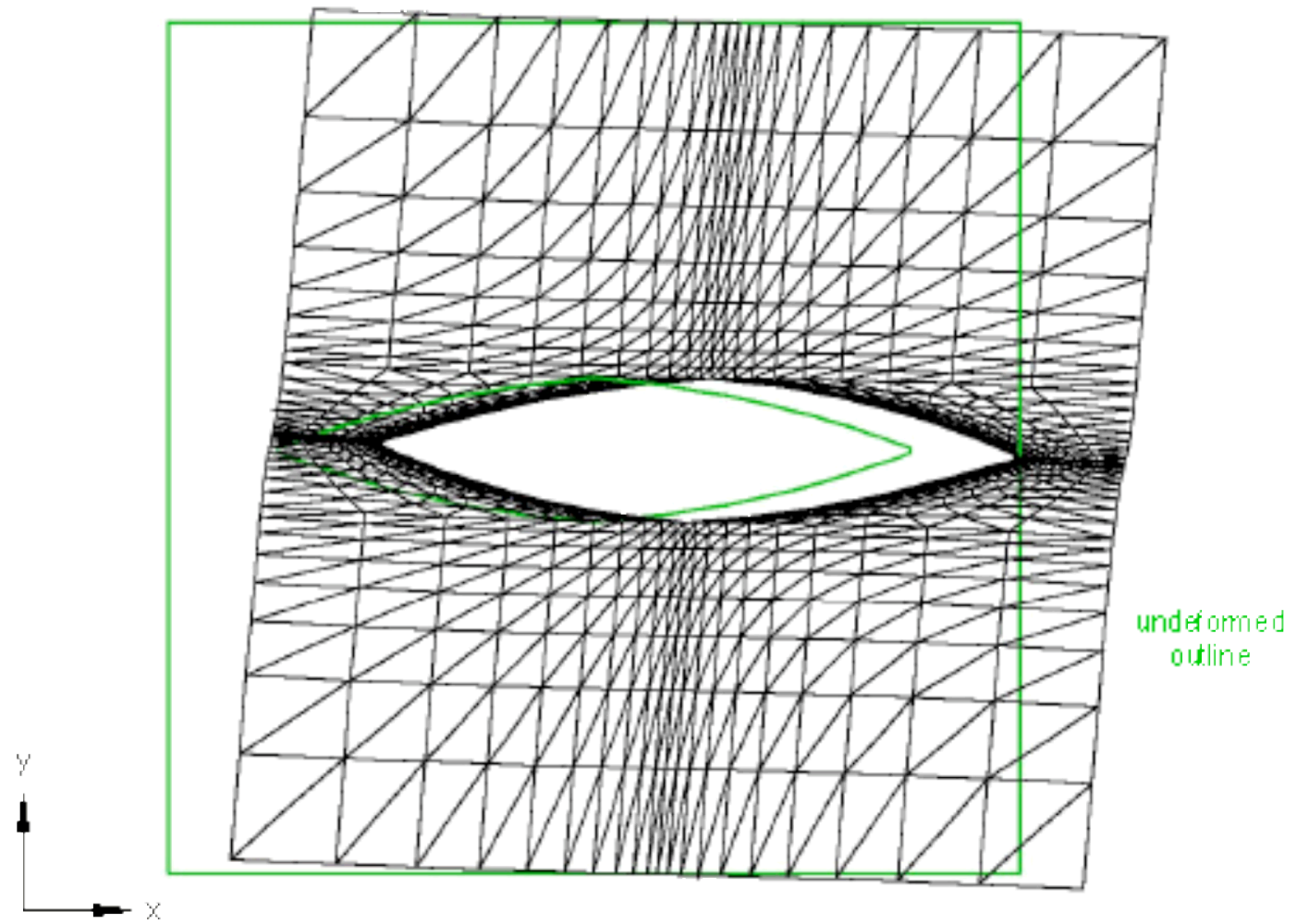

b. Detail of deformed center unit cell

Figure A3. Analysis of model with nine unit cells subjected to simple shear loading 


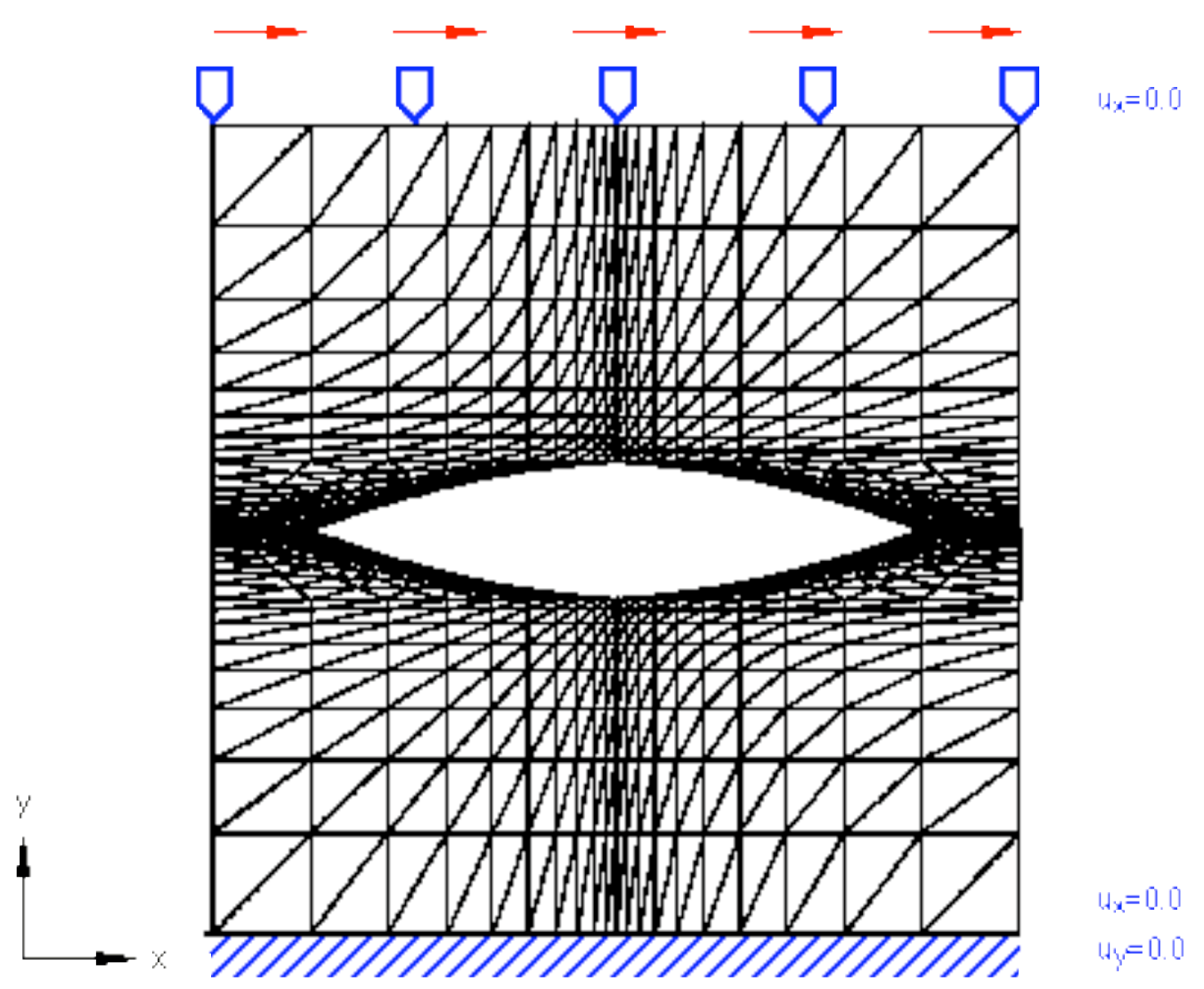

a. Finite element model with load and boundary conditions

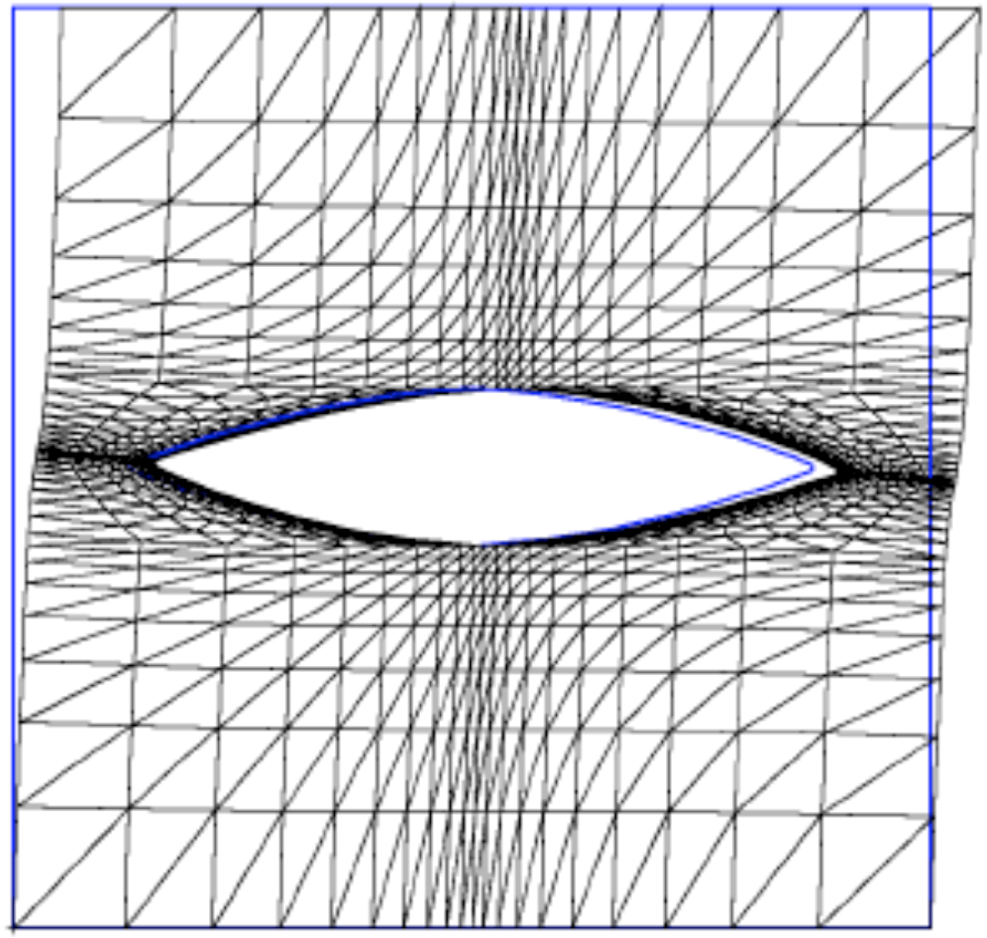

und or ormed

outline

b. Deformed finite element mesh

Figure A4: Finite element model subjected to simple shear loading 


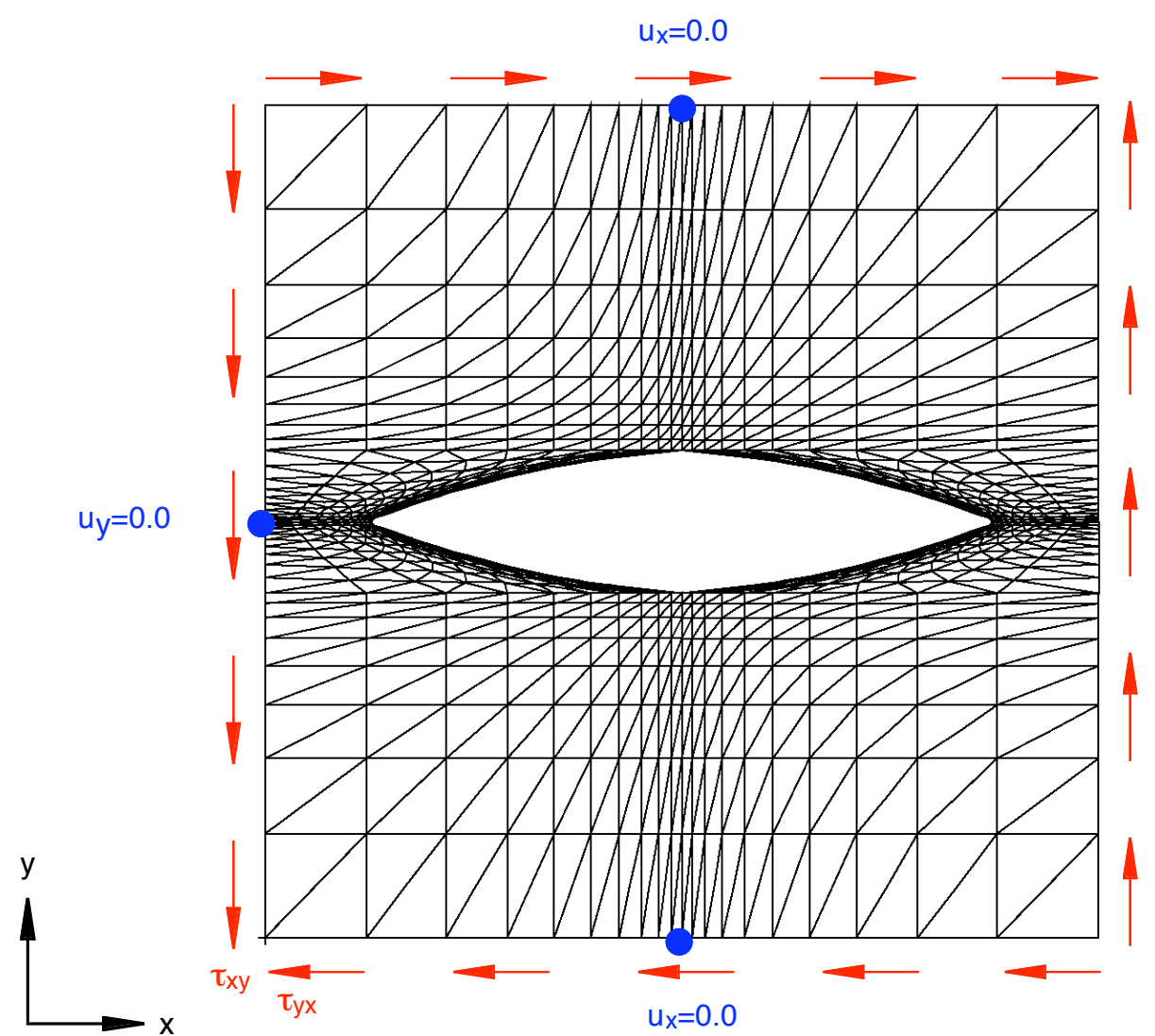

a. Finite element model with load and boundary conditions

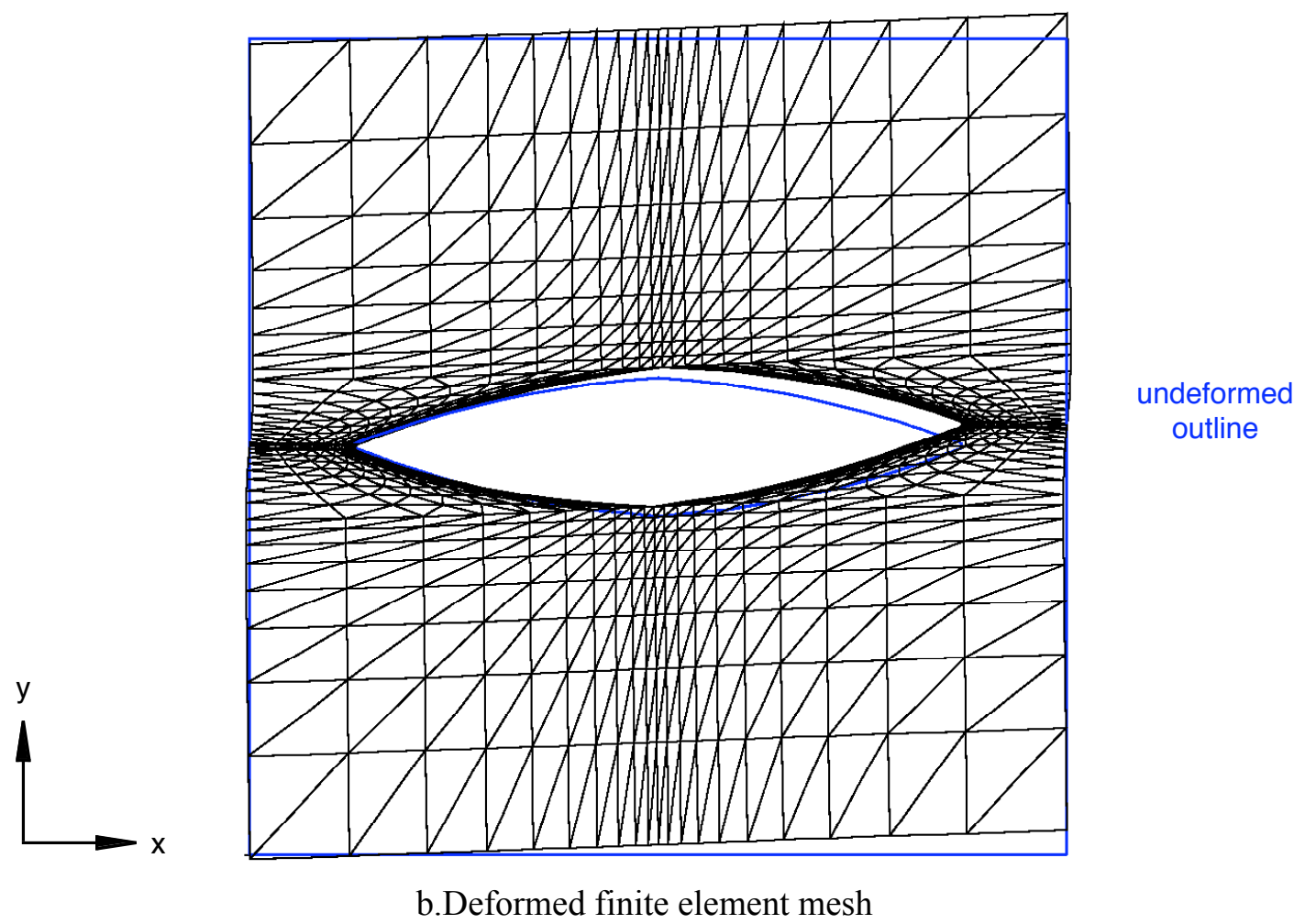

Figure A5: Finite element model of unit cell subjected to positive shear loading 


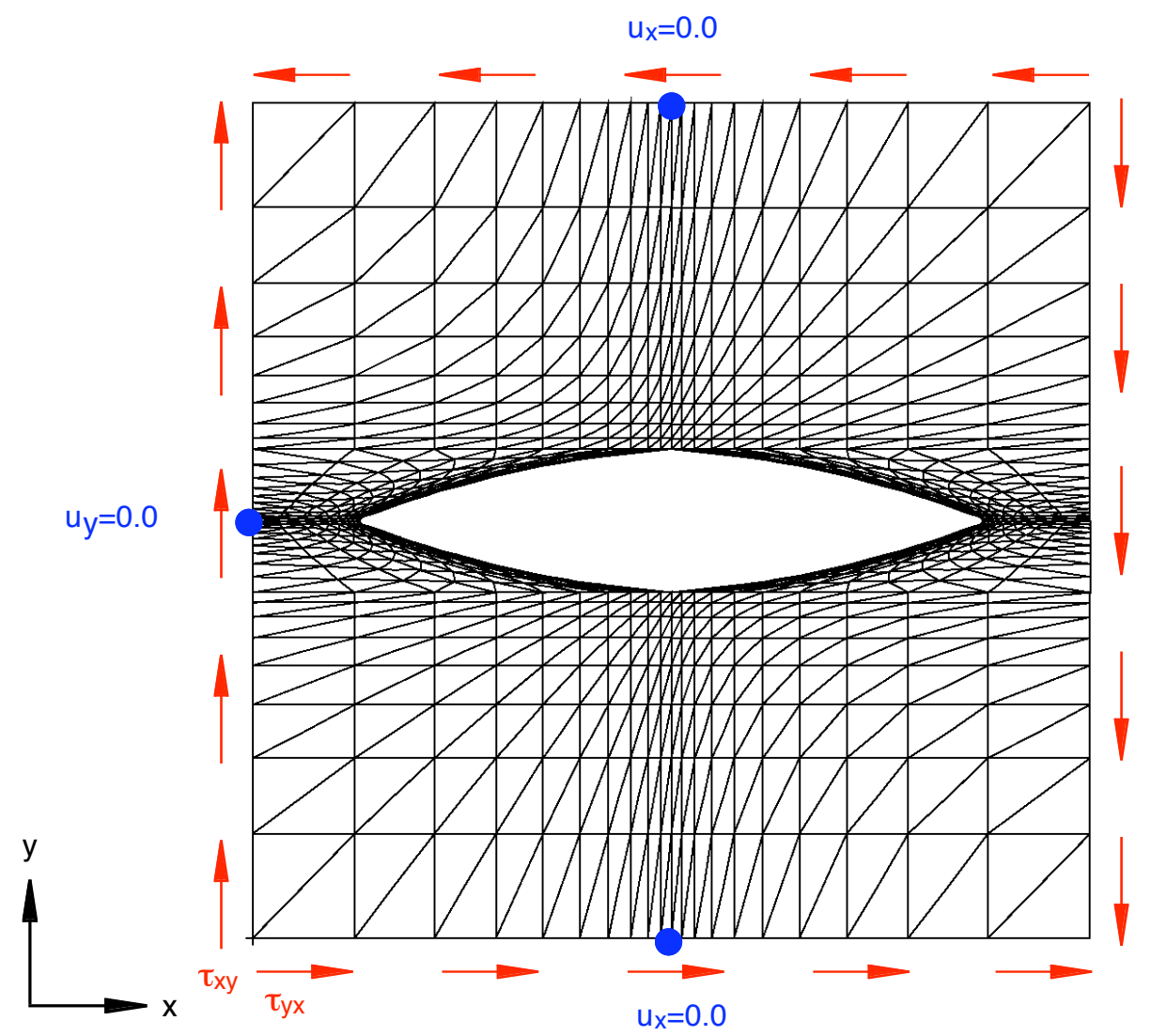

a. Finite element model with load and boundary conditions
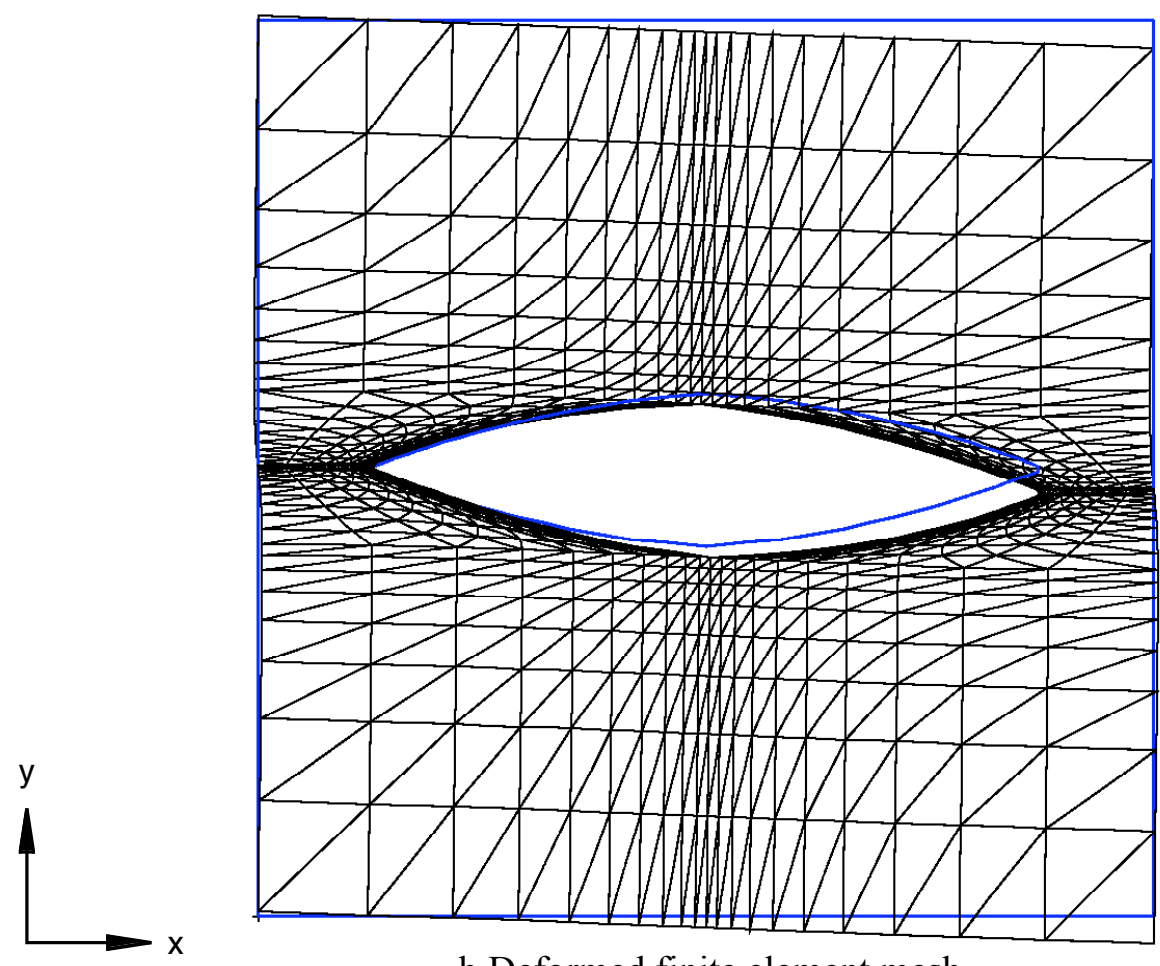

undeformed

outline

b.Deformed finite element mesh

Figure A6: Finite element model of unit cell subjected to negative shear loading 
The public reporting burden for this collection of information is estimated to average 1 hour per response, including the time for reviewing instructions, searching existing data sources, gathering and maintaining the data needed, and completing and reviewing the collection of information. Send comments regarding this burden estimate or any other aspect of this collection of information, including suggestions for reducing this burden, to Department of Defense, Washington Headquarters Services, Directorate for Information Operations and
Reports (0704-0188), 1215 Jefferson Davis Highway, Suite 1204, Arlington, VA 22202-4302. Respondents should be aware that notwithstanding any other provision of law, no person shall be subject to any penalty for failing to comply with a collection of information if it does not display a currently valid OMB control number.

PLEASE DO NOT RETURN YOUR FORM TO THE ABOVE ADDRESS.
1. REPORT DATE $(D D-M M-Y Y Y Y)$
2. REPORT TYPE
3. DATES COVERED (From - To)
01- $06-2005$
Technical Memorandum

4. TITLE AND SUBTITLE

Influence of Compression and Shear on the Strength of Composite

Laminates With Z-Pinned Reinforcement

5a. CONTRACT NUMBER

5b. GRANT NUMBER

5c. PROGRAM ELEMENT NUMBER

6. $\operatorname{AUTHOR(S)}$

5d. PROJECT NUMBER

O'Brien, T. Kevin; and Krueger, Ronald

5e. TASK NUMBER

5f. WORK UNIT NUMBER

23R-762-25-9137-01

\section{PERFORMING ORGANIZATION NAME(S) AND ADDRESS(ES)}

NASA Langley Research Center U.S. Army Research Laboratory

Hampton, VA 23681-2199

Vehicle Technology Directorate

NASA Langley Research Center

Hampton, VA 23681-2199

8. PERFORMING ORGANIZATION REPORT NUMBER

L-19141

9. SPONSORING/MONITORING AGENCY NAME(S) AND ADDRESS(ES)

National Aeronautics and Space Administration

Washington, DC 20546-0001

and U.S. Army Research Laboratory

Adelphi, MD 20783-1145

\section{DISTRIBUTION/AVAILABILITY STATEMENT}

Unclassified - Unlimited

Subject Category 24

Availability: NASA CASI (301) 621-0390

\section{SUPPLEMENTARY NOTES}

An electronic version can be found at http://ntrs.nasa.gov

\section{ABSTRACT}

The influence of compression and shear loads on the strength of composite laminates with z-pins is evaluated parametrically using a 2D Finite Element Code (FLASH). Meshes were generated for three unique combinations of z-pin diameter and density. A laminated plate theory analysis was performed on several layups to determine the bi-axial stresses in the zero degree plies. These stresses, in turn, were used to determine the magnitude of the relative load steps prescribed in the FLASH analyses. Results indicated that increasing pin density was more detrimental to in-plane compression strength than increasing pin diameter. FLASH results for lamina with z-pins were consistent with the closed form results, and FLASH results without z-pins, if the initial fiber waviness due to $z$-pin insertion was added to the fiber waviness in the material to yield a total misalignment. Addition of $10 \%$ shear to the compression loading significantly reduced the lamina strength compared to pure compression loading. Addition of $50 \%$ shear to the compression indicated shear yielding rather than kink band formation as the likely failure mode. Two different stiffener reinforced skin configurations with z-pins, one quasi-isotropic and one orthotropic, were also analyzed. Six unique loading cases ranging from pure compression to compression plus $50 \%$ shear were analyzed assuming material fiber waviness misalignment angles of 0,1 , and 2 degrees. Compression strength decreased with increased shear loading for both configurations, with the quasi-isotropic configuration yielding lower strengths than the orthotropic configuration.

\section{SUBJECT TERMS}

Z-pins; In-plane compression strength; Finite element analysis

16. SECURITY CLASSIFICATION OF:

\begin{tabular}{l|l|l|l|} 
a. REPORT & b. ABSTRACT & c. THIS PAGE
\end{tabular}

$\mathrm{U}$

U

$\mathrm{U}$

\section{LIMITATION OF} ABSTRACT
18. NUMBER 19a. NAME OF RESPONSIBLE PERSON

OF

PAGES
STI Help Desk (email: help@sti.nasa.gov) 19b. TELEPHONE NUMBER (Include area code)
71
(301) 621-0390 